\title{
Revisão e atualização da lista das aves do Rio Grande do Sul, Brasil
}

\author{
Glayson A. Bencke ${ }^{1,9}$, Rafael A. Dias ${ }^{2,3}$, Leandro Bugoni ${ }^{4}$, Carlos Eduardo Agne ${ }^{5,9}$, \\ Carla S. Fontana ${ }^{6}$, Giovanni N. Maurício ${ }^{7,9}$ \& Diogenes B. Machado ${ }^{8}$
}

1. Museu de Ciências Naturais, Fundação Zoobotânica do Rio Grande do Sul, Rua Dr. Salvador França 1427, 90690-000 Porto Alegre, RS. (gabencke@fzb.rs.gov.br)

2. Setor de Ornitologia, LABECO, Universidade Católica de Pelotas, Rua Félix da Cunha 412, 96010-000 Pelotas, RS (rafael_antunes_dias@yahoo.com.br)

3. Programa de Pós-Graduação em Ecologia, Instituto de Biociências, Universidade Federal do Rio Grande do Sul, Av. Bento Gonçalves 9500, 91501-970 Porto Alegre, RS.

4. Laboratório de Aves Aquáticas, Instituto de Ciências Biológicas, Universidade Federal do Rio Grande, Caixa Postal 474, Av. Itália km 8, 96201-900 Rio Grande, RS. (lbugoni@yahoo.com.br)

5. Laboratório de Biologia Genômica e Molecular, Programa de Pós-Graduação em Zoologia, Faculdade de Biociências, Pontifícia Universidade Católica do Rio Grande do Sul, Av. Ipiranga 6681, 90619-900 Porto Alegre, RS. (caduornito@yahoo.com.br)

6. Laboratório de Ornitologia, Museu de Ciências e Tecnologia, Programa de Pós-Graduação em Zoologia, Faculdade de Biociências, Pontifícia Universidade Católica do Rio Grande do Sul, Av. Ipiranga 6681, 90619-900 Porto Alegre, RS. (carla@pucrs.br)

7. Grupo Especial de Estudo e Proteção do Ambiente Aquático do Rio Grande do Sul, Rua Tiradentes 2247, 96010-165 Pelotas, RS. (gnachtigallmauricio@yahoo.com.br)

8. Laboratório de Ecologia Quantitativa, Programa de Pós-Graduação em Ecologia, Instituto de Biociências, Universidade Federal do Rio Grande do Sul, Porto Alegre, RS. (diornito@gmail.com)

9. Comitê Brasileiro de Registros Ornitológicos - CBRO.

\begin{abstract}
Revision and updating of the list of birds of Rio Grande do Sul, Brazil. The list of birds of the state of Rio Grande do Sul (281,749 sq. km), southern Brazil, is revised and updated. Species were included in the list according to two main criteria: (i) occurrence in the state documented with tangible evidence - study skin or complete specimen, photograph, video or vocal recording - published in the literature or available for independent verification in scientific collections or archives of public access, or (ii) at least one state record supported by non-material evidence allowing an unequivocal diagnosis of the taxon, such as a circumstantiated report, published or provided to the authors, containing a detailed description of or reference to the diagnostic features observed. Species mentioned for the state that do not conform to these criteria were not included in the main list and were regarded as probable or hypothetical, according to the evidence available and the distributional coherence of the existing records. The final list comprises 661 species, of which 649 are documented by physical evidence. Another 10 and 16 species are listed as probable and hypothetical, respectively. Compared with the previous list, 44 species were added and seven were excluded or substituted, resulting in a net increase of 37 species. Fregetta grallaria (Vieillot, 1818), Polytmus guainumbi (Pallas, 1764), Nonnula rubecula (Spix, 1824), Stymphalornis acutirostris Bornschein, Reinert \& Teixeira, 1995, Fluvicola albiventer (Spix, 1825), and Xenopsaris albinucha (Burmeister, 1869) are mentioned for the state for the first time. The number of species added since the last review corresponds to an average increase of slightly more than four species per year. By examining the recent additions in retrospect, it is clear that the number of bird species known to occur in Rio Grande do Sul should continue to grow at a similar rate over the next decade or so. In view of this, some guidelines for improving future revisions of the state checklist are proposed. In order to better understand new occurrences of birds over time, the use of adequate criteria to distinguish range extensions from range expansions, and instances of vagrancy from pseudo-vagrancy, is recommended.
\end{abstract}

KEYWORDS. Avifauna, distribution records, new occurrences, documentation, collections.

RESUMO. Neste artigo, a lista das aves do estado do Rio Grande do Sul $\left(281.749 \mathrm{~km}^{2}\right)$ é revisada e atualizada. A inclusão de espécies na lista seguiu dois critérios principais: (i) ocorrência no estado documentada por evidência tangível - pele ou espécime completo, foto, vídeo ou gravação de áudio - publicada na literatura ou disponível para verificação independente em coleções ou arquivos científicos de acesso público, ou (ii) pelo menos um registro no estado acompanhado de evidência não-material que permita a identificação segura do táxon, tal como um relato circunstanciado, publicado ou fornecido aos autores, contendo descrição detalhada ou referência às características diagnósticas observadas. Espécies com registros específicos para o estado que não estão em conformidade com esses critérios não foram incluídas na lista principal e foram consideradas "prováveis" ou "hipotéticas", de acordo com as evidências disponíveis e a coerência distribucional dos registros existentes. A lista resultante contém 661 espécies, das quais 649 estão documentadas por evidências físicas. Outras 10 e 16 espécies são consideradas de ocorrência provável e hipotética, respectivamente. Em comparação com a lista anterior, 44 espécies foram adicionadas e sete táxons foram excluídos ou substituídos, resultando em um incremento de 37 espécies. Fregetta grallaria (Vieillot, 1818), Polytmus guainumbi (Pallas, 1764), Nonnula rubecula (Spix, 1824), Stymphalornis acutirostris Bornschein, Reinert \& Teixeira, 1995, Fluvicola albiventer (Spix, 1825) e Xenopsaris albinucha (Burmeister, 1869) são aqui mencionadas para o estado pela primeira vez. O número de espécies adicionadas desde a última revisão da lista corresponde a um aumento médio de pouco mais de quatro espécies por ano. A análise retrospectiva das adições recentes indica que o número de espécies de aves com ocorrência assumida no Rio Grande do Sul deverá continuar crescendo a uma taxa similar ao longo da próxima década. Em vista disso, são propostas ações práticas para aperfeiçoar o processo de revisão da lista estadual no futuro. Também é recomendada a aplicação de critérios adequados para distinguir entre extensões e expansões de distribuição, e entre casos de vagância e pseudo-vagância, para que as novas ocorrências de aves registradas no estado ao longo do tempo possam ser mais bem interpretadas.

PALAVRAS-CHAVE. Avifauna, registros de distribuição, novas ocorrências, documentação, coleções.

Quase dez anos se passaram desde a última atualização da lista da avifauna do Rio Grande do Sul, publicada por BENCKE (2001). Nesse período consolidouse o Comitê Brasileiro de Registros Ornitológicos (CBRO), que desde 1999 vem se ocupando da organização e da atualização periódica da lista nacional a partir da avaliação crítica dos registros de ocorrência e das novas propostas taxonômicas e nomenclaturais publicadas na literatura 
científica. Nesse período também surgiu o South American Classification Committee (SACC), vinculado à American Ornithologists' Union (AOU), que tem por objetivo prover uma classificação de referência para as aves da América do Sul e manter uma lista permanentemente atualizada da avifauna do continente. Mais importante, porém, o número de espécies de aves conhecidas no Rio Grande do Sul aumentou ao longo da última década a uma taxa consideravelmente maior do que a registrada nas duas décadas anteriores, refletindo o incremento no número de ornitólogos que atuam no estado e a consequente intensificação dos inventários de campo (Bencke et al., 2009). Além disso, a crescente disponibilização de publicações científicas, catálogos de coleções biológicas e acervos sonoros ou fotográficos na internet tem facilitado enormemente a consulta a fontes bibliográficas antigas e a verificação de materiaistestemunho depositados no exterior, o que tem permitido esclarecer uma série de dúvidas que ainda persistiam a respeito de alguns registros.

No presente artigo a lista das aves do Rio Grande do Sul é revisada, sendo apresentadas as alterações acumuladas desde a última atualização (i.e., BENCKE, 2001), bem como as razões para as mudanças introduzidas e as informações que as substanciam. Adicionalmente, a classificação seguida na lista estadual é indexada à do CBRO, com o objetivo não só de assegurar a concordância taxonômica e nomenclatural com a lista nacional, mas também de facilitar futuras revisões.

A primeira lista razoavelmente completa da avifauna sul-rio-grandense foi publicada por BELTON (1978a) e atualizada por esse autor em suas obras subsequentes (Belton, 1984, 1985, 1994). As listagens anteriores (IHERING, 1899; GLIESCH, 1930), apesar de incluírem um número relativamente grande de espécies, foram elaboradas com base em uma cobertura geográfica bastante incompleta do território estadual e, logo, podem ser consideradas parciais. A lista de BENCKE (2001) foi a primeira a adotar critérios explícitos para a inclusão de espécies - ainda que não totalmente isentos de subjetividade - e também a primeira a especificar a evidência comprobatória de maior peso disponível para cada táxon.

Um ponto em comum entre todas essas iniciativas é que elas resultaram do trabalho individual de seus autores. A atualização aqui apresentada, por sua vez, é o resultado do esforço conjunto de um grupo de ornitólogos, o que representa um avanço em relação às listas anteriores, na medida em que reflete a tomada de decisões por consenso e não mais com base em uma perspectiva particular. Ainda que informalmente constituído, o comitê regional formado para a presente revisão reúne tanto taxonomistas como profissionais dedicados a outras áreas da ornitologia, incluindo um especialista em aves marinhas, que representam quase todas as principais instituições do Rio Grande do Sul onde se realizam pesquisas ornitológicas na atualidade.

Neste artigo, as alterações à lista estão organizadas nas seguintes seções, de acordo com a sua natureza: (i) espécies adicionadas, (ii) espécies excluídas, (iii) espécies sem documentação mantidas na lista, (iv) outras alterações consideradas, (v) atualizações de documentação, (vi) alterações de nomes em português, (vii) espécies de ocorrência provável e (viii) espécies de ocorrência hipotética. A lista completa é apresentada no Apêndice I e pode ser consultada ou obtida em formato digital no endereço http:/ /www.fzb.rs.gov.br/museu/projetos.

\section{Métodos}

A Lista de referência das aves do Rio Grande do Sul (BENCKe, 2001) serviu como ponto de partida para a presente revisão. Com base nessa fonte, foram incorporadas as novas ocorrências e revisadas as evidências materiais ou circunstanciais que fundamentam a inclusão de cada espécie, assim como a taxonomia e a nomenclatura. Os critérios de inclusão, por outro lado, diferiram ligeiramente dos adotados na lista anterior. Adicionalmente, alguns poucos nomes regionais em português foram substituídos. O status de ocorrência das espécies não foi atualizado e será revisado em um artigo complementar futuro. As definições e procedimentos adotados são detalhados a seguir.

Abrangência geográfica. A região coberta por esta reavaliação compreende toda a superfície territorial continental do Rio Grande do Sul (RS), que é de 281.748,54 $\mathrm{km}^{2}$ (incluindo águas interiores), bem como o mar territorial e zona econômica exclusiva (ZEE) correspondente, até o limite de 200 mn (milhas náuticas), ou 370 km, da linha da costa. A pequena Ilha dos Lobos é a única área insular oceânica do estado e está localizada a apenas 1,8 km do litoral de Torres, junto à divisa com Santa Catarina.

Classificação e sequência taxonômica. Seguiu-se integralmente a classificação adotada na mais recente lista do Comitê Brasileiro de Registros Ornitológicos (CBRO, 2011). As muitas alterações taxonômicas implementadas em relação a BENCKE (2001) não são justificadas aqui, podendo ser rastreadas por consulta às listas anteriores do CBRO ou ao sítio web do SACC.

Critérios de inclusão. Foram incluídas na lista (i) as espécies cuja ocorrência no RS está documentada por evidência material disponível para verificação, na forma de espécime parcial ou completo depositado em coleção biológica científica (conforme definição na Instrução Normativa Ibama $\mathrm{N}^{\mathrm{o}} 160$, de 27 de abril de 2007), fotografia ou sonograma publicado em fonte bibliográfica, ou ainda imagem, vídeo ou amostra vocal armazenada em arquivo científico, e (ii) as espécies sem documentação verificável conhecida, mas com pelo menos um registro no RS substanciado por evidência não material que permita a diagnose inequívoca da espécie envolvida, como, por exemplo, relato circunstanciado, publicado ou disponibilizado aos autores, contendo descrição detalhada ou menção às características diagnósticas registradas.

No caso das espécies sem documentação, a coerência distribucional ou biogeográfica dos registros conhecidos para o território gaúcho foi frequentemente utilizada como critério de avaliação acessório. A coerência distribucional está relacionada à distância de um registro isolado em relação à área de distribuição geográfica conhecida da espécie. Assim, quanto mais próximo o RS estiver dessa área, tanto mais coerente é, sob o ponto de vista distribucional, um eventual registro da espécie no 
estado, e vice-versa. Na aplicação desse critério auxiliar, levou-se em conta também a capacidade de dispersão das espécies, a sua condição de migratórias ou residentes, a época do registro, a presença de hábitats adequados no estado e a existência de registros documentados em regiões vizinhas.

Já a coerência biogeográfica é dada pela presença de espécies acompanhantes que compartilham um centro de origem comum e apresentam requisitos de hábitat semelhantes. Por exemplo, um registro não documentado de uma espécie atlântica associada a florestas de planície em uma mata semidecídua do interior do RS pode parecer improvável se analisado isoladamente, mas se torna plausível se outras espécies típicas de baixadas costeiras estiverem presentes na mesma região. É o caso, por exemplo, do pequeno conjunto de espécies típicas ou exclusivas do Brasil oriental encontrado por $\mathrm{H}$. von Ihering nos arredores de Taquara ao final do século XIX (BERLEPSCH \& IHERING, 1885), que incluía Phaethornis eurynome (Lesson, 1832), Clytolaema rubricauda (Boddaert, 1783), Lophornis magnificus (Vieillot, 1817), Myrmeciza squamosa Pelzeln, 1868, Myrmotherula gularis (Spix, 1825) e Eleoscytalopus indigoticus (Wied, 1831), hoje desaparecidos daquela região ou mesmo do estado.

$\mathrm{Na}$ validação das evidências relacionadas às espécies de ocorrência documentada, o condicionante "disponível para verificação" implica que a coleção ou arquivo onde o material comprobatório está depositado seja de acesso público, incluindo acervos digitais na internet, desde que permitam a rastreabilidade dos itens em depósito. Assim, exemplares de coleções biológicas particulares (sensu Instrução Normativa Ibama $N^{\circ} 160$ ) não foram considerados evidências válidas. Por coerência, espécimes perdidos que constituíam a única evidência da ocorrência de certas espécies no estado foram tratados de forma semelhante e a avaliação de tais espécies seguiu o mesmo procedimento adotado no caso de táxons sem documentação conhecida.

As espécies que possuem um ou mais registros específicos para o RS divulgados na literatura mas não atendem aos critérios acima são tratadas em categorias à parte. A ocorrência dessas espécies no estado não é assumida e sua eventual inclusão na lista estadual depende da obtenção de evidências adicionais. São consideradas prováveis as espécies cujos registros em território gaúcho possuam coerência distribucional ou biogeográfica, faltando, porém, elementos adicionais que permitam uma avaliação independente de sua verossimilhança e/ou uma determinação taxonômica segura. As espécies consideradas hipotéticas são aquelas conhecidas apenas por registros não circunstanciados e cuja ocorrência no RS não é coerente com o seu padrão distribucional. Também foram enquadradas nessa categoria as espécies conhecidas por registros baseados em informações não resgatáveis ou não fidedignas.

Atualizações de documentação. Todas as informações sobre as evidências que servem de base para a inclusão das espécies na lista foram revisadas. Para as espécies de ocorrência documentada que foram adicionadas à lista ou passaram a dispor de documentação após 2001, a evidência é apontada ou publicada aqui.
Em geral, apenas a evidência de maior peso é indicada, observando-se a seguinte ordem de precedência: pele taxidermizada (ou espécime completo conservado em meio líquido) > material osteológico > fotografia ou vídeo > gravação de áudio > registro visual circunstanciado. Mais de uma evidência é mencionada no caso de espécies de identificação problemática ou quando a evidência principal é insatisfatória, ambígua ou tem disponibilidade incerta.

Algumas poucas espécies adicionadas à lista cujos registros estão em processo de divulgação por terceiros não tiveram as respectivas evidências físicas publicadas aqui para preservar o seu ineditismo. A ocorrência dessas espécies foi assumida com base na verificação do materialtestemunho disponibilizado aos autores, em geral fotografias. Encorajam-se fortemente os observadores que cederam informações inéditas a divulgarem os detalhes de seus registros o mais breve possível.

Os museus e arquivos sonoros ou de imagens citados no texto, com seus respectivos acrônimos, são os seguintes: Museu de Ciências Naturais (MCN), Fundação Zoobotânica do Rio Grande do Sul, Porto Alegre, RS; Museu de Ciências e Tecnologia da Pontifícia Universidade Católica do Rio Grande do Sul (MCP), Porto Alegre, RS; Coleção de Aves da Universidade Federal do Rio Grande (CAFURG), Rio Grande, RS; Museu de História Natural da Universidade Católica de Pelotas (MUCPEL), Pelotas, RS; Museu de Zoologia da Universidade do Vale do Rio dos Sinos (MZU), São Leopoldo, RS; Museu de Zoologia, Universidade de São Paulo (MZUSP), São Paulo, SP; Museu Nacional (MN), Universidade Federal do Rio de Janeiro, Rio de Janeiro, RJ; Museu Oceanográfico Univali (MOVI), Universidade do Vale do Itajaí, Balneário Piçarras, SC; Museu de Biologia Prof. Mello Leitão (MBML), Santa Teresa, ES; American Museum of Natural History (AMNH), Nova Iorque, EUA; Arquivo Sonoro Prof. Elias Coelho (ASEC), Universidade Federal do Rio de Janeiro, Rio de Janeiro, RJ; xeno-canto - base de dados digital de vozes de aves (www.xeno-canto.org); Macaulay Library, Cornell Lab of Ornithology, Ithaca, EUA (arquivo online em http:// macaulaylibrary.org); Visual Resources for Ornithology (VIREO), The Academy of Natural Sciences, Filadélfia, EUA (http://vireo.acnatsci.org). Coordenadas geográficas são indicadas apenas para as localidades de registros inéditos. Para as demais localidades do estado mencionadas no texto, essa informação pode ser obtida nas fontes bibliográficas citadas ou no gazetteer de BELTON (1994).

\section{Espécies adicionadas}

Diomedea sanfordi Murphy, 1917 - albatroz-realdo-norte. CARlos et al. (2004) citaram uma fêmea capturada em espinhel pelágico em agosto de 1999 no ponto $33^{\circ} 45^{\prime} 38^{\prime}$ 'S, 5054'12"'W, isóbata de $1.200 \mathrm{~m} \mathrm{e}$ temperatura superficial de $17^{\circ} \mathrm{C}$. Embora não tenha sido explicitado nessa fonte, o registro se deu dentro da ZEE, a cerca de $95 \mathrm{mn}$ da costa gaúcha. Portanto, deve ser tratado como um registro válido para o RS. O exemplar (CAFURG 357) também é mencionado por DÉNES \& SilveIRA (2007) e DÉNES et al. (2007). Adicionalmente, 
quatro exemplares da espécie foram fotografados em águas do RS em datas distintas, conforme descrito a seguir: i) 29 de maio de 2006 (34 $\left.15^{\prime} \mathrm{S}, 51^{\circ} 04^{\prime} \mathrm{W}\right)$, linha escura na borda cortante da maxila evidente, parte superior das asas totalmente escura, visível barra escura larga na parte inferior das asas entre a junta carpal e a extremidade, porção distal das retrizes exteriores escuras (portanto um imaturo); ii) 28 de agosto de 2007 (localização precisa no texto de Fregetta grallaria abaixo, mesma data), exemplar com borda da maxila negra, parte superior das asas inteiramente negras, cabeça, cauda e dorso totalmente brancos, correspondendo a um adulto, possivelmente macho (estágio 2 de HARRISON, 1985); a borda de ataque inferior da asa escura, sugerida como característica diagnóstica por HARRISON (1985) e BROOKE (2004), também foi evidente; iii) 30 de agosto de 2007, um fotografado pela manhã e, à tarde, dois vistos simultaneamente em $34^{\circ} 13^{\prime} \mathrm{S}, 5^{\circ} 0^{\circ} 49^{\prime} \mathrm{W}$, a $130 \mathrm{mn}$ da costa, próximo à fronteira uruguaia mas ainda em águas gaúchas. Todos os exemplares foram identificados como "albatrozes-reais" pela presença de linha negra na maxila e como D. sanfordi com base na mancha na parte inferior das asas, próximo à borda de ataque e junta carpal. Um dos exemplares fotografado à tarde possuía borda cortante da maxila negra e a parte superior das asas inteiramente negra, o que permite identificá-lo como um albatroz-real proveniente da Nova Zelândia (D. sanfordi ou D. epomophora Lesson, 1825), enquanto a extremidade das retrizes escura, uropígio, costas e cabeça inteiramente brancas, além da borda de ataque inferior da asa, entre a extremidade e a junta carpal, com pronunciada mancha negra, o identifica como D. sanfordi, possivelmente um macho adulto ou subadulto, devido à ausência de manchas escuras na cabeça. A ocorrência de D. epomophora no RS, por sua vez, é comprovada por três exemplares anilhados nas colônias reprodutivas e encontrados em praias gaúchas ou capturados por barcos de pesca em águas adjacentes (Olmos, 2002), um dos quais reportado por SANDER (1982). Adicionalmente, há um espécime recente originário da praia de Cidreira (MCP 2.328) e um crânio de um macho coletado na praia do Cassino em 6 de outubro de 1980 (CAFURG 169). O crânio de D. epomophora citado por SANDER (1982), BELTON (1994) e BENCKE (2001) requer reavaliação em razão do recente reconhecimento de $D$. sanfordi e D. epomophora como espécies distintas.

Diomedea dabbenena Mathews, 1929 - albatrozde-tristão. Essa espécie endêmica do arquipélago de Tristão da Cunha é difícil, senão impossível, de ser separada de $D$. exulans Linnaeus, 1758 com base apenas em caracteres visuais (BROOKE, 2004; ONLEY \& SCOFIELD, 2007). Por outro lado, o uso de medidas do bico, sobretudo quando o sexo é conhecido, permite uma identificação segura (CuthBert et al., 2003). Quatro exemplares de $D$. dabbenena capturados com tarrafa no mar em 5, 6, 8 e 28 de agosto de 2007 foram medidos, sexados por meio de análise molecular (três machos e uma fêmea) e identificados por meio das funções discriminantes de CuthBert et al. (2003). As capturas ocorreram em frente a Rio Grande, sendo três em águas da ZEE e uma em águas internacionais ( 8 de agosto). O exemplar de 28 de agosto (fêmea juvenil; foto publicada em CHEBEZ, 2008:93) possuía plumagem predominantemente marrom e linha negra na borda cortante da maxila, características de $D$. amsterdamensis Roux, Jouventin, Mougin, Stahl \& Weimerskirch, 1983, do oceano Índico (BROOKE, 2004). Embora insuficientemente descritas na literatura, essas características estão presentes em alguns exemplares de D. dabbenena de Tristão da Cunha (Richard Cuthbert, com. pess.; ONLEY \& SCOFIELD, 2007). Os registros de $D$. dabbenena aqui apresentados somam-se a outros de Neves \& Olmos (2001), Olmos (2002) e DÉNes et al. (2007) ao largo da costa brasileira e águas adjacentes, incluindo o RS, e a dois exemplares depositados na CAFURG (002 e 359). Já a ocorrência de $D$. exulans no estado é comprovada por seis exemplares depositados no MOVI (detalhes em DÉNEs et al., 2007), por uma pele originária de Capão da Canoa (MCP 2.327) e pela recaptura de diversos indivíduos anilhados (e.g., Otmos, 2002). Adicionalmente, nove exemplares de D. exulans, citados em BugOni \& Furness (2009a) e Bugoni et al. (2008, 2010), foram capturados com tarrafa em águas territoriais do estado em agosto de 2007, cinco dos quais portando anilhas britânicas e provenientes da Geórgia do Sul. Alguns desses registros de $D$. dabbenena e $D$. exulans estão documentados por imagens publicadas em CHEBEZ (2008) - foto da página 94, equivocadamente citada como tendo sido obtida nos arredores de Trindade, e foto erroneamente atribuída a Fábio Olmos na página 95.

Macronectes halli Mathews, 1912 - pardelãogigante-de-bico-vermelho. BENCKE (2001) considerou a ocorrência de $M$. halli no RS pendente de confirmação. Posteriormente, a presença da espécie no estado foi documentada em alguns estudos (BugONi et al., 2003; CARlos et al., 2005; CARlos \& VoIsin, 2008), existindo três espécimes (CAFURG 216, 272 e 275), e registrada sem documentação em outros, incluindo uma captura com tarrafa de um exemplar que foi anilhado (BugONI \& Furness, 2009a; BugOni et al., 2008, 2010). A espécie parece ser frequente e abundante durante o inverno na fronteira com o Uruguai, em águas profundas e durante ou após a passagem de frentes polares. Isso é evidente, por exemplo, a partir das observações e fotografias de L. Bugoni (L.B.) de vários indivíduos vistos simultaneamente no final de julho e em todo o mês de agosto nas condições descritas acima, por exemplo, em uma imagem obtida em 28 de julho de 2007 (3306' $\mathrm{S}$, $50^{\circ} 28^{\prime} \mathrm{W}$; cerca de $102 \mathrm{mn}$ da costa), mostrando nove $M$. halli e oito Macronectes giganteus (Gmelin, 1789).

Pterodroma macroptera (Smith, 1840) - pardelade-cara-cinza. As menções anteriores para o Brasil mostraram-se baseadas em mera extrapolação a partir de mapas gerais de distribuição apresentados na literatura e exemplares de museu que provaram ser Puffinus griseus, além de observações não documentadas ao largo da costa gaúcha e brasileira (TEIXEIRA et al., 1988; BugOni, 2006). Com base nisso, $P$. macroptera foi listada entre as espécies de ocorrência provável no RS por BENCKE (2001). Um espécime autêntico (CAFURG 360) foi coletado próximo ao Farol do Albardão, Santa Vitória do Palmar, em março de 2004 (Bugoni, 2006). Esse parece ser o único exemplar conhecido do Brasil.

Pachyptila vittata (Forster, 1777) - faigão-de-bicolargo. Inicialmente citado para o RS com base em um 
exemplar coletado em outubro de 1979 na praia do Cassino (Belton, 1984; VoOREn \& FERnANDEs, 1989) e depositado na CAFURG. Por esse exemplar ter sido perdido, a espécie foi excluída da lista do RS por BELTON (1994) e considerada de ocorrência provável por BENCKE (2001). CARLOS (2005) reencontrou o espécime (agora sob o n. ${ }^{\circ} 281$ ) e confirmou a identificação do mesmo. O exemplar do RS é, possivelmente, a única evidência física da ocorrência da espécie no Brasil.

Fregetta grallaria (Vieillot, 1818) - painho-debarriga-branca. Um exemplar do morfo claro (Figs 1,2) foi fotografado por L.B. em 28 de agosto de 2007 entre 115 e $140 \mathrm{mn}$ da costa gaúcha $\left(33^{\circ} 49^{\prime}-33^{\circ} 39^{\prime} \mathrm{S}, 50^{\circ} 03^{\prime}-\right.$ $50^{\circ} 23^{\prime} \mathrm{W}$, profundidade $1.500-1.600 \mathrm{~m}$, temperatura superficial do $\operatorname{mar} 12^{\circ} \mathrm{C}$ ), o que parece ser o primeiro registro documentado da espécie no estado. Nas fotos em vista ventral, a cabeça, pescoço e parte superior do peito, todas escuras, estão bem demarcadas do ventre completamente branco, correspondendo ao morfo claro da espécie (BRoOKe, 2004; ONLEy \& SCOFIELd, 2007). NeVES et al. (2006) relataram registros não documentados e sem localização precisa de três exemplares de $F$. grallaria em águas ao largo da costa do RS e Santa Catarina. As estações correspondentes a esses registros estão em águas do RS, a cerca de $100 \mathrm{mn}$ da costa: 11 de dezembro ( $30^{\circ} 43^{\prime}$ S , $\left.48^{\circ} 27^{\prime} \mathrm{W}\right), 19$ de dezembro ( $\left.33^{\circ} 05^{\prime} \mathrm{S}, 50^{\circ} 15^{\prime} \mathrm{W}\right)$ e 20 de dezembro de 1997 (3334'S, 5042’W) (Tatiana Neves, com. pess.). Já o crânio mencionado por BELTON (1994), coletado ao norte de Pinhal em setembro de 1990 e depositado no MZU, ainda não teve sua identidade específica determinada, podendo ser de $F$. grallaria ou de Fregetta tropica (Gould, 1844), espécie próxima mencionada para águas adjacentes à ZEE de Santa Catarina (RuMBOLL \& JEHL-JR, 1977) e Uruguai (JiMÉNEZ et al., 2009), ou mesmo pertencer a outro Hydrobatidae.

Sula dactylatra Lesson, 1831 - atobá-grande. FRAnz et al. (2008) publicaram os primeiros registros dessa espécie para o RS, os quais estão documentados por fotos e por um espécime.

Ixobrychus exilis (Gmelin, 1789) - socoí-vermelho. A ocorrência dessa espécie no RS foi considerada provável por BENCKE (2001), com base em um registro auditivo não confirmado no município de São Gabriel, em fevereiro de 1998. AgNe (2004) relatou a coleta de um exemplar atropelado, encontrado no centro de Passo Fundo em abril de 1997. O espécime aparentemente não foi preservado e apenas uma fotografia de má qualidade foi publicada. BENCKE (2010) apresentou novas informações sobre a ocorrência de I. exilis no RS, incluindo documentação sonográfica e remetendo a dois vídeos gravados na lagoa do Morro do Forno em 2008, ambos disponibilizados na internet.

Chondrohierax uncinatus (Temminck, 1822) caracoleiro. KRÜGEL (2003) apresentou os primeiros registros confirmados no RS, documentados por filmagens e gravações de áudio (ASEC 10.046-10.051). Em adição, são conhecidos registros prováveis ou suspeitos para São Leopoldo, Sapucaia do Sul e Terra Indígena de Guarita (na divisa entre Redentora e Erval Seco), em 1977, 1989 e 2002, respectivamente (BENCKE, 2001; BencKe et al., 2003). Previamente considerado de ocorrência hipotética no RS (BENCKE, 2001).
Accipiter superciliosus (Linnaeus, 1766) - gaviãomiudinho. Um recente registro no Parque Estadual do Turvo, documentado por fotografias, foi divulgado por BENCKE (2010).

Neocrex erythrops (Sclater, 1867) - turu-turu. Um indivíduo foi observado em um valo eutrofizado nas cercanias do Parque Eólico Sangradouro, Osório, no litoral norte do estado, primeiramente por Márcio Repenning e depois por esse observador em companhia de C. S. Fontana (C.S.F.) e Jan K. F. Mähler Jr. O registro foi divulgado em MÄHLER-JR et al. (2007). Embora nenhuma documentação tenha sido obtida, $N$. erythrops é de identificação relativamente fácil e as características diagnósticas observadas, incluindo o pequeno tamanho da ave, a plumagem predominantemente cinza e a forma da marca vermelha na base do bico e escudo frontal, permitiram uma determinação inequívoca (M. Repenning, com. pess.). Além disso, a espécie é bastante propensa à vagância (TAYLOR \& VAN PERLO, 1998), havendo vários registros afastados de sua área de distribuição normal, incluindo um bem ao sul do RS, para a península Valdés, Chubut, Argentina (CAMPERI, 1992). Os registros para a laguna Setubal, Santa Fé (DE LA PEÑA, 2002), e para Pato Branco, Paraná (Straube et al., 2004), parecem ser os mais próximos do território gaúcho.

Porphyrio flavirostris (Gmelin, 1789) - frangod'água-pequeno. Até recentemente, o único registro no RS consistia na observação de um adulto nas proximidades da Estação Ecológica do Taim, em novembro de 1986 (REMSEN-JR. \& PARKER, 1990). Com base nesse registro, a espécie foi considerada provável no estado por BENCKE (2001). Um indivíduo capturado e fotografado no início de outubro de 2008 na área urbana de Pelotas (DiAs et al., 2010b) comprova a sua ocorrência no RS.

Limnodromus griseus (Gmelin, 1789) - maçaricode-costas-brancas. Uma ave em plumagem nãoreprodutiva quase completa - com algumas escapulares e coberteiras alares velhas, provavelmente um imaturo foi fotografada por Paulo Fenalti ao sul de Tramandaí (30 04'57' 'S, 5009'53'’W), em 31 de janeiro de 2011. $\mathrm{O}$ registro proveu a primeira documentação para o gênero no RS e confirmou a ocorrência de L. griseus no estado, considerada provável por BENCKE (2001). Independentemente, José A. F. Sanabria (per Caio J. Carlos, com. pess.) fotografou a espécie na mesma data e um pouco ao sul do ponto acima, provavelmente tratandose do mesmo indivíduo em ambos os registros. Nas fotos do exemplar (Figs 3-5) são visíveis as seguintes características morfológicas e estruturais, que apontam para L. griseus e, em conjunto, permitem sua diferenciação de L. scolopaceus (Say, 1822): bico relativamente curto (1,6 vezes o comprimento da cabeça) e alto na base, com ponta ligeiramente recurvada e base distintamente tingida de amarelo; tarsos relativamente curtos e amarelos, sem tonalidade esverdeada; supercílio levemente arqueado, mais largo na fronte; região da garganta e pescoço anterior extensivamente branca; baixo peito manchado, formando um limite mal definido entre o peito cinza e o ventre branco; flancos com marcas e barras esparsas, contrastando pouco com a barriga branca; dorso relativamente plano; cauda com as retrizes centrais 
predominantemente cinza, faltando as barras, e as laterais barradas, com as barras brancas tão largas quanto ou mais largas que as escuras (HAYMAN et al., 1991; LEE \& BIRCH, 2006; O'BRIEN et al., 2006). Por outro lado, o ângulo loral é relativamente baixo $\left(16^{\circ}\right)$, característica que, segundo LEE \& BIRCH (2006), sugere L. scolopaceus, porém ainda estando dentro do intervalo de variação de L. griseus (ver MALOSH, 2006 para uma visão crítica acerca desse critério de identificação).

Xema sabini (Sabine, 1819) - gaivota-de-sabine. PARRINI \& CARVAlHo (2009) apresentaram o primeiro registro dessa espécie no Brasil: um exemplar em plumagem não reprodutiva fotografado em novembro de 2009 ao sul da praia do Cassino, Rio Grande, RS. Em adição às informações e imagens apresentadas na fonte original, foi informado por um dos autores do registro que o padrão de coloração das asas típico da espécie pôde ser observado durante dois voos curtos realizados pela ave (Ricardo Parrini, com. pess.). A análise das imagens e uma consulta a Bernard Zonfrillo (University of Glasgow, Escócia), familiarizado com a espécie, indicaram tratar-se de um juvenil em plumagem de primeiro inverno, o que está de acordo com a data da observação.

Leucophaeus pipixcan (Wagler, 1831) - gaivotade-franklin. Registros recentes para o litoral gaúcho, dois dos quais documentados por fotografias, foram divulgados por DiAs et al. (2010a).

Sternula antillarum Lesson, 1847 - trinta-réismiúdo. O registro fotográfico de um indivíduo em plumagem não-reprodutiva na Lagoa do Peixe, em novembro de 2008, foi recentemente apresentado por Aldabe et al. (2010a). O trinta-réis-miúdo já havia sido mencionado para o RS sem referência a detalhes por Novelli (1997). Porém, a foto apresentada nessa fonte, obtida na praia do Cassino (Ronaldo Novelli per José F. Pacheco, com. pess.), representa na verdade um indivíduo juvenil em primeiro ano de Sterna hirundinacea Lesson, 1831, conforme determinado por Caio J. Carlos (com. pess.) e pelos autores a partir da análise de imagens e exemplares de museu. Previamente considerado provável no estado (BENCKE, 2001).

Chlidonias leucopterus (Temminck, 1815) - trintaréis-negro-de-asa-branca. Espécie do Velho Mundo fotografada na Lagoa do Peixe em novembro de 2008 (Aldabe et al., 2010b). Os registros no RS são os primeiros para o Brasil e América do Sul.

Brotogeris tirica (Gmelin, 1788) - periquito-rico. Os primeiros registros autênticos para o RS, acompanhados de documentação fotográfica, foram recentemente divulgados por BENCKE (2010). Uma menção anterior no catálogo de PETERs (1937), que provavelmente serviu de base para a inclusão do RS na distribuição da espécie em outras obras compilatórias (e.g., MEYER DE Schauensee, 1970), já foi refutada por Belton (1984), por estar aparentemente baseada em um espécime da coleção desacreditada de Joyner no antigo Museu Britânico ( $c f$. IHERING, 1899; BELTON, 1994).

Brotogeris chiriri (Vieillot, 1818) - periquito-deencontro-amarelo. A exemplo de Amazona aestiva (ver a espécie seguinte), esse psitacídeo exótico no RS vem sendo registrado regularmente na zona urbana de Porto Alegre há mais de uma década (BENCKe, 2001; FonTANA,
2005), podendo ser considerado estabelecido na cidade. Uma foto de um indivíduo em liberdade no Jardim Botânico de Porto Alegre foi publicada por BENCKE (2010).

Amazona aestiva (Linnaeus, 1758) - papagaioverdadeiro. Devido à inexistência de espécimes provenientes do estado e às incertezas que cercam as afirmações de IHERING $(1898,1899)$ sobre a presença dessa espécie nas Missões e Alto Uruguai, a ocorrência de populações nativas de $A$. aestiva no RS foi considerada hipotética por BENCKE (2001). Por outro lado, o papagaioverdadeiro ocorre como espécie introduzida na zona urbana de Porto Alegre há mais de 15 anos, havendo inclusive relatos e evidências indiretas de nidificação na cidade (Borsato et al., 1993; BENCKE, 2001; FonTANA, 2005; G. A. Bencke - G.A.B., obs. pess.). Assim, embora sua ocorrência como espécie naturalizada no RS não tenha sido assumida anteriormente (BELTON, 1994; BENCKE, 2001), esse psitacídeo pode hoje ser considerado estabelecido em Porto Alegre. Uma foto de um exemplar em liberdade no Jardim Botânico da cidade, obtida em outubro de 2006, é publicada aqui como documentação para os registros existentes (Fig. 6), visto que a foto que aparece em EFE et al. (2001) é de um indivíduo de cativeiro (Leonardo V. Mohr, com. pess.). Indivíduos livres, presumivelmente oriundos de solturas ou escapes, têm sido observados também nas cidades de São Leopoldo, Santa Cruz do Sul (G.A.B., obs. pess.) e Pelotas (R. A. Dias - R.A.D. e G. N. Maurício - G.N.M., obs. pess.). Independentemente, Arlindo L. Disconzi (com. pess.) reuniu registros fotográficos e relatos da presença de $A$. aestiva no interior de diversos municípios da região das Missões e Alto Uruguai, incluindo fotos de um exemplar que havia caído do ninho em São Luiz Gonzaga, em 2001, e de uma ave abatida em Santiago, em 2006. Em ambos os locais, indivíduos vivos foram observados e fotografados na natureza. Resta confirmar se esses registros resultam de uma ocorrência espontânea da espécie no quadrante noroeste do RS, o que parece plausível diante da existência de populações autóctones em áreas adjacentes da Argentina, ou se são decorrência de múltiplos eventos de introdução no estado.

Coccyzus euleri Cabanis, 1873 - papa-lagarta-deeuler. Antes considerado provável no estado (BENCKE, 2001), teve sua ocorrência confirmada por meio de uma gravação de áudio e fotografias obtidas no Parque Estadual do Turvo em 2004 e 2010, respectivamente, havendo um registro adicional não documentado para a Terra Indígena de Guarita (BENCKE, 2010).

Chordeiles pusillus Gould, 1861 - bacurauzinho. $\mathrm{O}$ registro de três indivíduos observados no verão de 2006 em Quaraí, no sudoeste do RS, foi relatado por REPENNING \& FONTANA (2008), que incluíram uma descrição das características diagnósticas visualizadas. Com base nesse registro circunstanciado, o bacurauzinho é aqui incluído na lista estadual. Ademais, um pequeno bacurau de voo rápido e errático, asas estreitas, afiladas e angulosas, com barra branca sobre as primárias, e cauda relativamente curta, observado por G.A.B. ao anoitecer do dia $1^{\circ}$ de dezembro de 2010 sobre uma mata ripária na restinga da Carambola ( $30^{\circ} 04^{\prime} 12^{\prime}$ 'S , 55 46'36'W), Alegrete, só poderia ter sido dessa espécie. A descoberta de C. pusillus como espécie nidificante em Misiones, 
Argentina, em meados da década passada (KRAUCZUK, 2000), confere certa coerência distribucional à ocorrência no RS.

Phaethornis pretrei (Lesson \& Delattre, 1839) rabo-branco-acanelado. Recentemente registrado na área urbana de Campinas do Sul, região norte do RS. O registro foi documentado por meio de fotografias, filmagem e gravação de áudio (DAMIANI, 2009).

Eupetomena macroura (Gmelin, 1788) - beija-flortesoura. O registro de Ruschi (1956) para os arredores de Porto Alegre, aceito por BELTON (1978a, 1984, 1994), foi descartado por BENCKE (2001) devido à inexistência de material comprobatório. Por outro lado, esse autor considerou a ocorrência de E. macroura no RS como provável com base no relato de Walter A. Voss, que avistou a espécie durante alguns dias no zoológico de Sapucaia do Sul, em 1976 (BELTON, 1994). No verão de 2008/2009, Petersen \& Petry (2009) observaram e fotografaram um indivíduo em Capão da Canoa, litoral norte do RS, confirmando a ocorrência da espécie e suprindo a falta de documentação para o estado.

Colibri serrirostris (Vieillot, 1816) - beija-flor-deorelha-violeta. Atualmente, existe documentação da ocorrência da espécie (fotografias e gravações de áudio) para três localidades do nordeste do RS (FonTANA et al., 2008; REPENNING et al., 2010). O registro de RusCHI (1956) para a região metropolitana de Porto Alegre, aceito por BeLton (1978a, 1984, 1994), foi considerado infundado por BENCKE (2001) devido à aparente inexistência de material comprobatório.

Polytmus guainumbi (Pallas, 1764) - beija-flor-debico-curvo. Observado em diversas ocasiões no município de Manoel Viana por Marilise M. Krügel, Everton R. Behr, Daniel T. Gressler e Vagner L. Camilotti durante o ano de 2006 (M. M. Krügel, com. pess.). Fotos que documentam a descoberta, obtidas por V. L. Camilotti, foram disponibilizadas aos autores para verificação.

Nonnula rubecula (Spix, 1824) - macuru. Recentemente fotografado no Parque Estadual do Turvo por Dante Meller (fotografia disponibilizada aos autores para verificação). Uma nota relatando a descoberta já foi submetida para publicação (D. Meller, com. pess.).

Stymphalornis acutirostris Bornschein, Reinert \& Teixeira, 1995 - bicudinho-do-brejo. Uma população isolada atribuível a essa espécie foi descoberta no litoral norte do RS em outubro de 2008 por G.A.B., Jan K. F. Mähler Jr, Ismael Franz e Andreas Kindel. Posteriormente, três espécimes foram coletados com a colaboração de Márcio Repenning e depositados no MCP e MCN. O status taxonômico dessa população está em estudo, mas uma avaliação preliminar indica que é muito similar, tanto morfológica quanto vocalmente, à população-típica de $S$. acutirostris, apresentando apenas sutis diferenças em caracteres passíveis de variação contínua, cujas implicações em termos de diagnosticabilidade são ainda incertas.

Scytalopus iraiensis Bornschein, Reinert \& Pichorim, 1998 - macuquinho-da-várzea. Devido a incertezas de natureza taxonômica, essa espécie foi listada por BencKe (2001) como Scytalopus sp. Embora a possibilidade de tratar-se de $S$. iraiensis tenha sido reconhecida, somente análises subsequentes de espécimes e gravações de áudio obtidas no sul do estado permitiram a identificação segura do material-testemunho como pertencente a esse táxon (Maurício, 2005; VASCONCELOS et al., 2008). Mais recentemente, estudos moleculares envolvendo todos os Scytalopus brasileiros corroboraram essa conclusão (MATA et al., 2009).

Scytalopus pachecoi Maurício, 2005 - tapaculoferreirinho. Espécie recentemente descrita que ocorre em três distintos setores do RS e em áreas adjacentes da Argentina (província de Misiones) e do estado de Santa Catarina (Maurício, 2005). Foi por longo tempo confundida com Scytalopus speluncae (Ménétriès, 1835), do qual é diagnosticável tanto por caracteres de plumagem quanto vocais e genéticos (MAURício, 2005; MATA et al., 2009). Ambas as espécies são simpátricas na região dos Campos de Cima da Serra (Maurício, 2005).

Asthenes pyrrholeuca (Vieillot, 1817) - lenheirode-rabo-comprido. Registros visuais nos municípios de Uruguaiana e Quaraí, os primeiros para o Brasil, foram divulgados por BENCKE et al. (2002) e REPENNING \& FONTANA (2008), respectivamente. Mais recentemente, em 2009, um exemplar (MCP 2.804) foi encontrado morto em uma rodovia em São Gabriel (REBELATo et al., no prelo), fornecendo suporte aos registros anteriores.

Hemitriccus margaritaceiventer (d'Orbigny \& Lafresnaye, 1837) - olho-de-ouro. O primeiro registro para o RS, baseado no reconhecimento da voz da espécie, foi recentemente divulgado por BENCKE (2010). Em 13 de janeiro de 2011, G.A.B. e R.A.D. retornaram ao local desse registro (arroio do Salso, São Borja) e documentaram sua ocorrência por meio de fotografias (Figs 7,8) e gravações de áudio (XC 70.381 e 70.382).

Phyllomyias griseocapilla Sclater, 1862 piolhinho-serrano. BENCKE (2010) apresentou detalhes sobre a ocorrência dessa espécie na Mata Atlântica do RS, previamente divulgada em BENCKE et al. (2006). Embora não exista documentação para os registros, as vocalizações descritas são compatíveis com o repertório vocal conhecido de P. griseocapilla (GonzAGA \& Castiglioni, 2001; Minns et al., 2010). Além disso, a observação de indivíduos a curta distância ou através de luneta na Reserva Biológica da Serra Geral permitiu a visualização de pormenores da plumagem, como o píleo acinzentado, os lados do peito e flancos anteriores amarelo-limão, em contraste com o centro do peito e abdômen esbranquiçados, e as margens amareloesverdeadas das rêmiges internas e coberteiras superiores da asa, sem formar barras como em outros tiranídeos similares. Essas características, em combinação com a voz, permitem uma determinação inequívoca da espécie, bem como sua diferenciação de Phyllomyias virescens (Temminck, 1824), P. fasciatus (Thunberg, 1822) e Tyranniscus burmeisteri (Cabanis \& Heine, 1859), também presentes na região (G.A.B., obs. pess.).

Serpophaga griseicapilla Straneck, 2007 alegrinho-trinador. Essa espécie foi por muito tempo confundida com Serpophaga subcristata (Vieillot, 1817), tendo sido reconhecida primeiramente por STRANECK (1993), que utilizou o nome específico griseiceps Berlioz, 1959. No entanto, esse nome se mostrou inaplicável (HERZOG \& BARNETT, 2004) e o táxon permaneceu sem uma designação válida até que STRANEcK (2007) o descreveu 
como Serpophaga griseicapilla. Os primeiros registros no RS e no Brasil, acompanhados de documentação sonográfica, foram divulgados por BENCKE et al. (2002), sob Serpophaga griseiceps. Registros adicionais foram apresentados por BENCKE et al. (2007) e BENCKE (2010), e uma gravação encontra-se publicada em MinNs et al. (2010).

Serpophaga munda Berlepsch, 1893 - alegrinhode-barriga-branca. Esse táxon foi tratado como subespécie de Serpophaga subcristata por BENCKE (2001), mas vem sendo considerado uma espécie distinta pelo CBRO e SACC há vários anos. BELTON $(1985,1994)$ mencionou um espécime do RS atribuível a munda, coletado por E. Kaempfer em Arroio del Rei no final de agosto de 1931 (o qual, porém, foi listado sob $S$. subcristata straminea por ZIMMER, 1955), e uma observação em Santa Isabel do Sul, em julho de 1991. AcCORdi \& HARTz (2006) relataram o aparecimento de exemplares da raça $S$. s. munda durante o outono e inverno no Banhado dos Pachecos, Viamão, mas não informaram como a identificação foi confirmada. Todos esses registros de inverno presumivelmente referem-se a indivíduos migratórios provenientes das áreas de reprodução da espécie, situadas ao longo do sopé oriental dos Andes (Herzog, 2001; Ridgely \& Tudor, 2009). Já a população residente com características de munda mencionada para a fronteira com o Uruguai por BENCKE (2001) não é claramente atribuível a esse táxon, por razões biogeográficas e distribucionais, e requer estudos.

Agriornis murinus (d'Orbigny \& Lafresnaye, 1837) - gauchinho. Um indivíduo foi observado e fotografado junto ao litoral no balneário do Cassino, Rio Grande, em abril de 2009 (DiAs et al., 2010b). Segundo os autores, esse registro e uma observação adicional efetuada no mesmo local em julho de 2009 constituem as primeiras menções da espécie e do gênero para o Brasil.

Fluvicola albiventer (Spix, 1825) - lavadeira-decara-branca. No arquivo online do VIREO há uma foto (n. ${ }^{\circ}$ d01/34/078) obtida no RS por John Dunning, fotógrafo de aves falecido em 1987. Uma consulta ao administrador do VIREO confirmou que o diapositivo original traz a anotação "Rio Grande do S Brasil" escrita a lápis sobre a moldura e que a caligrafia é consistente com inscrições feitas à mão em outros diapositivos originais de Dunning. Adicionalmente, um código na moldura do slide indica que o filme foi revelado em maio de 1981, o que pressupõe que a foto foi obtida um pouco antes. É estranho que BELTON $(1985,1994)$ não tenha mencionado a espécie, visto que Dunning buscou a colaboração desse ornitólogo no RS, com o objetivo de aumentar a sua coleção de imagens de aves neotropicais. O livreto Aves silvestres do Rio Grande do Sul (Belton, 1982), ilustrado com as fotos de Dunning, é fruto dessa associação. Nessa obra consta que Dunning e Belton trabalharam juntos em 1973 e 1974. Assim, pode-se supor que Dunning obteve a foto de $F$. albiventer em uma expedição posterior e que Belton não tomou conhecimento desse registro. Essa hipótese é reforçada pelo fato de que Belton esteve fora do estado durante a maior parte do ano de 1981, incluindo todo o primeiro semestre (BELTON, 1994), quando supostamente a foto de Dunning foi obtida. No Uruguai, $F$. albiventer está presente ao longo da costa do rio Uruguai, desde
Paysandú a Colonia, e ao longo do Rio da Prata e do litoral atlântico, de Colonia a Rocha (AzPIROz, 2001; Claramunt \& Cuello, 2004; Rocha, 2006). No território argentino adjacente, distribui-se de Misiones e Corrientes, onde parece restringir-se às proximidades do rio Paraná, até Entre Ríos e Buenos Aires, onde ocorre ao longo do rio Uruguai e Rio da Prata (DARRIEU \& CAMPERI, 1992; Narosky \& Di Giácomo, 1993; CheBeZ, 1996; DE LA PeÑA, 2006). Em todas essas regiões, a espécie é considerada um residente estival (AzPIROZ, 2001; GIRAUDO et al., 2003; NAROSKY \& YZURIETA, 2003; RAFFO et al., 2009). Portanto, sendo migratória no sul de sua distribuição geográfica e estando presente em áreas próximas à fronteira uruguaia e argentina, uma ocorrência ao menos ocasional no RS é plausível. Assim, o registro de Dunning é aceito aqui como evidência da ocorrência de $F$. albiventer no estado, constituindo o único registro conhecido para o território gaúcho até o momento. A espécie foi recentemente registrada também no litoral de Santa Catarina (Amorim \& Piacentini, 2007).

Oxyruncus cristatus Swainson, 1821 - arapongado-horto. Um indivíduo foi fotografado e filmado por G.A.B. em floresta atlântica de encosta no lado gaúcho do cânion Josafaz (29¹9'11's, 5003'06”W; 480 m), município de Mampituba, durante expedição com integrantes do Clube de Observadores de Aves de Porto Alegre (Walter Hasenack, Ruben Poerschke e Marcelo Medaglia), em 15 de novembro de 2010 (Fig. 9). Previamente, conheciam-se no RS apenas dois registros auditivos para o Parque Estadual do Turvo, com base nos quais a espécie foi considerada hipotética no estado (BENCKE, 2001), e outro não confirmado para a Floresta Nacional de São Francisco de Paula (BARNETT et al., 2004).

Xenopsaris albinucha (Burmeister, 1869) - tijerila. Um indivíduo foi capturado e fotografado em Passo Fundo por Nêmora P. Prestes e colaboradores em abril de 2008. Uma fotografia foi disponibilizada aos autores para verificação. O registro encontra-se em fase de publicação (N. P. Prestes, com. pess.). Um segundo registro no estado ocorreu próximo à cidade de Barra do Quaraí, onde um indivíduo foi observado por Ricardo Parrini e Carlos Eduardo Carvalho em novembro de 2009 (R. Parrini, com. pess.).

Saltator coerulescens Vieillot, 1817 - sabiá-gongá. A ocorrência dessa espécie no oeste e noroeste do RS, documentada por gravações e por registro fotográfico, foi recentemente relatada por BENCKE (2010).

Orthogonys chloricterus (Vieillot, 1819) catirumbava. Um espécime foi coletado no estado em maio de 2003. Detalhes sobre esse e outros registros na Mata Atlântica gaúcha constam em BENCKE (2010).

Phrygilus fruticeti (Kittlitz, 1833) - canário-andinonegro. GRANTSAU (2002) relatou a coleta de um espécime no Banhado do Taim, em 1971. Embora esse exemplar permaneça depositado em coleção particular, uma foto diagnóstica foi publicada no artigo original. Há ainda um registro visual de Walter A. Voss para Candiota, em 1987, divulgado em BENCKE (2001), com base no qual a espécie foi anteriormente considerada provável no RS.

Sporophila lineola (Linnaeus, 1758) - bigodinho. A ocorrência dessa espécie no nordeste do RS a partir de 2004, documentada por fotografias e gravações de áudio, foi relatada por BENCKE (2010). 

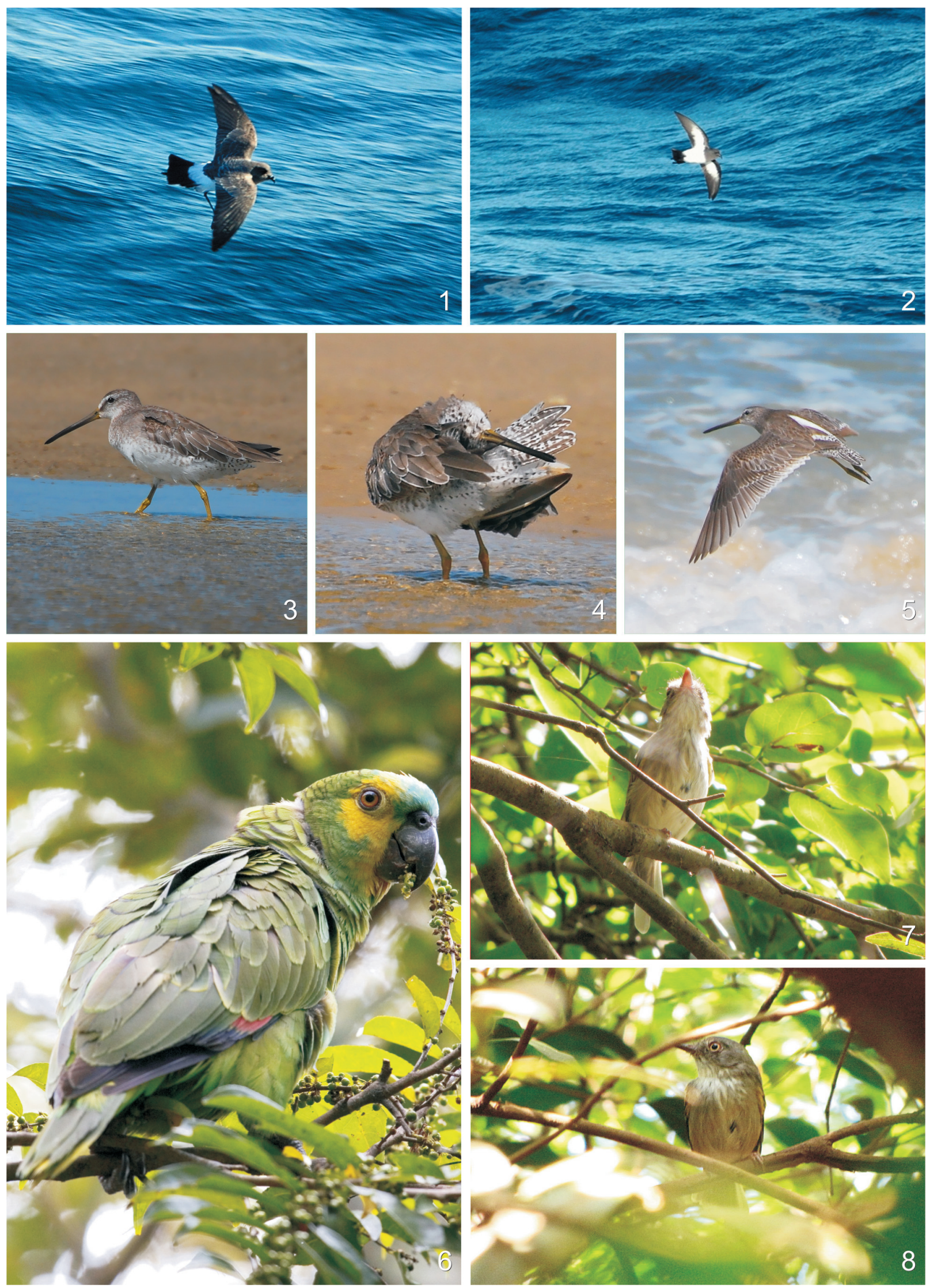

Figuras 1-8. 1, 2, Fregetta grallaria (Vieillot, 1818) ao largo da costa do RS, entre $33^{\circ} 49^{\prime}-33^{\circ} 39^{\prime} \mathrm{S}$ e $50^{\circ} 03^{\prime}-50^{\circ} 23^{\prime} \mathrm{W}$, agosto de 2007 (Leandro Bugoni); 3-5, Limnodromus griseus (Gmelin, 1789), Tramandaí, janeiro de 2011 (Paulo Fenalti); 6, Amazona aestiva (Linnaeus, 1758), Jardim Botânico de Porto Alegre, outubro de 2006 (Adriano Becker); 7, 8, Hemitriccus margaritaceiventer (d'Orbigny \& Lafresnaye, 1837), arroio do Salso, São Borja, janeiro de 2011 (Glayson Bencke). 
Sporophila leucoptera (Vieillot, 1817) - chorão. Dois machos adultos foram observados em São Borja, na fronteira com a Argentina, em junho de 2008, estando o registro documentado por fotografias (BECKER, 2009).

\section{Espécies excluídas}

Spiziapteryx circumcincta (Kaup, 1852) falcãozinho-cinza. A inclusão dessa espécie na lista estadual por BENCKE (2001) baseou-se na observação de um indivíduo no município de Herval por Scherezino B. Scherer e Ana C. de Menezes, em outubro de 1998. Entretanto, uma nova análise desse registro indica que a descrição fornecida não permite descartar a possibilidade de confusão com um jovem Accipiter bicolor (Vieillot, 1817), espécie presente na região de Herval (BELTON, 1994) e que também possui ventre riscado na fase juvenil e asas arredondadas (Ferguson-Lees \& Christie, 2005). Assim, tendo em vista a ausência de documentação para o único registro em território brasileiro e a falta de elementos que permitam uma identificação segura, a presença do falcãozinho-cinza no estado é aqui considerada incerta e a espécie passa à condição de provável até que evidências mais convincentes de sua ocorrência estejam disponíveis. Outras linhas de evidência igualmente oferecem pouco suporte ao registro de Scherer e Menezes. Spiziapteryx circumcincta ocorre em savanas, estepes arbustivas, bosques xerófilos e semidesertos da Patagônia argentina ao oeste do Paraguai e sul da Bolívia, tipicamente habitando as formações de arvoretas espinhentas que caracterizam o Espinal e o Chaco (White et al., 1994; mas ver Leveau \& Leveau, 2003 e SÁNCHEZ \& SAVIGNY, 2005 para registros recentes em outros ambientes). Sua principal área de ocorrência na Argentina situa-se a oeste do rio Paraná, estando presente apenas raramente nas províncias junto à fronteira com o RS (CONTRERAS, 1986; White et al., 1994; DE LA PeÑa, 2006). Os parcos registros uruguaios são para áreas de espinal em Paysandú e Artigas, no norte do país (Arballo \& Cravino, 1999; AzPiroz, 2001; Rocha, 2008; Olmos, 2009). Portanto, sob o ponto de vista biogeográfico, a presença de Spiziapteryx circumcincta no RS seria esperada no extremo oeste, principalmente em fitofisionomia de parque espinilho, onde a formação de espinal, caracterizada pela dominância fisionômica das arvoretas Prosopis nigra, P. affinis, Acacia caven, Parkinsonia aculeata (Leguminosae) e Aspidosperma quebracho-blanco (Apocynaceae), alcança sua expressão máxima em território brasileiro. Uma série de aves típicas desse ambiente e que exibem distribuição similar à de $S$. circumcincta são encontradas ali (BELTON, 1994), mas a maioria não ocorre em Herval e municípios vizinhos, embora existam intrusões de Acacia caven nessa região, junto ao rio Jaguarão. Além disso, a espécie é sedentária ao longo de sua distribuição geográfica e as localidades mais próximas de ocorrência conhecida situam-se a $400 \mathrm{~km}$ de distância (White et al., 1994; Arballo \& Cravino, 1999). Logo, é baixa a probabilidade de o registro gaúcho referir-se a um indivíduo vagante, especialmente na primavera.

Forpus xanthopterygius (Spix, 1824) - tuim. O espécime desaparecido de GLIESCH (1930) constitui a única referência concreta sobre a ocorrência dessa espécie no RS (BENCKE, 2001). A procedência desse espécime é desconhecida devido a um erro de impressão na lista de Gliesch, conforme já advertido por BELTON (1984). Assim, embora seja mais provável que o exemplar tenha vindo de alguma localidade do norte ou noroeste do estado, é possível que seja oriundo do mercado público de Porto Alegre, onde Gliesch obteve alguns de seus espécimes. Os registros para Puerto Valle e San Gará, em Corrientes (Giraudo et al., 2003), e para Corpus Christi, em Misiones (Krauczuk, 2008), ambos ao longo do rio Paraná, juntamente com aqueles no leste de Santa Catarina, até $28^{\circ} \mathrm{S}$ (Rosário, 1996), parecem ser os mais próximos do $\mathrm{RS}$, mas o desconhecimento da origem do exemplar de Gliesch impede uma avaliação mais consistente da coerência distribucional do registro gaúcho. Por fim, é improvável que essa espécie bastante conspícua e típica de ambientes alterados tenha-se extinguido no RS desde então, e a falta de qualquer outra evidência de sua presença, decorridos 80 anos desde a única menção para o estado, constitui fato relevante. Com base nesses elementos, o tuim é aqui excluído da lista do RS até que evidências mais seguras estejam disponíveis, passando à condição de espécie de ocorrência hipotética.

Ramphodon naevius (Dumont, 1818) - beija-florrajado. A inclusão dessa espécie na lista do RS baseia-se num espécime de Porto Alegre sem data de coleta conhecida, citado por Gliesch (1930). Porém, esse exemplar não mais está disponível para exame (ver adiante, sob Alectrurus risora) e o registro para Porto Alegre carece inteiramente de coerência biogeográfica e distribucional. Por essas razões, a ocorrência de $R$. naevius no RS é aqui considerada hipotética.

Glaucis hirsutus (Gmelin, 1788) - balança-rabo-debico-torto. Esse beija-flor foi incluído na lista do RS por BENCKE (2001) com base em VIELLIARD (1994), que apontou a existência de um espécime procedente de Porto Alegre na coleção do MBML, coletado por A. Ruschi em 1946. Contudo, a ocorrência de G. hirsutus no RS e, particularmente, em Porto Alegre carece de coerência distribucional e biogeográfica, sendo escassos e mal documentados os registros ao sul do estado de São Paulo (Fernando C. Straube, Vítor de Q. Piacentini, com. pess.). Além disso, a localidade de coleta indicada na etiqueta do exemplar do MBML (Fazenda Retiro, Nazareth) não consta em guias históricos e mapas antigos de Porto Alegre e arredores, conforme verificado por FonTANA (2005), contra BENCKE (2001). Em vista desses fatos, e levando-se em conta as dúvidas que pairam sobre outros registros de Ruschi (Pacheco, 1995; Bencke, 2001; Pacheco \& Bauer, 2001), a espécie é aqui excluída da lista estadual e considerada de ocorrência hipotética no RS.

\section{Espécies sem documentação mantidas na lista}

Anas discors Linnaeus, 1766 - marreca-de-asa-azul. Conhecida no RS apenas por uma recuperação de anilha de um macho jovem anilhado em Saskatchewan, Canadá, em agosto de 1971 e reencontrado perto de Viamão em novembro de 1972 (Belton, 1994). Embora esse registro careça de documentação e a área de invernagem principal de A. discors estenda-se somente até o norte da América 
do Sul (MAdGe \& BuRn, 1988), a espécie foi mantida na lista estadual considerando que uma eventual confusão com algum outro anatídeo migratório na região onde o exemplar foi anilhado parece improvável e que são conhecidos diversos registros sul-americanos presumivelmente de aves vagantes - em áreas situadas ao sul do RS, incluindo um espécime do Uruguai (Arballo \& CRAVINO, 1999). Um erro de identificação só seria esperado em relação a Anas cyanoptera Vieillot, 1816. Contudo, aparentemente não se conhecem registros da raça norte-americana - A. c. septentrionalium - ao sul do Equador (BLAKE, 1977); além disso, Saskatchewan situa-se levemente fora da distribuição reprodutiva dessa subespécie (GAMMONLEY, 1996), mas totalmente dentro da área de reprodução de $A$. discors.

Parabuteo unicinctus (Temminck, 1824) - gaviãoasa-de-telha. Mantido na lista em vista da existência de diversos registros no RS, obtidos por diferentes pesquisadores em distintas regiões do estado. Esses registros, em parte circunstanciados, estão sumariados em BENCKE (2001) e BENCKE et al. (2003). Adicionalmente, há um espécime antigo sem procedência conhecida, mas provavelmente oriundo do estado, no Museu Carlos Ritter, Pelotas (BENCKE, 2001). A espécie ocorre em regiões vizinhas do Uruguai (Arballo \& Cravino, 1999) e Argentina (NAROSKY \& YZURIETA, 2003).

Falco rufigularis Daudin, 1800 - falcão-degarganta-branca. Embora careçam de documentação, os registros para o Parque Estadual do Turvo, sumariados em BENCKE et al. (2003), são aqui aceitos com base em dois aspectos principais. Primeiro, a identificação de $F$. rufigularis em campo só poderia oferecer dificuldades em relação ao extremamente raro falcão-de-peitovermelho, $F$. deiroleucus Temminck, 1825, que possui porte perceptivelmente maior, e, segundo, a ocorrência da espécie no extremo norte do estado é esperada dada a sua presença nos departamentos vizinhos de Guaraní e San Pedro, na província de Misiones, Argentina (Navas \& Bó, 1991; CHEBEZ, 1996).

Philomachus pugnax (Linnaeus, 1758) combatente. Há dois registros para o estado (MAURício \& Dias, 2000; Pacheco, 2000) dessa espécie do Velho Mundo encontrada com certa frequência na América do Sul (REMSEN-JR et al., 2010). Assume-se a ocorrência no RS com base nas características diagnósticas observadas e mencionadas por MAURício \& DiAs (2000).

Chlidonias niger (Linnaeus, 1758) - trinta-réisnegro. Há apenas um punhado de observações não documentadas no RS, visto que os "diversos" registros para o Parque Nacional da Lagoa do Peixe citados em BENCKE (2001) carecem de sustentação (ver revisão em DiAs et al., 2010a). A ocorrência no estado é assumida com base em DiAs et al. (2010a), que relataram a observação das manchas escuras diagnósticas nas laterais do peito, em frente às asas, em indivíduos avistados junto à desembocadura da Lagoa dos Patos. A origem dos exemplares observados no RS é indeterminada, já que a raça C.n. surinamensis, que nidifica na América do Norte, foi registrada na Argentina (ConTrERAS, 1979), enquanto C. n. niger, do Velho Mundo, é citada para o nordeste do Brasil (SICK, 1997).

Anodorhynchus glaucus (Vieillot, 1816) - arara-azul- pequena. Apesar da inexistência de documentação, essa espécie presumivelmente extinta foi mantida na lista com base nas claras evidências circunstanciais de sua presença pretérita na fronteira oeste e no centro-sul do estado, sumariadas e discutidas em BENCKE (2001) e BENCKE et al. (2003). O ponto no oeste do RS indicado no mapa publicado por Alvarenga (2007), que não corresponde a nenhuma localidade de ocorrência conhecida da espécie, refere-se ao relato histórico de Friedrich Sellow para Caçapava do Sul (Herculano Alvarenga, com. pess.), estando, portanto, em posição incorreta. Esse autor sugeriu que A. glaucus e Anodorhynchus leari Bonaparte, 1856 possuíam distribuição contínua no passado (há cerca de 10 mil anos) e que provavelmente representam os extremos de um mesmo táxon.

Notharchus swainsoni (Gray, 1846) - capitão-domato. Há apenas um registro visual não documentado no RS, obtido por dois observadores no Parque Estadual do Turvo (BENCKE, 2001). A manutenção da espécie na lista está amparada na descrição dos caracteres diagnósticos observados em campo, os quais permitem a identificação segura da ave (BENCKE, 2001). Além disso, o registro possui coerência distribucional, visto que a espécie é conhecida da vizinha província argentina de Misiones, meridionalmente até os departamentos de Cainguás e San Pedro (Chebez, 1996; Schmidtuz et al., 2001).

Campephilus leucopogon (Valenciennes, 1826) pica-pau-de-barriga-preta. Essa espécie tem sido mantida na lista das aves do RS com base em um exemplar supostamente proveniente da fronteira com o Uruguai, coletado por Auguste St. Hilaire por volta de 1821. Porém, as evidências de que esse espécime procede do RS são circunstanciais e, em parte, especulativas (BELTON, 1984), não permitindo descartar a possibilidade de que o mesmo tenha sido obtido em território uruguaio. No entanto, um indivíduo foi observado por C.S.F. em Quaraí (30²8'52"'S, $56^{\circ} 20^{\prime} 40^{\prime}$ 'W), em 27 de dezembro de 2008. Na ocasião, um pica-pau escuro de cerca de $30 \mathrm{~cm}$ de comprimento total, com cabeça e crista vermelhas e uma conspícua mancha cor de creme nas costas, pousou em uma árvore a cerca de $8 \mathrm{~m}$ de distância, posteriormente voando em direção ao rio Quaraí, fronteira com o Uruguai. Assim, embora a procedência do espécime de St. Hilaire seja incerta, a espécie foi mantida na lista com base nesse registro atual. Em adição, numerosos registros recentes, vários dos quais documentados, foram mencionados por AzPIROZ \& MENÉNDEZ (2008) para o norte do Uruguai, pelo menos uma das localidades citadas distando menos de $80 \mathrm{~km}$ da divisa com o estado.

Chloris chloris (Linnaeus, 1758) - verdelhão. A única menção dessa espécie exótica para o RS baseia-se na observação de dois indivíduos em Barra do Chuí pelos ornitólogos uruguaios E. Arballo e J. Cravino, em outubro de 1990 (BENCKE, 2001). Embora o registro não esteja circunstanciado, a espécie é inconfundível e ocorre ao longo do litoral uruguaio até a fronteira com o Brasil (AzPIROZ, 2001; RochA, 2008; Olmos, 2009), razão pela qual foi mantida na lista. Visto ser pouco comum no Uruguai (AzPIROz, 2001; Rocha, 2008; Olmos, 2009), a ausência de registros frequentes no território gaúcho adjacente não causa surpresa. 


\section{Outras alterações consideradas}

Scytalopus speluncae (Ménétriès, 1835) - tapaculopreto. O CBRO (2009) acatou a recente proposta (RAPOSO et al., 2006) de considerar o nome $S$. speluncae como aplicável a uma espécie cinza-claro ocorrente nas serras do centro-leste mineiro. Concomitantemente, esse comitê aceitou o nome novo S. notorius Raposo, Stopiglia, Loskot \& Kirwan, 2006 como designação para o táxon cinza-escuro das serras costeiras e planaltos do sul e sudeste do Brasil, historicamente tratado sob o nome $S$. speluncae. Contudo, uma nova análise dessa questão (MAurí́cio et al., 2010; ver também WhitNey et al., 2010) sustenta que o espécime-tipo de $S$. speluncae não apresenta os caracteres diagnósticos da forma cinza-claro e sim os da forma cinza-escuro, acomodando-se perfeitamente dentro da variação individual dessa última, conclusão que leva a considerar $S$. notorius como sinônimo-júnior de $S$. speluncae. Adota-se aqui essa última proposta, que também foi acatada em CBRO (2010), a qual corresponde ao tratamento empregado em quase toda a literatura ornitológica neotropical, antiga ou recente, inclusive em fontes referenciais como BELTON (1985, 1994), SicK (1997) e REMSEN-JR et al. (2010).

Sporophila zelichi Naroski, 1977 - caboclinho-decoleira-branca. BENCKE (2004) relatou a observação de um macho de caboclinho com plumagem plenamente compatível com a descrita para S. zelichi na Reserva Biológica de São Donato, oeste do estado. Até então, o táxon em questão era conhecido apenas de poucas localidades da Argentina, Paraguai e Uruguai (BIRDLifE INTERNATIONAL, 2004). Segundo os critérios aqui adotados, S. zelichi seria passível de inclusão na lista de aves do estado com base nesse registro circunstanciado. Contudo, uma análise pormenorizada do seu status taxonômico (ARETA, 2008), fundamentalmente baseada em caracteres vocais e ecológicos, levou à conclusão de que essa forma não constitui uma espécie válida, sustentando fortemente a antiga suspeita de que a mesma seria apenas um morfo de S. palustris. Por essa razão, S. zelichi não é incluída na lista das aves do RS [para uma discussão detalhada sobre o tema, ver REMSEN-JR et al. (2010, proposta 376), que acataram a proposta de ARETA (2008) de sinonimização de S. zelichi em S. palustris].

\section{Atualizações de documentação}

Dendrocygna autumnalis (Linnaeus, 1758) marreca-asa-branca. A única documentação conhecida para o RS - diapositivos que substanciam os registros de GuADAGNin et al. (1995) no oeste do estado - não está depositada em arquivo que permita fácil acesso e rastreabilidade. Nova documentação fotográfica (Figs 10, 11) foi recentemente obtida por G.A.B. e R.A.D. na localidade de Rincão do São Donato (28 54 '55'S, $\left.56^{\circ} 05^{\prime} 26^{\prime \prime} \mathrm{W}\right)$, município de Maçambará. Na ocasião, 12 indivíduos acompanhados de algumas Dendrocygna viduata (Linnaeus, 1766) descansavam em um pequeno banhado formado junto ao sangradouro de um açude, pouco ao sul do rio Butuí.

Aptenodytes patagonicus Miller, 1778 - pinguimrei. BARQUETE et al. (2006) revisaram os seis registros da espécie conhecidos até então no Brasil, todos documentados, dos quais cinco ocorreram no RS, incluindo o de MoHR (2004) em Tavares. Os registros gaúchos citados por esses autores estão documentados por fotografias. Em adição, um espécime (CAFURG 428) oriundo do Centro de Recuperação de Animais Marinhos, de Rio Grande, foi capturado ainda vivo a cerca de $30 \mathrm{~km}$ ao sul do Cassino, em 11 de fevereiro de 2006.

Jabiru mycteria (Lichtenstein, 1819) - jabiru ou tuiuiú. Além dos registros visuais e do exemplar de origem incerta mencionados em BeLTON (1994) e MAURício \& DiAS (2000), fotografias obtidas em Alegrete e Venâncio Aires foram publicadas por Ruschel \& COSTA (2003) e PUtZKE (2006), respectivamente.

Morus capensis (Lichtenstein, 1823) - atobá-docabo. Vooren (2004) publicou uma das fotografias que documentam os seus registros de dois indivíduos sobre a plataforma continental do RS, em julho/agosto de 1982 e abril de 1983. Esses registros foram previamente divulgados em Vooren (1985) e, juntamente com outro exemplar observado em Santa Catarina a pelo menos 80 mn da costa (Olmos, 1997), parecem ser os únicos da espécie no Brasil (REBSTOCK et al., 2010).

Sula leucogaster (Boddaert, 1783) - atobá-pardo. Além dos dois registros de aves anilhadas nas Ilhas Moleques do Sul (SC) e recuperadas no litoral do RS, originalmente relatados por BEGE \& PAULI (1989) e RosÁrIO (1996) e mais tarde compilados por BenCKe (2001) e detalhados em MoHr et al. (2005), outros dois exemplares foram recuperados com anilha no RS, um proveniente de Santa Catarina e outro do Paraná (EFe et al., 2006). МонR et al. (2005) publicaram a foto de um exemplar encontrado vivo no Parque Nacional da Lagoa do Peixe, em dezembro de 2004, provendo a única evidência material disponível para o estado até agora.

Nyctanassa violacea (Linnaeus, 1758) - savacude-coroa. Não são conhecidos espécimes do estado, visto que o exemplar de Torres listado por GLIESCH (1930) procede do lado catarinense do rio Mampituba (BENCKE et al., 2003), conforme se depreende a partir do relato de GLIESCH (1925). Por outro lado, documentação fotográfica obtida no estuário da Lagoa dos Patos, inclusive de atividades reprodutivas, consta em GianUCA (2007).

Egretta caerulea (Linnaeus, 1758) - garça-azul. Ocorrências documentadas por fotografias foram relatadas por Mohr (2003) e Gianuca et al. (2008). A reprodução da espécie no RS foi recentemente constatada em Rio Grande (GianUCA et al., 2009), de onde provém um ninhego coletado em 24 de janeiro de 2009 (MCP 2.662).

Mesembrinibis cayennensis (Gmelin, 1789) - corócoró. Fotos de um indivíduo, uma das quais é publicada aqui (Fig. 12), foram feitas por L.B. em 24 de dezembro de 2008 no município de Caseiros ( $\left.28^{\circ} 16^{\prime} \mathrm{S}, 51^{\circ} 41^{\prime} \mathrm{W}\right)$, setor nordeste do estado. Exemplares isolados ou grupos de até cinco indivíduos têm sido vistos nesse local desde 2003, ao longo de todo o ano (L.B., obs. pess.). Existe um exemplar empalhado no Museu Carlos Ritter, Pelotas, que provavelmente foi coletado no RS, mas sua origem é incerta (BENCKE, 2001). Não se conhece outra documentação publicada para o estado.

Phoenicoparrus andinus (Philippi, 1854) flamingo-andino. A única documentação referida na 
literatura científica é uma fotografia publicada em uma revista agropecuária, que segundo BORNSCHEIN \& REINERT (1996) foi tirada na Lagoa do Peixe no outono de 1992. Considerando que a imagem não foi apresentada em uma publicação científica, divulga-se aqui, em complementação, documentação fotográfica diagnóstica obtida por G.A.B. em 14 de janeiro de 2010 próximo à trilha da Figueira ( $\left.31^{\circ} 19^{\prime} \mathrm{S}, 51^{\circ} 03^{\prime} \mathrm{W}\right)$, Parque Nacional da Lagoa do Peixe (Fig. 13).

Cathartes burrovianus Cassin, 1845 - urubu-decabeça-amarela. Até aqui, a inclusão dessa espécie comum na lista estadual não estava embasada por evidências físicas publicadas ou disponíveis para verificação (BENCKE, 2001). Uma foto diagnóstica obtida por G.A.B. em 4 de abril de 2007 ao longo da estrada do arroio Pai-Passo $\left(30^{\circ} 00^{\prime} \mathrm{S}, 5^{\circ} 51^{\prime} \mathrm{W}\right)$, a sul-sudoeste de Alegrete, é publicada aqui para suprir a carência de documentação para o RS (Fig.14). Há um espécime antigo, de procedência incerta mas provavelmente oriundo do estado, no Museu Carlos Ritter, Pelotas.

Sarcoramphus papa (Linnaeus, 1758) - urubu-rei. IHERING (1899) afirmou ter notícias de exemplares caçados em Taquari, São Leopoldo e Vacaria, e, segundo BELTON (1984), haveria ainda um exemplar de Erechim. Contudo, nenhum desses espécimes foi localizado até agora. Uma fotografia de um indivíduo adulto obtida no município de Bom Jesus foi publicada em FonTANA et al. (2009), constituindo a primeira documentação segura para o RS.

Pandion haliaetus (Linnaeus, 1758) - águiapescadora. Há diversos registros no RS (BELTON, 1994; Maurício \& Dias, 2000), mas o único espécime proveniente do estado (GLIESCH, 1930) se perdeu e não se conhece outra documentação. Por essa razão, uma fotografia obtida por R.A.D. na Granja Quatro Irmãos (32 ${ }^{\circ} 12^{\prime}$ S, $52^{\circ} 35^{\prime} \mathrm{W}$ ), Rio Grande, em 3 de fevereiro de 1999 , é aqui apresentada (Fig. 15) para prover uma evidência material recente da presença da espécie no RS. Esse registro é mencionado em MAURício \& DiAs (2000).

Pseudastur polionotus (Kaup, 1847) - gaviãopombo-branco. KIRWAN \& WILLIAMS (1999) fotografaram um par entre Cambará do Sul e o cânion Fortaleza em fevereiro de 1997. Segundo um dos autores desse registro, as fotos seriam depositadas no VIREO (BENCKE, 2001). No entanto, não há qualquer registro relativo a essas imagens no referido arquivo (Doug Wechsler, com. pess.). Consequentemente, a documentação existente não está disponível para verificação. Por outro lado, há diversos registros visuais no RS (sumariados em BENCKE et al., 2003), obtidos por diferentes pesquisadores em distintas localidades do quadrante nordeste do estado, e também em regiões adjacentes de Santa Catarina (ACCORDI \& Barcellos, 2008; SoARes et al., 2008). O registro de G.N.M. e Cristian M. Joenck para o alto rio das Antas, São José dos Ausentes, em julho de 2002 (citado em BENCKE et al., 2003), envolveu a observação de um casal em atividade de cópula sobre uma araucária (Araucaria angustifolia). Ambas as aves eram adultas e apresentavam tamanho aproximado ao de Heterospizias meridionalis (Latham, 1790), tendo cabeça, pescoço e todo o lado inferior brancos, manto escuro com lustro prateado no alto dorso e cauda com metade basal preta e metade apical branca. Os registros para Viamão divulgados por Voss (1982) foram confirmados pelo exame de uma rêmige encontrada no local.

Herpetotheres cachinnans (Linnaeus, 1758) acauã. BELTON (1978b) relatou ter gravado a voz dessa espécie perto de Garruchos, em 5 de agosto de 1973, a qual foi identificada por Helmut Sick. Essa gravação serviu de base para indicar a existência de documentação sonora para a ocorrência do acauã no RS em BENCKE (2001). Contudo, o exame da gravação de Belton, depositada no arquivo bioacústico da Macaulay Library (ML Audio 18.853), mostra claramente que a voz gravada é de Micrastur semitorquatus (Vieillot, 1817), espécie que Belton não chegou a conhecer no RS (BELTON, 1994). Informações complementares associadas à gravação confirmam que a ave gravada não foi observada e que o grau de certeza atribuído à identificação da espécie foi de $80 \%$. BELTON (1978b) afirmou ainda ter confirmado a identificação por comparação com uma gravação de $H$. cachinnans feita por Paul Schwartz, mas nenhuma das várias gravações desse autor depositadas na Macaulay Library assemelha-se à voz gravada por Belton, exceto pelo timbre. Em resumo, a única evidência comprobatória da presença de $H$. cachinnans no RS disponível para consulta em acervo de acesso público é inválida. Há vários registros recentes do acauã no estado, especialmente no litoral norte (BENCKE et al., 2003). Uma gravação do canto solo da espécie, obtida por G.A.B. ao sul da lagoa do Morro do Forno, divisa Três Cachoeiras/Dom Pedro de Alcântara, em 2 de outubro de 2008, consta no arquivo digital do xeno-canto (XC 62.322).

Porzana flaviventer (Boddaert, 1783) - sanãamarela. Observada em São Leopoldo, em novembro de 1975 (Voss, 1977), e em Pelotas, em agosto de 1998 (Maurício \& Dias, 2000). Um espécime (MCP 1.993) foi coletado por C.S.F. em 30 de novembro de 2007 no Parque Eólico de Osório, após colisão com um aerogerador. Há ainda uma gravação (ML Audio 91.072), citada em BENCKE (2001), cuja identificação requer confirmação.

Numenius phaeopus (Linnaeus, 1758) - maçaricode-bico-torto. Em adição aos registros visuais mencionados em BeLTON (1994), há documentação fotográfica da praia do Cassino, Rio Grande, feita por Cláudio D. Timm, em 2 de abril de 2010 (Fig. 16), e por R.A.D. em 30 de outubro de 2008 (Fig. 17), e também de Tavares, obtida em 18 de abril de 2010 por Oscar A. Fenalti (Fig. 18). No Brasil existem registros das subespécies $N$. p. hudsonicus, da América do Norte, e N. p. phaeopus, do Velho Mundo (Olson, 1982; Piersma et al., 1996; Sick, 1997; Silva E Silva \& Olmos, 2006). As aves fotografadas no litoral gaúcho exibem cabeça pálida, supercílio cremeesbranquiçado pouco estriado (especialmente em frente ao olho), faixas látero-coronal e ocular escuras, partes inferiores acaneladas, dorso escuro, cauda amarronzada e porção inferior das asas marrom-acanelado fortemente barrado. Essas características são diagnósticas de N. p. hudsonicus (sensu BosAnQuet, 2000; Vinicombe, 2010). ZINK et al. (1995) demonstraram que as duas subespécies são geneticamente distintas e exibem histórias evolutivas independentes, podendo ser elevadas à categoria de espécie. 

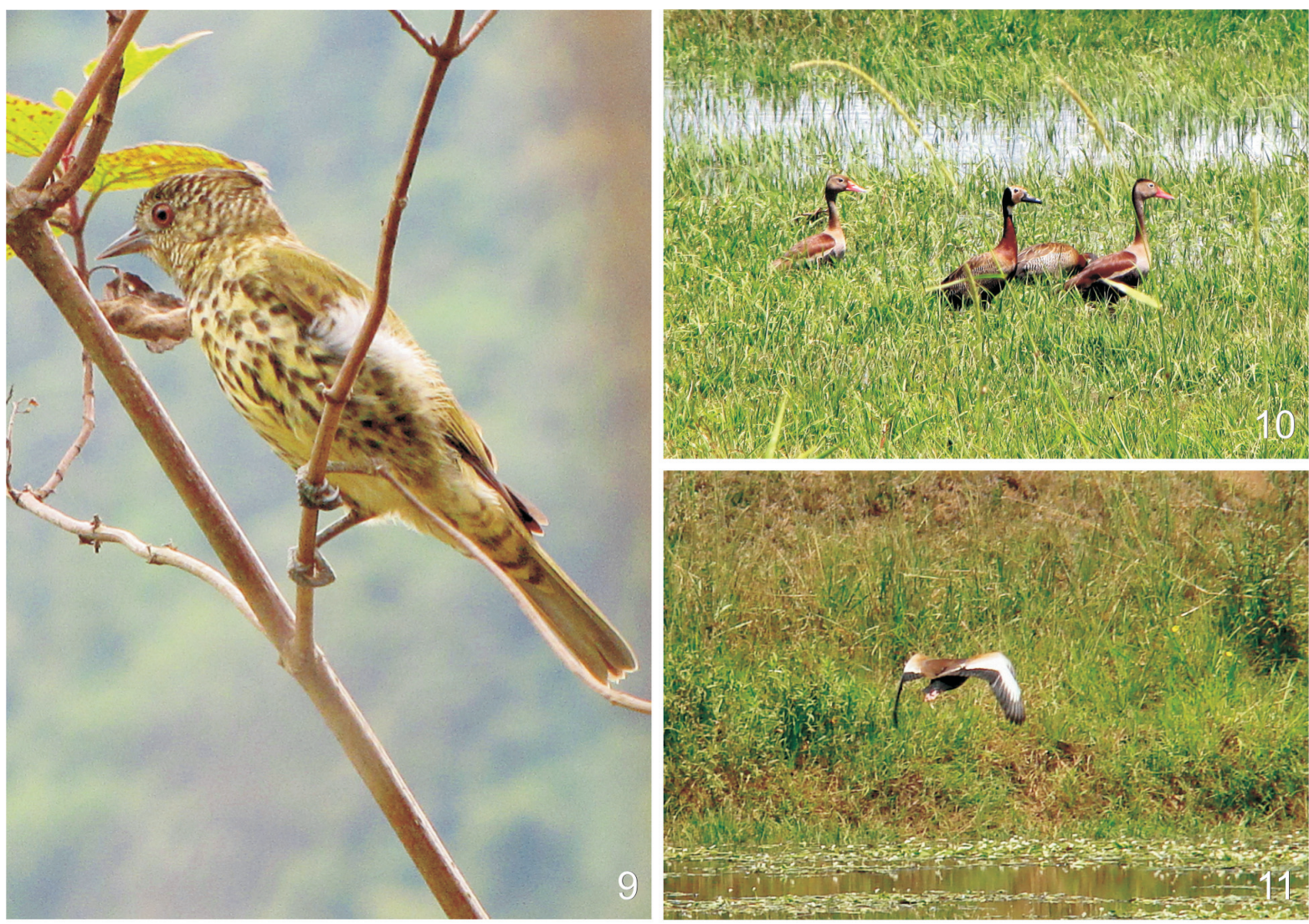

9
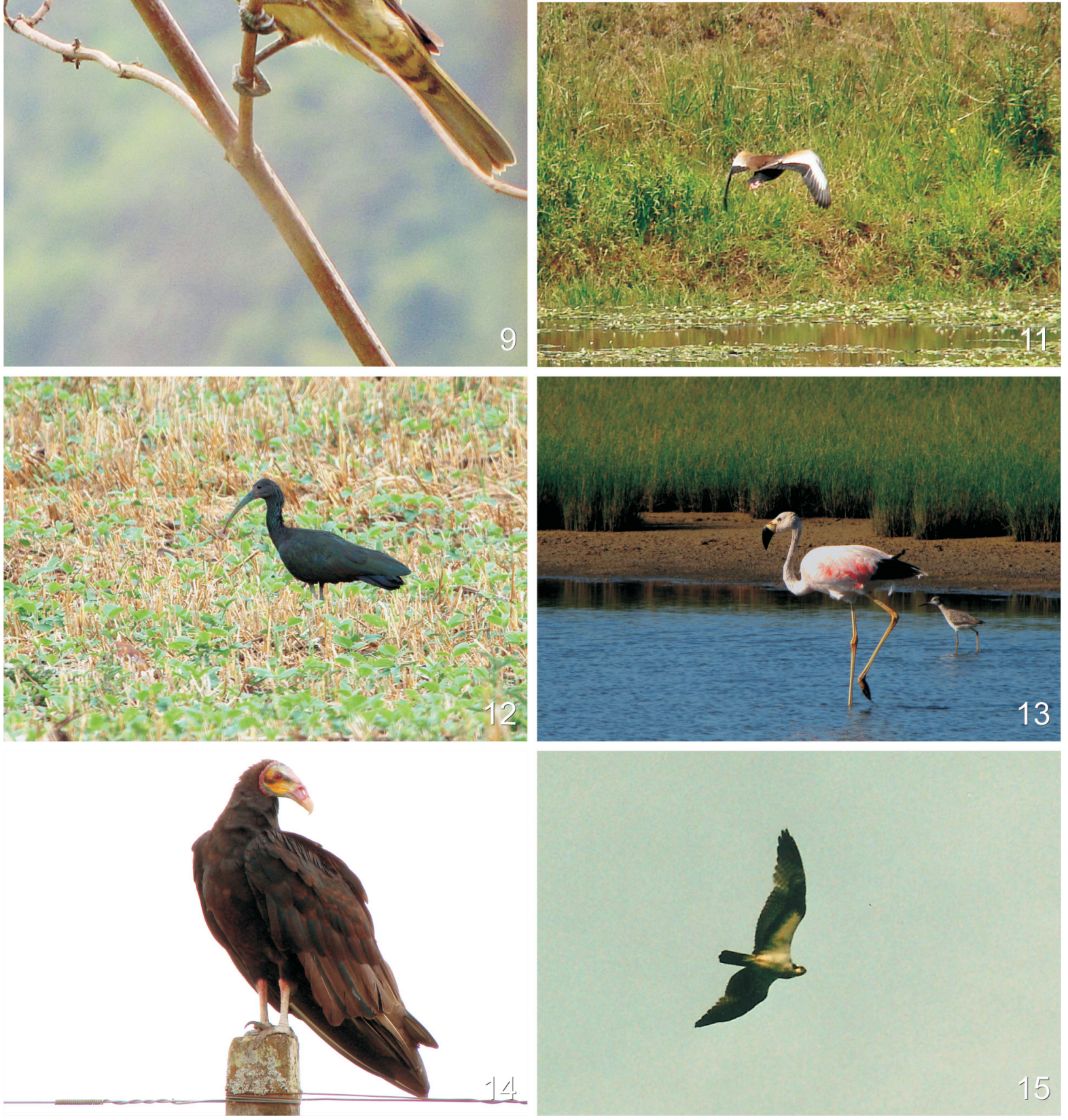

Figuras 9-15. 9, Oxyruncus cristatus Swainson, 1821, cânion Josafaz, Mampituba, novembro de 2010 (Glayson Bencke); 10, 11, Dendrocygna autumnalis (Linnaeus, 1758), junto com D. viduata (Linnaeus, 1766), Rincão do São Donato, Maçambará, janeiro de 2011 (G. Bencke e Rafael Dias); 12, Mesembrinibis cayennensis (Gmelin, 1789), Caseiros, dezembro de 2008 (Leandro Bugoni); 13, Phoenicoparrus andinus (Philippi, 1854), Parque Nacional da Lagoa do Peixe, janeiro de 2010 (G. Bencke); 14, Cathartes burrovianus Cassin, 1845, Alegrete, abril de 2007 (G. Bencke); 15, Pandion haliaetus (Linnaeus, 1758), Granja Quatro Irmãos, Rio Grande, fevereiro de 1999 (R. Dias). 
Stercorarius pomarinus (Temminck, 1815) gaivota-rapineira-pomarina. Há registros fotográficos no mar e material osteológico coletado na costa do RS e depositado no MZU (BENCKE, 2001), além de um exemplar filmado na Lagoa do Peixe em novembro de 2002 (BARNETT et al., 2004). Em adição a esses registros, há vários outros feitos por Carolus M. Vooren em fevereiro de 2005 ao longo de todo o litoral do RS em isóbatas de 7-20 m, tendo S. pomarinus ocorrido em $56 \%$ das estações amostradas, em bandos de até 30 aves (TRAVERSI \& Vooren, 2010). Indivíduos da espécie também foram observados por L.B. junto com S. parasiticus (Linnaeus, 1758) e S. longicaudus Vieillot, 1819 durante dois cruzeiros de pesca em fevereiro de 2006, quando o barco pescava atuns ao redor de uma boia ancorada ao largo do litoral sul gaúcho $\left(33^{\circ} 57^{\prime} \mathrm{S}, 5^{\circ} 26^{\prime} \mathrm{W}\right.$; $77 \mathrm{mn}$ da costa). Stercorarius pomarinus era claramente distinto pelo maior tamanho e pela característica cauda alongada e retorcida. Com exceção do material osteológico mencionado acima, as demais evidências materiais conhecidas não estão disponíveis para verificação. André Barcelos Silveira, acompanhado por C. E. Agne (C.E.A.), obteve documentação fotográfica adicional na praia de Cidreira, em 2 de maio de 2010 (Figs 19, 20). As fotos ilustram uma ave em plumagem reprodutiva quase completa, sendo evidentes as seguintes características diagnósticas: corpo robusto com peito saliente, bico também robusto, capuz escuro estendendo-se até a região malar, retrizes centrais alongadas e de ponta arredondada, projetandose bem além da extremidade da cauda, e coberteiras inferiores da asa uniformemente escuras, indicando tratarse de um adulto.

Larus atlanticus Olrog, 1958 - gaivota-de-rabo-preto. A única documentação divulgada até agora consistia em uma fotografia em preto-e-branco publicada em DiAs \& Maurício (1998). Entretanto, essa documentação é insatisfatória devido à baixa qualidade da impressão, que dificulta a identificação. Uma nova fotografia, obtida por R.A.D. em 18 de junho de 2008 na praia do Cassino, Rio Grande, é aqui apresentada em complementação (Fig. 21).

Anous stolidus (Linnaeus, 1758) - trinta-réis-escuro. Essa espécie foi citada para o estado com base em um esqueleto depositado na coleção osteológica do MCN sob o n. 267 (BENCKE, 2001). Uma pele proveniente do litoral sul (CAFURG 427) e uma observação na praia de Mostardas (DiAs et al., 2010a) constituem registros adicionais e comprovam de forma inequívoca a ocorrência da espécie no RS.

Columbina squammata (Lesson, 1831) - fogoapagou. Antes conhecida no RS apenas por um registro auditivo na região do Alto Uruguai (BELTON, 1994), essa espécie foi gravada no município de Vacaria em 2000 e 2002, estando a gravação depositada no ASEC (SILVA, 2006). Mais recentemente, REPENNING et al. (2010) informaram ter observado e fotografado a espécie em Bom Jesus, no início de 2009.

Columba livia Gmelin, 1789 - pombo-doméstico. Imagens dessa espécie exótica e sinantrópica aparecem com certa frequência na mídia impressa e eletrônica do estado, porém nenhuma é facilmente rastreável. Existe um espécime de Porto Alegre (MCP 1.664), coletado em 26 de abril de 1999.
Dromococcyx pavoninus Pelzeln, 1870 - peixe-fritopavonino. A gravação referida por BENCKE (2001) não está depositada em arquivo científico. Por outro lado, duas gravações feitas por Davis W. Finch em agosto de 1993 constam no acervo da Macaulay Library (ML Audio 68.420 e 68.477). Essas gravações foram obtidas, respectivamente, na Terra Indígena de Nonoai e no Parque Estadual do Turvo. Uma terceira gravação depositada nesse mesmo arquivo (MLAudio 25.436), feita por Flávio Silva em Iraí em 24 de agosto de 1981, igualmente corresponde à voz de D. pavoninus, embora esteja catalogada como Dromococcyx phasianellus (Spix, 1824).

Pulsatrix koeniswaldiana (Bertoni \& Bertoni, 1901) - murucututu-de-barriga-amarela. Fotografias que documentam a ocorrência dessa espécie no RS foram publicadas em BENCKE (2010).

Antrostomus sericocaudatus Cassin, 1849-bacuraurabo-de-seda. A gravação referida por Bencke (2001) está atualmente arquivada no xeno-canto (XC 67.471).

Chaetura cinereiventris Sclater, 1862 andorinhão-de-sobre-cinzento. Uma breve gravação obtida recentemente no Parque Estadual do Turvo por G.A.B. e incorporada ao acervo do xeno-canto (XC 65.592) constitui a primeira evidência documental da ocorrência da espécie no RS.

Pteroglossus bailloni (Vieillot, 1819) - araçari-banana. Essa espécie não dispunha de documentação para o RS (BENCKE, 2001). No entanto, a foto que ilustra P. bailloni em FonTANA et al. (2003), publicada sem indicação de local e data, foi obtida no Parque Estadual do Turvo por Norberto Jaeger, provavelmente ao redor do ano de 2000. Adicionalmente, a foto de um indivíduo capturado em abril de 2008 no município de Frederico Westphalen por Fábio A. F. Jacomassa é apresentada aqui (Fig. 22).

Pteroglossus castanostis Gould, 1834 - araçaricastanho. Meller \& Rocha (2010) divulgaram uma fotografia obtida no Parque Estadual do Turvo, provendo a primeira documentação para o estado. Adicionalmente, a foto que ilustra $P$. castanotis em FonTANA et al. (2003), publicada sem indicação de local e data, foi obtida na mesma área por Norberto Jaeger, provavelmente ao redor do ano de 2000.

Hypoedaleus guttatus (Vieillot, 1816) - chocãocarijó. Além das duas gravações de W. Belton depositadas na Macaulay Library (ver adiante, sob Ramphocaenus melanurus), há uma terceira gravação do RS nesse mesmo arquivo (ML Audio 68.462), feita por Davis W. Finch no Parque Estadual do Turvo, em 28 de agosto de 1993.

Psilorhamphus guttatus (Ménétriès, 1835) tapaculo-pintado. Em adição à documentação sonográfica apresentada em BENCKE et al. (2000), uma fotografia de um macho obtida no município de Rolante foi publicada em BENCKe (2010).

Cichlocolaptes leucophrus (Jardine \& Selby, 1830) - trepador-sobrancelha. A gravação da voz de um indivíduo não visualizado na Floresta Nacional de São Francisco de Paula em novembro de 2002 constitui a primeira documentação da ocorrência dessa espécie no RS (BARNETT et al., 2004). A gravação foi enviada ao ASEC para arquivamento (BARNETT et al., 2004), mas até o momento não foi catalogada (Luiz P. Gonzaga, com. pess.). Adicionalmente, existem diversos registros visuais ou 

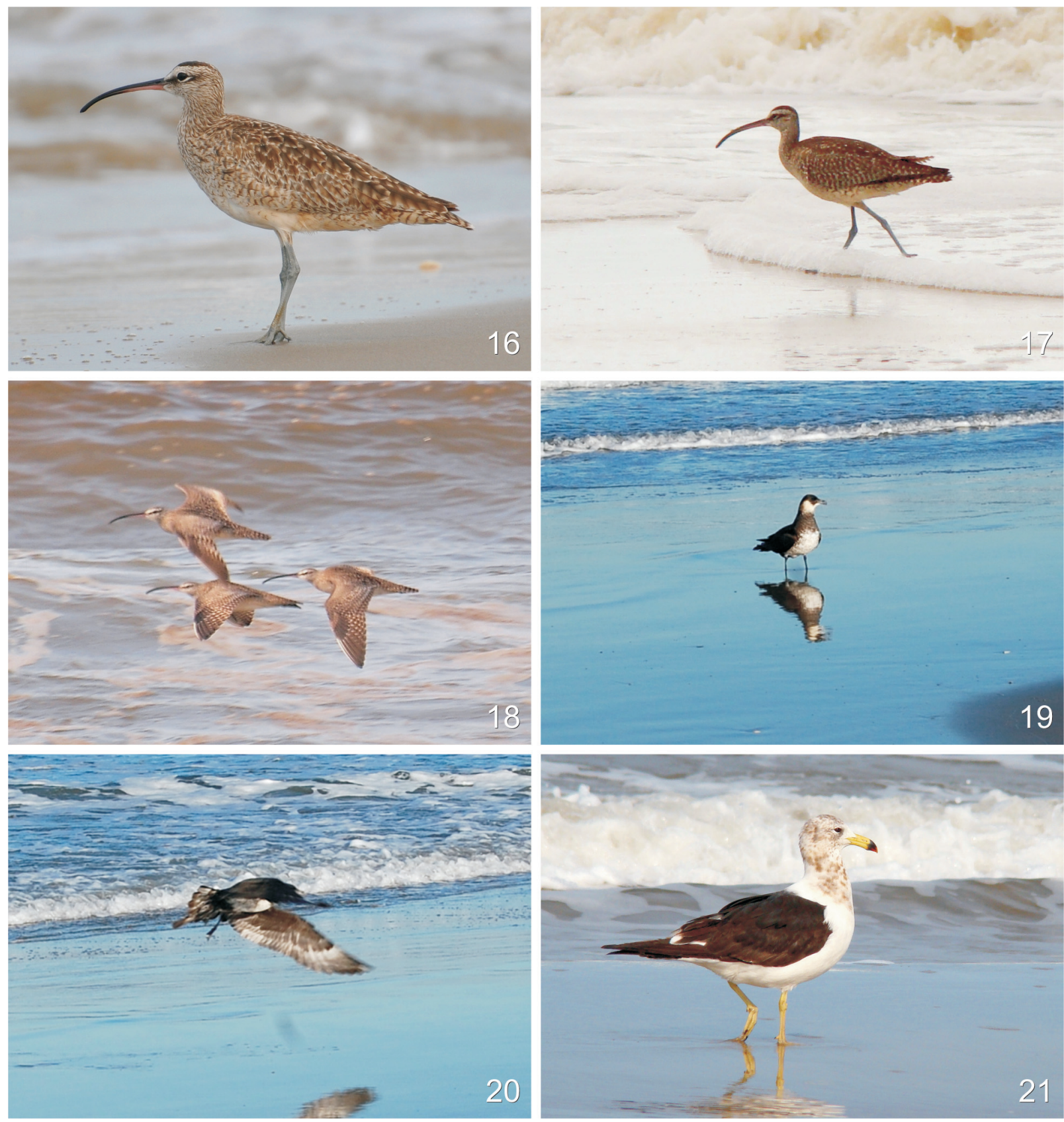

Figuras 16-21. 16, Numenius phaeopus (Linnaeus, 1758), praia do Cassino, Rio Grande, abril de 2010 (Cláudio Timm); 17, N. phaeopus, mesmo local, outubro de 2008 (Rafael Dias); 18, N. phaeopus, Tavares, abril de 2010 (Oscar Fenalti); 19, 20, Stercorarius pomarinus (Temminck, 1815), praia de Cidreira, maio de 2010 (André B. Silveira); 21, Larus atlanticus Olrog, 1958, praia do Cassino, junho de 2008 (R. Dias).

auditivos no setor nordeste do estado (BENCKE et al., 2003; G.A.B., C.S.F., obs. pess.).

Culicivora caudacuta (Vieillot, 1818) - papamoscas-do-campo. BENCKE (2001) mencionou gravações de áudio obtidas na Reserva Biológica do Ibirapuitã, Alegrete, as quais, no entanto, não estão disponíveis em arquivo público. Desde então, a espécie tem sido encontrada no estado em diversas outras oportunidades. Atualmente, existem registros documentados para o nordeste do RS, onde pelo menos duas populações reprodutivas vêm sendo estudadas (FonTANA et al., 2008; REPENNING et al., 2010). Uma fotografia de um adulto no ninho, obtida em Vacaria, foi publicada nessa última fonte.

Alectrurus tricolor (Vieillot, 1816) - galito. A afirmação de WiEd (1831) de que F. Sellow coletou $A$. tricolor no RS tem sido aceita como evidência para a inclusão dessa espécie na lista do estado, primeiramente por IHERING (1899) e mais recentemente por BELTON (1978a, 1985, 1994) e BENCKe (2001). No entanto, a existência e o paradeiro do exemplar de Sellow aparentemente nunca foram verificados e CORY \& HELLMAYR (1927) declararam que "não existe nenhuma referência confiável para a ocorrência relatada no (...) Rio Grande do Sul". Wied escreveu: "Os exemplares dessa ave [=Muscicapa alector] que estão em minha coleção zoológica são oriundos em parte da região de São Romão, no rio São Francisco, e em parte, graças à generosidade do viajante Sr. Sellow, da Província do Rio Grande do Sul" (traduzido 
do alemão). Portanto, é evidente que Wied obteve (ao menos) dois espécimes de A. tricolor, pois refere duas localidades de coleta distintas, e que esses exemplares foram efetivamente incorporados a sua coleção pessoal. De acordo com Allen (1889), as coleções zoológicas de Wied foram compradas do Museu de Paris pelo Museu Americano de História Natural em 1870. Uma consulta ao administrador da coleção ornitológica do AMNH revelou a existência de dois espécimes de A. tricolor coletados por Wied no acervo daquele museu, ambos portando apenas a inscrição "Brasilien" na etiqueta original (Paul Sweet, com. pess.). A falta de informações mais precisas nas etiquetas não é razão para se suspeitar que os exemplares do AMNH não sejam os descritos por WIED (1831). Allen (1889) comentou que os espécimes da coleção desse naturalista não foram numerados e que a maioria traz apenas o nome da espécie, o sexo e a inscrição "Brasilia" ou "Brasilien" na etiqueta original. Salvo em raras exceções, nenhuma outra informação relevante foi fornecida em um catálogo manuscrito que Wied preparou para a sua coleção ornitológica pouco antes de sua morte (Allen, 1889). Apesar disso, a procedência indicada nas obras publicadas por Wied (Beiträge zur Naturgeschichte von Brasilien e Reise nach Brasilien) tem sido invariavelmente adotada por autores de catálogos e compêndios ornitológicos tradicionais como localidade-típica dos táxons descritos por ele (e.g., Sharpe, Sclater, Peters, Cory, Hellmayr e Pinto). Portanto, estabelecer a correspondência entre os espécimes da coleção de Wied e as localidades citadas em suas obras tem sido uma prática comum e aceita por gerações de ornitólogos. Com base no exposto, é possível assumir com um razoável grau de certeza que o espécime de $A$. tricolor coletado por Sellow no RS de fato existe, permanecendo até hoje como a única evidência concreta da ocorrência histórica dessa espécie no estado (embora talvez não mais se possa saber qual dos dois exemplares existentes no acervo do AMNH corresponde à ave coletada por Sellow, pois ambos são machos). Outra possibilidade, bastante remota, é que ambos os espécimes do AMNH sejam provenientes da região de São Romão. Para que essa hipótese seja válida, é necessário assumir que Wied obteve mais de dois exemplares para a sua coleção (não há evidências nesse sentido) e que justamente aquele originário do estado tenha sido subsequentemente perdido.

Alectrurus risora (Vieillot, 1824) - tesoura-docampo. Essa espécie é conhecida no RS somente pelos espécimes muito antigos referidos por WIED (1831) e GLIESCH (1930), e por uma menção na obra de BuRMEISTER (1856). O espécime de Gliesch, coletado em São José do Norte em 1914, está desaparecido, juntamente com grande parte da coleção desse zoólogo (BELTON, 1994), e quase certamente não existe mais, visto que não está entre as peças que ainda restam na Faculdade de Veterinária da Universidade Federal do Rio Grande do Sul, em Porto Alegre (G.A.B. e C.S.F., obs. pess.). O espécime de Wied, por sua vez, não parece ter tido seu paradeiro checado pelos diversos autores que se ocuparam da ornitologia gaúcha. WiED (1831) deixou claro que obteve apenas um espécime (macho) de A. risora para a sua coleção, proveniente "da província brasileira do Rio Grande do
Sul". Esse naturalista não revelou, porém, como o exemplar foi obtido. É certo que não foi o próprio Wied que o coletou, pois ele jamais visitou o RS. Isso é atestado já no texto que encabeça o relato sobre Muscicapa alector (=Alectrurus tricolor), M. psalura $(=A$. risora) e $M$. coronata (=Pyrocephalus rubinus) em seu livro: "Descrição de alguns papa-moscas brasileiros que, no entanto, não foram encontrados nas regiões por mim visitadas" [Rio de Janeiro, Espírito Santo, Minas Gerais e Bahia; BoKermann (1957)]. Por consulta a outros trechos da obra, pode-se suspeitar que ele tenha recebido o exemplar de certo militar de sobrenome Feldner, que o acompanhou em algumas de suas viagens e esteve no RS, ou, mais provavelmente, de F. Sellow, com o qual mantinha algum intercâmbio de espécimes e informações. Uma consulta ao responsável pela coleção ornitológica do AMNH, onde a coleção de Wied está depositada (Allen, 1889), confirmou que o exemplar ainda existe, constando em sua etiqueta original a inscrição "Paraguay, Brasilien" (P. Sweet, com. pess.). A referência ao Paraguai na etiqueta é intrigante. Porém, dado que Wied não obteve outros exemplares da espécie e que a maioria de suas etiquetas não contém dados de procedência precisos (ver sob Alectrurus tricolor), não há nenhuma dúvida de que o exemplar do AMNH seja a ave que ele descreveu. Já Burmeister (1856) possivelmente apenas compilou o registro de WIED (1831), a cuja obra se referiu diversas vezes na seção introdutória de seu livro. Em seu relato, Burmeister escreveu que a espécie "só está em casa no sul do Brasil, na fronteira com o Paraguai, principalmente na Província do Rio Grande do Sul, estendendo-se para oeste até o sopé das cordilheiras", em nenhum momento dando a entender que tenha coletado ou obtido qualquer espécime (contra BeLton, 1985, 1994).

Manacus manacus (Linnaeus, 1766) - rendeira. Gravações de áudio obtidas no Parque Estadual de Itapeva, Torres, constituem a única evidência material referida para o RS até agora (BENCKE, 2001). Porém, essas gravações não estão disponíveis para verificação. Uma fotografia de um macho obtida por Adriano Becker em companhia de G.A.B. no mesmo local (29²0'58' S, 4945'26”'W), em 11 de janeiro de 2005, é publicada aqui (Fig. 23).

Tangara peruviana (Desmarest, 1806) - saírasapucaia. Rosa \& AGNE (2010) apresentaram o primeiro registro documentado para o RS. A espécie foi fotografada no município de Torres, nas proximidades do Parque Estadual de Itapeva, em agosto de 2008.

Paroaria capitata (d'Orbigny \& Lafresnaye, 1837) - cavalaria. Existem duas populações disjuntas dessa espécie no RS, uma ao longo da fronteira oeste do estado, de ocorrência espontânea (BELTON, 1994; ACCORDI, 2003), e outra na porção inferior da bacia do rio Jacuí, aparentemente formada a partir de introdução na natureza (AcCordi \& Barcellos-Silveira, 2005). A única documentação disponível refere-se à população do leste do estado, cuja ocorrência e reprodução estão documentadas por fotografias (ACCORDI \& BARCELlOSSilveIRA, 2005). Em complementação, publica-se aqui uma foto obtida por Gina Bellagamba em Uruguaiana, em 28 de outubro de 2010 (Fig. 24), como documentação referente à população indígena da espécie. 
Hemithraupis ruficapilla (Vieillot, 1818) - saíraferrugem. Uma revisão dos registros no RS, incluindo uma foto obtida na Reserva Biológica da Serra Geral, Maquiné, foi apresentada por BENCKE (2010).

Sporophila cinnamomea (Lafresnaye, 1839) caboclinho-de-chapéu-cinzento. BENCKE (2001) indicou como incerta a existência de um espécime do RS com base em IHERING (1899), que escreveu: "Espécie duvidosa, indicada no Museu Heineano como proveniente do 'Rio Grande'. Será o Rio Grande do Sul?". Aqui Ihering possivelmente se referiu à obra Museum Heineanum, um catálogo da coleção ornitológica particular de Ferdinand Heine elaborado por CABANIS (1850-1863). Nessa obra, ao tratar de Sporophila minuta (Linnaeus, 1758), Cabanis apenas fez referência à existência de espécies semelhantes no sul do Brasil, entre elas $S$. cinnamomea, para a qual apontou "Rio Grande" como localidade típica. Portanto, diferentemente do que concluiu Bencke (2001), nunca houve um exemplar dessa espécie no museu de Heine e a existência de espécimes gaúchos pode ser descartada. A questão já fora esclarecida por Hellmayr (1938) e, complementarmente, por PINTO (1944), que advertiram sobre a correta localização da pátria típica de $S$. cinnamomea, a qual não corresponde ao RS, mas sim ao rio Araguaia, que outrora também foi chamado de rio Grande. Bencke (2001) mencionou a existência de gravações de áudio obtidas em Candiota, no centro-sul do estado, mas essas gravações não foram depositadas em arquivo público até o momento. Por outro lado, uma foto de um macho adulto tirada por R.A.D. no RS foi publicada em BENCKE et al. (2006:56), embora sem indicação de local e data. Com o propósito de qualificar essa evidência, fornecem-se aqui detalhes sobre o registro: Fazenda Aroeira “A” (31 ${ }^{\circ} 46$ '02"'S, 5350'41” W), Candiota, 29 de dezembro de 2005 . Há vários outros registros recentes da espécie no RS, em parte documentados por fotografias e gravações, inclusive comprovando sua reprodução no estado (BENCKE et al., 2003; BenCKe, 2004; REPENNING \& FontANA, 2008; C.S.F., R.A.D., G.A.B., obs. pess.).

Procacicus solitarius (Vieillot, 1816) - iraúna-debico-branco. Os escassos registros conhecidos no norte e noroeste do estado não estão documentados (BENCKE et al., 2003). Fotos diagnósticas de um indivíduo foram obtidas em 2 de dezembro de 2010 no Parque Estadual do Espinilho, Barra do Quaraí, por Renato Grimm. Duas fotos são publicadas aqui para documentar a ocorrência da espécie no RS (Figs 25, 26).

Molothrus oryzivorus (Gmelin, 1788) - iraúnagrande. Os registros até agora conhecidos em território gaúcho carecem de documentação (BENCKE, 2001). Um indivíduo foi observado e fotografado em Centro Novo, junto à sede do Parque Estadual do Turvo, por Paulo Fenalti, Caco Schwertner e G.A.B., em 5 de setembro de 2010. Uma das fotos é publicada aqui como evidência documental da ocorrência da espécie no RS (Fig. 27).

Sturnella defilippii (Bonaparte, 1850) - peitovermelho-grande. A existência de espécimes do RS foi posta em dúvida por BENCKE (2001). Contudo, no catálogo de Hellmayr (1937), obra não consultada por aquele autor, há clara alusão a espécimes de São Lourenço [do Sul], presumivelmente coletados por Ihering.
Carduelis carduelis (Linnaeus, 1758) - pintassilgoeuropeu. A gravação de Barra do Chuí mencionada por DiAs (2000) está agora depositada no xeno-canto (XC 65.732). Nesse mesmo arquivo sonoro há outra gravação (XC 8.147), feita em Pelotas por Fernando Jacobs, em 9 de novembro de 2006. No entanto, segundo informação que acompanha o registro, não foi possível determinar se a ave gravada era ou não proveniente de cativeiro. Há também um espécime (MUCPEL 389) coletado na área urbana de Jaguarão, em 30 de março de 2008. Como esse exemplar foi encontrado debilitado no pátio de uma residência, também existe a suspeita de que possa ser oriundo de soltura ou escape. A espécie não tem sido observada na cidade de Jaguarão e arredores entre julho de 2009 e o presente (Maycon S. S. Gonçalves, com. pess.), embora seja conhecida para o vizinho departamento uruguaio de Cerro Largo (DiAs, 2000).

Estrilda astrild (Linnaeus, 1758) - bico-de-lacre. Há um espécime (MUCPEL 393) coletado na periferia da cidade de Pelotas e outro (MCP 2.965) proveniente de Santa Maria. Esses exemplares representam, aparentemente, as primeiras evidências tangíveis da ocorrência dessa espécie exótica no RS (BENCKE, 2001), embora os primeiros registros de aves em liberdade no estado remontem pelo menos ao início da década de 1960 e, possivelmente, até algumas décadas antes (Voss, 1979; Oliveira, 1980; ver também Fontana, 2005). Em adição, existe uma gravação de baixa qualidade depositada no xeno-canto (XC 7.893), obtida por Fernando Jacobs em Figueiras, também em Pelotas, em outubro de 2006.

\section{Alterações de nomes em português}

Procellariiformes. Os nomes regionais em português de vários representantes das famílias Diomedeidae e Procellariidae foram alterados (Tabela I) com o objetivo de padronizar a nomenclatura utilizada para espécies congenéricas ou afins, de abolir o uso de designações estrangeiras há muito em desuso em seus países de origem (e.g., "fura-bucho") ou de priorizar nomes utilizados popularmente, em especial por pescadores.

Fulica armillata Vieillot, 1817 e F. rufifrons Philippi \& Landbeck, 1861 - carqueja-de-bico-maculado e carqueja-de-escudo-roxo. Tratando-se de espécies que, no Brasil, são largamente restritas ao RS, não há razão para que recebam nomes em português diferentes na lista estadual e nacional. Os nomes utilizados pelo CBRO (2011) - respectivamente, carqueja-de-bico-manchado e carqueja-de-escudo-vermelho - são mais apropriados do que os regionais, cunhados em BeLton (1978a), e são adotados aqui.

Limnoctites rectirostris (Gould, 1839) e Limnornis curvirostris Gould, 1839 - junqueiro-de-bico-reto e junqueiro-de-bico-curvo. Os nomes em português atualmente em uso para essas espécies foram criados artificialmente na década de 1970 por um grupo reduzido de ornitólogos e observadores de aves, em um esforço para nominar espécies de aves do RS que não dispunham de um nome vernáculo (ver Belton, 1978a). Os nomes propostos aparentemente são meras traduções adaptadas dos respectivos nomes em inglês dessas espécies. Esses nomes foram posteriormente adotados 
Tabela I. Nomes em português de espécies de Diomedeidae e Procellariidae alterados na presente revisão.

\begin{tabular}{|c|c|c|}
\hline Espécie & Nome em BENCKE (2001) & Nome proposto \\
\hline Diomedea epomophora Lesson, 1825 & albatroz-real & albatroz-real-do-sul \\
\hline Macronectes giganteus (Gmelin, 1789) & pardelão-gigante & pardelão-gigante-de-bico-verde \\
\hline Fulmarus glacialoides (Smith, 1840) & pardelão-prateado & petrel-prateado \\
\hline Lugensa brevirostris (Lesson, 1831) & fura-bucho-de-bico-curto & pardela-de-bico-curto \\
\hline Pterodroma mollis (Gould, 1844) & fura-bucho-de-coroa & pardela-de-colar \\
\hline Pterodroma incerta (Schlegel, 1863) & fura-bucho-de-capuz & pardela-de-capuz \\
\hline Pterodroma macroptera (Smith, 1840) & fura-bucho-de-cara-cinza & pardela-de-cara-cinza \\
\hline Calonectris borealis (Cory, 1881) & bobo-grande & pardela-de-bico-amarelo \\
\hline Calonectris edwardsii (Oustalet, 1883) & bobo-de-cabo-verde & pardela-de-cabo-verde \\
\hline Puffinus griseus (Gmelin, 1789) & bobo-escuro & pardela-escura \\
\hline Puffinus gravis (O’Reilly, 1818) & bobo-grande-de-sobre-branco & pardela-grande-de-sobre-branco \\
\hline Puffinus puffinus (Brünnich, 1764) & bobo-pequeno & pardela-pequena \\
\hline
\end{tabular}

na literatura ornitológica nacional sem contestação (por ex., SicK, 1985, 1997; WiLLIS \& ONIKI, 1991). Porém, nenhuma das duas espécies de "junqueiros" habita propriamente os juncais, nome dado às formações vegetais dominadas pela ciperácea paludícola Schoenoplectus californicus ou pelas juncáceas do gênero Juncus. Limnoctites vive exclusivamente em áreas úmidas dominadas pela apiácea Eryngium pandanifolium, planta espinhosa conhecida popularmente como gravatá ou caraguatá. Já Limnornis habita densas formações palustres com predomínio de ciperáceas genericamente conhecidas como "palhas" ou tiriricas, a exemplo de Scirpus giganteus. Limnornis também é encontrado em ambientes similares, como taboais (formações de Typha spp.) e pirizais (formações da ciperácea Cyperus giganteus). Em vista disso, o nome "junqueiro" é enganoso e inadequado para ambas as espécies, transformando-se em um obstáculo à comunicação. Na falta de nomes vernáculos legítimos de uso corrente no território estadual ou nacional, propõese o nome em português de "arredio-do-gravatá" para $L$. rectirostris, em reconhecimento ao seu parentesco próximo com representantes do gênero Cranioleuca (Olson et al., 2005), em parte conhecidos no Brasil como "arredios", bem como a sua associação estrita com os gravatazais de Eryngium pandanifolium. Sick (1997) registrou o nome vernáculo para $L$. rectirostris de "barreiro-do-brejo", o qual, contudo, não tem largo emprego popular no RS e parece igualmente inadequado. Para L. curvirostris, propõe-se o nome "joão-da-palha" em alusão a sua condição de membro da família Furnariidae, na qual várias espécies recebem o pré-nome genérico de "joão", e a sua associação a ambientes com predomínio de palhas.

Phacellodomus ruber (Vieillot, 1817) - garrincha-doburiti. O nome em português que vem sendo adotado no RS desde BELton (1978a) é inadequado como designação regional, pois as palmeiras usualmente conhecidas como buritis não têm ocorrência espontânea no estado, à exceção de Trithrinax brasiliensis (Arecaceae), a qual, porém, não coexiste com $P$. ruber em território gaúcho. Além disso, o nome "garrincha" é mais comumente utilizado para designar pássaros da família Troglodytidae. Propõe-se aqui o uso do nome "graveteiro", utilizado por Sick (1997) e adotado em CBRO(2011).

Drymornis bridgesii (Eyton, 1850) - arapaçuplatino. Ao contrário do que sugere o seu nome atual em português, essa espécie está ausente de grande parte da região do Prata, sendo típica das regiões biogeográficas do Chaco e Espinal (Ridgely \& Tudor, 1994). Assim, propõe-se aqui o nome "arapaçu-do-espinilho" em alusão a sua associação com a formação de parque espinilho no estado, que representa uma extensão do espinal em território brasileiro.

\section{Espécies de ocorrência provável}

Laterallus exilis (Temminck, 1831) - sanã-do-capim. A voz dessa espécie encontrada em áreas adjacentes da Argentina (BoDRATI, 2005; KRAUCZUK, 2008) foi ouvida por Bret Whitney no Banhado São Donato (29 $09^{\circ}$ 'S, $56^{\circ} 11^{\prime} \mathrm{W}$ ), fronteira oeste do estado, no entardecer do dia 3 de dezembro de 2007 (B. Whitney, com. pess.).

Thinocorus rumicivorus (Eschscholtz, 1829) agachadeira-mirim. Embora o relato circunstanciado que acompanha o registro de AnTAS (1992) contenha elementos suficientes para identificar a ave observada como pertencente ao gênero Thinocorus, não são fornecidas informações que permitam a determinação segura da espécie envolvida, razão pela qual $T$. rumicivorus é aqui mantido entre as espécies de ocorrência provável no RS, tal como em BENCKE (2001).

Progne elegans Baird, 1865 - andorinha-do-sul. Embora existam dois registros visuais de uma andorinha totalmente azul-escura no estado, não há documentação que permita a identificação segura da(s) espécie(s) envolvida(s). BARNETT et al. (2004) relataram ter observado P. subis (Linnaeus, 1758) ou P. elegans em novembro de 2002 no saco da Mangueira, Rio Grande. Em adição, há uma menção de "P. modesta" (P. elegans) para Osório em MÄHLER-JR et al. (2007). Na ocasião desse registro, foi possível observar uma fêmea com a parte ventral cinzenta (Jan K. F. Mähler Jr, com. pess.), o que diagnostica $P$. elegans. Porém, até que informações complementares sobre o registro de MÄHLER-JR et al. (2007) estejam publicadas e sua data exata seja conhecida, julgou-se prudente incluir $P$. elegans entre as espécies de ocorrência provável no RS.

Ramphocaenus melanurus Vieillot, 1819 - bicoassovelado. Um registro não confirmado, baseado em uma gravação de W. Belton obtida no Parque Estadual do Turvo em 25 de novembro de 1977 e identificada por H. Sick como sendo com bastante probabilidade de $R$. 
melanurus (Belton, 1985), pode ser definitivamente descartado. Ambas as gravações de Belton depositadas na Macaulay Library (ML Audio 19.934 e 19.935) correspondem à voz de Hypoedaleus guttatus, espécie então desconhecida no RS e registrada pela primeira vez no estado em 1986/1987, justamente no P. E. do Turvo (ver Nuestras Aves n. ${ }^{\circ}$ 12, p. 21, 1987). Curiosamente, SICK (1997) chamou a atenção para a semelhança do canto de $H$. guttatus com o de $R$. melanurus e não incluiu o RS na distribuição dessa última espécie. A ocorrência de $R$. melanurus na Argentina e no Paraguai é desconhecida (Hayes, 1995; Barnett \& Pearman, 2001; Narosky \& Yzurieta, 2003; Guyra Paraguay, 2005), de modo que também o registro isolado para Itapiranga, no oeste catarinense (RosáRIO, 1996), requer reavaliação. Assim, a única evidência da ocorrência da espécie no RS que se mantém é o registro visual de W. A. Voss para o Banhado dos Pachecos, Viamão, divulgado em Bencke (2001), o qual, no entanto, carece de coerência distribucional.

Sporophila hypochroma Todd, 1915 - caboclinhode-sobre-ferrugem. Essa espécie de caboclinho possui identificação problemática em decorrência da similaridade com os congêneres $S$. hypoxantha Cabanis, 1851 e $S$. cinammomea e das variações individuais de coloração da plumagem exibidas por essas últimas. Além disso, fenótipo similar ao de S. hypochroma poderia resultar de eventuais casos de hibridação, não raros em outros caboclinhos. Tais aspectos dificultam o reconhecimento em campo de S. hypochroma sem o estudo concomitante da voz e do comportamento. Um indivíduo foi fotografado em Dom Pedrito em dezembro de 2009, por G.A.B. e R.A.D., e outro em Barra do Quaraí, em 2 de fevereiro de 2010, por Bruno Salaroli (Fig. 28). Há ainda uma menção para Manoel Viana em KrüGel et al. (2007). O registro de Fontana et al. (2009) para a região dos Campos de Cima da Serra, acompanhado de documentação fotográfica, consistiu em um equívoco reparado em FontANA et al. (2008). Na Argentina, S. hypochroma se reproduz em Entre Rios e Corrientes (Roda \& LóPEz-LANúz, 2007); logo, uma ocorrência eventual no RS não está fora de questão e o registro em Barra do Quaraí seria o mais próximo das áreas de distribuição confirmada da espécie. Entretanto, o caboclinho-de-sobre-ferrugem é aqui incluído entre as espécies prováveis porque os registros até agora conhecidos não estão confirmados por meio de gravações de vocalização.

Outras espécies consideradas de ocorrência provável no RS são listadas no Apêndice II. As informações relativas aos registros dessas espécies podem ser encontradas em BENCKE (2001).

\section{Espécies de ocorrência hipotética}

Thalassarche chrysostoma (Forster, 1785) albatroz-de-cabeça-cinza. Petry \& Fonseca (2002) relataram ter encontrado, juntamente com colaboradores, um exemplar morto na praia ao sul de Pinhal, em maio de 1998; não houve coleta de material testemunho (BENCKE, 2001). Em uma análise retrospectiva, porém, é a opinião de um dos autores do registro (L.B.) que se tratava de um exemplar juvenil de Thalassarche chlororhynchos (Gmelin, 1789) em primeiro ano. O exemplar apresentava coloração do bico totalmente negra, sem as linhas amarelo-alaranjadas no culminicôrneo ( $T$. chlororhynchos) ou culminicôrneo e ramicôrneo ( $T$. chrysostoma), porém cabeça e pescoço cinza. Embora $T$. chrysostoma possua cabeça e pescoço cinza, como indicado pelo próprio nome em inglês da espécie (Greyheaded Albatross), exemplares de T. chlororhynchos provenientes de Tristão da Cunha frequentemente possuem coloração acinzentada na cabeça e pescoço, quando a plumagem é nova. Em consequência, a confusão entre as duas espécies parece ter ocorrido com alguma frequência na literatura. MuRPHy (1914), por exemplo, registrou vários Thalassogeron culminatus (Gould, 1843) $(=T$. chrysostoma $)$ ao largo da costa do RS, Uruguai e norte da Argentina, mas suspeitamente registrou apenas um T. chlororhynchos, espécie relativamente comum nessas latitudes. De modo similar, PAESSLER (1914) citou apenas T. culminatus em águas do RS, Uruguai, Argentina e Chile em 1912/1913. Siск $(1979,1997)$ relatou observações de T. chrysostoma por C. C. Olrog em alto mar entre São Paulo e Santa Catarina, quatro em 1954 e outros quatro em 1958. Para o estado de Santa Catarina, RosÁrio (1996) compilou os registros de Olrog mencionados por Sick e acrescentou "muitos indivíduos acompanhando o navio (jovens e adultos), junto com $D$. melanophris aos $28^{\circ} 30^{\prime} \mathrm{S}, 48^{\circ} 10^{\prime} \mathrm{W}$, costa de Laguna, no período de 2 a 4 de setembro de 1987". Os registros de Olrog e de Rosário, de um número expressivo de indivíduos tão ao norte da distribuição dessa espécie fortemente ligada a águas frias antárticas e subantárticas, também parecem ser resultado de confusão com $T$. chlororhynchos. Infelizmente, os principais guias de identificação de aves marinhas (HARRISON, 1985; ONLEY \& SCOFIELD, 2007) aparentemente baseiam suas ilustrações de T. chlororhynchos na forma do oceano Índico, atualmente reconhecida como espécie plena, $T$. carteri (Rothschild, 1903), ao não mostrar o colar e cabeça cinza comuns em adultos com plumagem nova da forma do Atlântico (mas ver Vooren \& Fernandes, 1989 e Brooke, 2004). Carlos (2008) é particularmente esclarecedor com relação às diferenças na plumagem entre as formas do Atlântico e Índico. Por fim, várias imagens obtidas por L.B. no RS (algumas publicadas em BUGONI \& FURNESS, 2009b) e imagens obtidas por observadores de bordo em vários locais do Brasil, suspeitas de representarem $T$. chrysostoma, retratam $T$. chlororhynchos. Os dois exemplares de T. chrysostoma coletados no Brasil, em São Paulo, MZUSP 73.513 (Olmos et al., 1995), e Rio de Janeiro, MN 33.293 (TeIXeIra et al., 1985), parecem ser os únicos registros documentados da espécie no Brasil.

Cochlearius cochlearius (Linnaeus, 1766) arapapá. BENCKE (2001) reavaliou os registros conhecidos até então para o RS e considerou a ocorrência de $C$. cochlearius no estado como hipotética devido à falta de documentação e também em razão da inexistência dos hábitats normalmente frequentados pela espécie ao longo da costa gaúcha. Mais recentemente, Vотто et al. (2006) relataram ter observado a espécie em 24 e 25 de outubro de 2001 no campus da FURG, Rio Grande. Na ocasião, os observadores confirmaram a identificação em campo com auxílio de bibliografia e descartaram uma eventual 

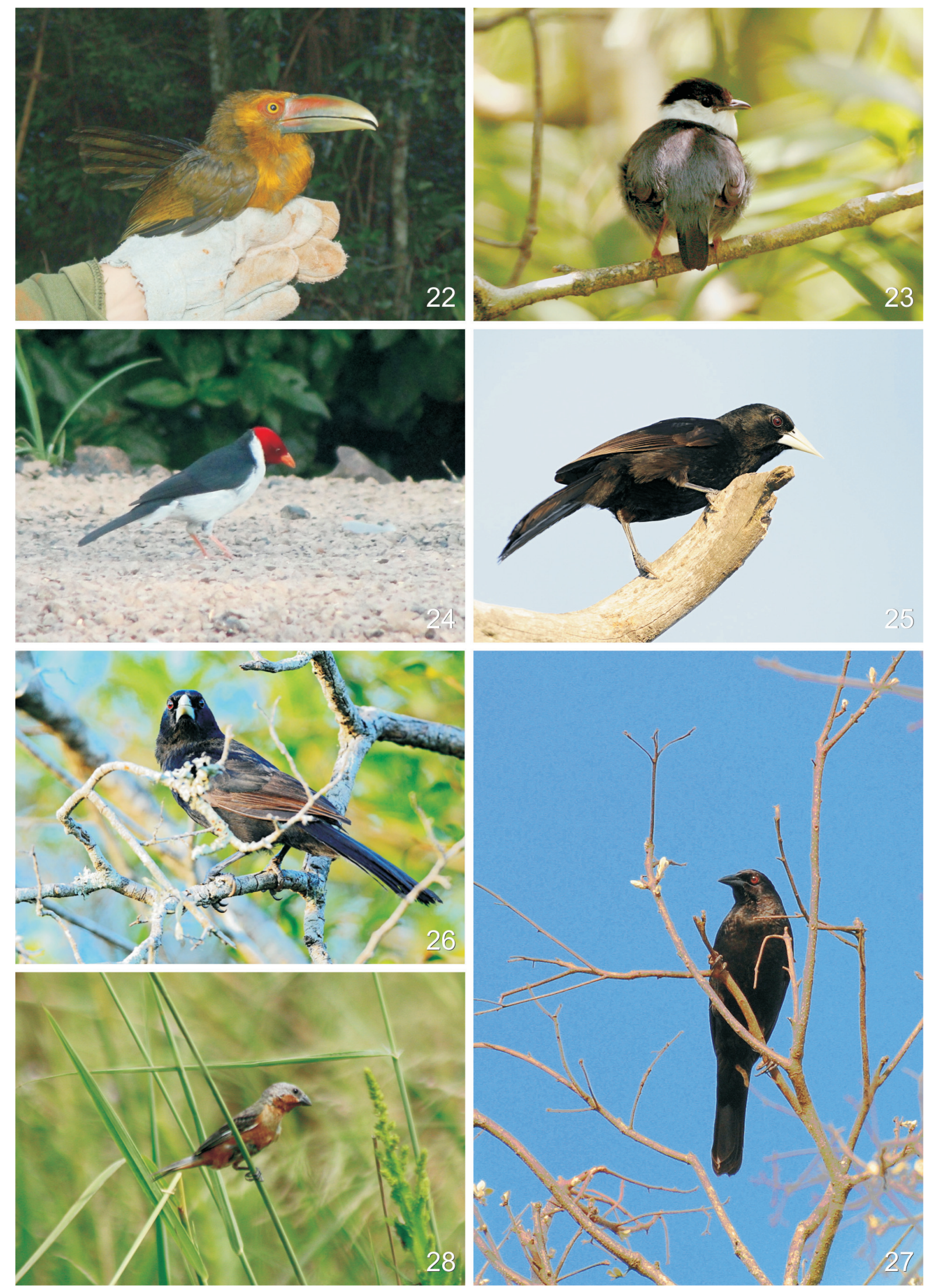

Figuras 22-28. 22, Pteroglossus bailloni (Vieillot, 1819), Frederico Westphalen, abril de 2008 (Fábio Jacomassa); 23, Manacus manacus (Linnaeus, 1766), Parque Estadual de Itapeva, Torres, janeiro de 2005 (Adriano Becker); 24, Paroaria capitata (d'Orbigny \& Lafresnaye, 1837), Uruguaiana, outubro de 2010 (Gina Bellagamba); 25, 26 Procacicus solitarius (Vieillot, 1816), Parque Estadual do Espinilho, Barra do Quaraí, dezembro de 2010 (Renato Grimm); 27, Molothrus oryzivorus (Gmelin, 1788), Parque Estadual do Turvo, Derrubadas, setembro de 2010 (Paulo Fenalti); 28, Sporophila cf. hypochroma Todd, 1915, Barra do Quaraí, fevereiro de 2010 (Bruno Salaroli). 
confusão com Nycticorax nycticorax (Linnaeus, 1758) (Votто et al., 2006). Não obstante a identificação ter sido positiva, optou-se por manter a espécie como hipotética no estado pelos motivos expostos por BENCKE (2001) e também porque os autores do registro não discutiram como a espécie foi diagnosticada, de modo que não se pode descartar uma eventual confusão com Nyctanassa violacea, ardeídeo similar de presença regular no estuário da Lagoa dos Patos (Gianuca, 2007).

Chordeiles acutipennis (Hermann, 1783) - bacuraude-asa-fina. Incluído aqui com base em Gliesch (1930), que mencionou um espécime de Torres, o qual se acredita estar perdido. Uma discussão sobre o caso consta em BELTON (1994).

Outras espécies consideradas de ocorrência hipotética no RS são listadas no Apêndice III. As informações relativas aos registros dessas espécies podem ser encontradas em BenCKe (2001). Stercorarius maccormicki Saunders, 1893 e Campylorhynchus turdinus (Wied, 1831), tratadas como prováveis por BENCKE (2001), são aqui consideradas hipotéticas com base em uma reanálise das evidências disponíveis à luz dos critérios adotados na presente lista.

\section{Comentários finais}

Com as alterações aqui implementadas, o número de espécies de aves com ocorrência assumida no RS ascende a 661, 37 a mais do que na revisão anterior (i.e., Bencke, 2001). As adições à lista somam 44, das quais uma corresponde a um táxon recentemente descrito (Scytalopus pachecoi), três resultam de desmembramentos taxonômicos (Diomedea sanfordi, $D$. dabbenena e Serpophaga munda), três substituem táxons incluídos na lista anterior apenas em nível de gênero (Fregetta grallaria, Limnodromus griseus e Scytalopus iraiensis) e 37 constituem genuínos acréscimos de espécies que anteriormente não possuíam ocorrência conhecida ou confirmada no RS. A ocorrência de F. grallaria, Polytmus guainumbi, Nonnula rubecula, Stymphalornis acutirostris, Fluvicola albiventer e Xenopsaris albinucha no estado é aqui divulgada pela primeira vez.

Por outro lado, quatro espécies foram excluídas da lista (Spiziapteryx circumcincta, Forpus xanthopterygius,
Ramphodon naevius e Glaucis hirsutus), por razões diversas. As espécies consideradas de ocorrência provável agora somam 10 e as de ocorrência hipotética perfazem um total de 16 . Uma sinopse das alterações implementadas é apresentada na Tabela II.

Das 661 espécies que figuram na lista, $649(98,2 \%)$ possuem pelo menos um registro no RS documentado por evidência material disponível para verificação: 583 estão documentadas por peles ou espécimes completos, 55 por fotografias, 10 por gravações de vocalizações e uma por material osteológico. Documentação inédita é aqui apresentada ou divulgada para 28 dessas espécies. As 12 espécies restantes $(1,8 \%)$ são conhecidas no estado somente por registros visuais circunstanciados (11) ou por recuperação de anilha (1). Essas espécies devem ser consideradas prioritárias para a obtenção de documentação no RS e quaisquer novos registros no estado devem ser divulgados, acompanhados de informações relevantes.

Em comparação com a lista anterior, aumentou o percentual de espécies com ocorrência documentada no estado (de 95,7\% para 98,2\%), mas diminuiu o de espécies documentadas por peles ou espécimes completos (de aproximadamente $91 \%$ para $88,2 \%$ ). Esse resultado reflete a crescente popularização de técnicas alternativas ("não invasivas") de documentação de registros, especialmente a fotografia de aves na natureza, estimulada pelos avanços tecnológicos nos equipamentos e pelo surgimento de bases interativas de compartilhamento de dados na internet (como o WikiAves e o xeno-canto). Uma consequência natural e altamente desejável dessa tendência é a maior contribuição de observadores amadores no processo de elaboração e revisão de listas de aves.

Em comparação com a lista brasileira (CBRO, 2011), as espécies do RS representam $36,1 \%$ das aves listadas para o país (661 de 1.832 espécies). Esse percentual pode ser mais bem avaliado quando se considera que o RS corresponde a apenas 3,3\% do território nacional e situase na fronteira meridional do país, em pleno subtrópico.

O número de espécies adicionadas à lista estadual ao longo dos últimos dez anos (44) equivale a um aumento médio de pouco mais de quatro espécies por ano. Visto que o incremento registrado entre as duas listas anteriores (i.e., Belton, 1994 e Bencke, 2001) foi

Tabela II. Sinopse das alterações implementadas na lista das aves do Rio Grande do Sul entre 2001 (BENCKE, 2001) e 2010 (presente artigo).

\begin{tabular}{|c|c|c|c|c|c|c|}
\hline \multicolumn{2}{|c|}{ Tipo de alteração } & \multicolumn{4}{|c|}{ Ocorrência } & \multirow{3}{*}{ Total } \\
\hline & & \multicolumn{2}{|c|}{ Assumida } & \multicolumn{2}{|c|}{ Não assumida } & \\
\hline & & Documentada & Não documentada & Provável & Hipotética & \\
\hline \multicolumn{2}{|l|}{ Totais 2001} & 597 & 27 & 18 & 12 & $624[+30]$ \\
\hline \multirow[t]{3}{*}{ Adições } & Espécies novas & +1 & & & & +1 \\
\hline & $\begin{array}{l}\text { Desmembramentos } \\
\text { taxonômicos }\end{array}$ & +3 & & & & +3 \\
\hline & Novas ocorrências & +37 & +3 & +3 & +1 & $+40[+4]$ \\
\hline Subtrações/ & Exclusões & & & & & \\
\hline \multirow[t]{3}{*}{ Outros } & Substituições & -2 & -1 & & & -3 \\
\hline & $\begin{array}{l}\text { Transferências de } \\
\text { categoria }\end{array}$ & -3 & -1 & $+1,-12$ & $+6,-3$ & $-4[-8]$ \\
\hline & $\begin{array}{l}\text { Ocorrências } \\
\text { documentadas }\end{array}$ & +16 & $(-16)$ & & & \\
\hline \multicolumn{2}{|l|}{ Totais 2010} & 649 & 12 & 10 & 16 & $661[+26]$ \\
\hline
\end{tabular}


proporcionalmente menor (23 espécies em sete anos, ou 3,3 por ano), pode-se pressupor que o número de espécies conhecidas no estado continuará a crescer nos próximos dez anos a uma taxa igual ou superior à registrada na última década.

Ainda que imprecisa, essa previsão remete a um panorama futuro de muitas alterações na composição da lista até que uma relativa estabilização seja atingida. Em vista disso, sugerem-se algumas ações práticas que tornariam mais fácil e eficiente a tarefa de reavaliar periodicamente a lista estadual. Essas sugestões incluem (i) a constituição formal de um comitê responsável pela atualização periódica da lista, (ii) a criação de um fórum permanente e participativo para a discussão das alterações propostas, (iii) a divulgação regular de atualizações, preferencialmente com periodicidade anual, (iv) a organização de um catálogo de todos os espécimes coletados no RS e depositados em museus do estado, país e exterior e (v) a complementação ao inventário das espécies de aves ocorrentes no RS por meio de levantamentos de campo direcionados a setores e ambientes ainda pouco explorados ou insuficientemente conhecidos do estado.

Por fim, já é bem conhecido que listas de espécies crescem indefinidamente, embora possam tender a uma estabilização com o passar do tempo. Assim, é fundamental sistematizar informações e estabelecer critérios que permitam distinguir entre extensões e expansões de distribuição geográfica, e entre casos de vagância e pseudo-vagância (DiAs et al., 2010a,b), para que se possa compreender melhor as novas ocorrências de espécies ao longo do tempo e, com isso, evoluir para um entendimento mais claro e preciso sobre a composição da avifauna no território estadual. Nesse contexto, cabe destacar que as adições à lista aqui implementadas não compreendem apenas casos de ocorrências esporádicas ou excepcionais no estado, mas também vários exemplos de legítimas extensões de distribuição (sensu FREY, 2009) - espécies que aparentemente sempre tiveram populações estabelecidas no RS e que até agora haviam passado despercebidas (ver Bencke, 2010 para exemplos). Tal constatação reforça a ideia de que a cobertura detalhada do território do RS com inventários ornitológicos, especialmente de longa duração, é o caminho para se chegar a uma relativa estabilização da lista, pelo menos no que diz respeito à avifauna de ocorrência regular no estado.

Agradecimentos. Alfredo Rocchi, Arlindo L. Disconzi, Bret M. Whitney, Carlos E. Carvalho, Daniel T. Gressler, Dante Meller, Everton R. Behr, Jan K. F. Mähler Jr, Márcio Repenning, Marilise M. Krügel, Marluci Rebelato, Nêmora P. Prestes, Ricardo Parrini e Vagner L. Camilotti gentilmente forneceram informações pessoais inéditas sobre novas ocorrências no estado. Adriano Becker, André Barcelos Silveira, Bruno Salaroli, Caco Schwertner, Cláudio D. Timm, D. Meller, Fábio A. F. Jacomassa, Gina Bellagamba, João Carlos P. Dotto, N. P. Prestes, Oscar A. Fenalti, Paulo Fenalti, Renato Grimm e V. L. Camilotti generosamente disponibilizaram ou cederam fotografias que documentam registros inéditos ou importantes. Outras informações relevantes sobre registros, identificação e distribuição de espécies ou espécimes de coleções científicas foram fornecidas por André Chiaradia, Bernard Zonfrillo, Caio José Carlos, Doug Wechsler e Dan Thomas (VIREO), Eduardo Carrano, Fernando C. Straube, Herculano Alvarenga, José Fernando Pacheco, Leonardo V. Mohr, Luiz Pedreira Gonzaga (ASEC), Luiz
Fernando Figueiredo, Maria Helena S. Vaz (MUCPEL), Maycon S. S. Gonçalves, Paul Sweet (AMNH), Ricardo Parrini, Richard J. Cuthbert, Robert Williams, Tatiana Neves e Vítor de Q. Piacentini. Walter A. Voss traduziu vários trechos de artigos científicos em alemão. Augusto Seidel preparou as pranchas de fotografias. C. J. Carlos colaborou em diversas questões relacionadas às aves marinhas. Por fim, F. C. Straube e C. J. Carlos fizeram valiosas críticas e sugestões que contribuíram para o aprimoramento do manuscrito final.

\section{REFERÊNCIAS BIBLIOGRÁFICAS}

ACCORDI, I. A. 2003. Contribuição ao conhecimento ornitológico da Campanha gaúcha. Atualidades Ornitológicas (112):12 (versão na íntegra em www.ao.com.br/download/accordi.pdf). AcCordi, I. A. \& Barcellos-Silveira, A. 2005. Distribuição atual do cavalaria Paroaria capitata (Passeriformes: Emberizidae) no Rio Grande do Sul: extensão natural de distribuição ou ação humana? Atualidades Ornitológicas (123):6.

2008. Novas ocorrências e registros notáveis sobre distribuição de aves em Santa Catarina, sul do Brasil. Biotemas 21(1):85-93.

AcCoRdi, I. A. \& HARTZ, S. M. 2006. Distribuição espacial e sazonal da avifauna em uma área úmida costeira do sul do Brasil. Revista Brasileira de Ornitologia 14(2):117-135.

Agne, C. E. 2004. Primeiro registro do socoí-vermelho, Ixobrychus exilis (Gmelin, 1789) para o Rio Grande do Sul. Atualidades Ornitológicas (120): 12.

Aldabe, J.; Rocchi, A. \& Mondón, G. 2010a. Primer registro de Sternula antillarum Lesson, 1847 (Aves, Charadriiformes) para el estado de Rio Grande do Sul, Brasil. Atualidades Ornitológicas (158):4-5

2010b. Primer registro de Chlidonias leucopterus (Charadriiformes: Sternidae) para Brasil y Sudamérica. Revista Brasileira de Ornitologia 18(3):261-262.

Allen, J. A. 1889. On the Maximilian types of South American birds in the American Museum of Natural History. Bulletin of the American Museum of Natural History 2(3):209-276.

Alvarenga, H. 2007. Anodorhynchus glaucus e A. leari (Psittaciformes, Psittacidae): osteologia, registros fósseis e antiga distribuição geográfica. Revista Brasileira de Ornitologia 15(3):427-432.

Amorim, J. F. \& Piacentini, V. Q. 2007. Novas áreas de ocorrência de três Passeriformes no sul do Brasil. Lundiana 8(1):69-73.

Antas, P. T. Z. 1992. Novos registros para a avifauna do Rio Grande do Sul. In: ENCONTRO NACIONAL DE ANILHADORES DE AVES, $1^{\circ}$, Anais... Pelotas, Universidade Católica de Pelotas, Educat. p.80-81.

Arballo, E. \& Cravino, J. L. 1999. Aves del Uruguay. Manual ornitológico. v. 1. Montevideo, Editorial Hemisferio Sur. $466 \mathrm{p}$.

Areta, J. I. 2008. The Entre Ríos Seedeater (Sporophila zelichi): a species that never was. Journal of Field Ornithology 79(4):352-363.

AzPiroz, A. 2001. Aves del Uruguay. Lista e introducción a su biología y conservación. Montevideo, Aves Uruguay, -GUPECA. 104p.

Azpiroz, A. B. \& MenÉndez, J. L. 2008. Three new species and novel distributional data for birds in Uruguay. Bulletin of the British Ornithologists' Club 128(1):38-56.

Barnett, J. M. \& M. Pearman. 2001. Lista comentada de las aves argentinas. Barcelona, Lynx Edicions. 164p.

Barnett, J. M.; Minns, J.; Kirwan, G. M. \& Remold, H. 2004. Informações adicionais sobre as aves dos estados do Paraná, Santa Catarina e Rio Grande do Sul. Ararajuba 12(1):55-58.

Barquete, V.; Bugoni, L.; Silva-Filho, R. P. \& Adornes, A. C. 2006. Review of records and notes on King Penguin (Aptenodytes patagonicus) and Rockhopper Penguin (Eudyptes chrysocome) in Brazil. Hornero 21(1):45-48.

Becker, R. G. 2009. Primeiro registro de Sporophila leucoptera (Emberizidae) no Rio Grande do Sul, Brasil. Revista Brasileira de Ornitologia 17(3-4):213-216.

Bege, L. A. R. \& Pauli, B. T. 1989. As aves nas ilhas Moleques do Sul. Florianópolis, FATMA. 61p.

Belton, W. 1978a. A list of birds of Rio Grande do Sul, Brazil. Iheringia, Série Zoologia, (52):85-102. 
1978b. Supplementary list of new birds for Rio Grande do Sul, Brazil. Auk 95(2):413-415.

1982. Aves silvestres do Rio Grande do Sul. Porto Alegre, Fundação Zoobotânica do Rio Grande do Sul. 169p.

1984. Birds of Rio Grande do Sul, Brazil. Part 1: Rheidae through Furnariidae. Bulletin of the American Museum of Natural History 178(4):369-636.

1985. Birds of Rio Grande do Sul, Brazil. Part 2: Formicariidae through Corvidae. Bulletin of the American Museum of Natural History 180(1):1-242.

1994. Aves do Rio Grande do Sul, distribuição e biologia. São Leopoldo, Unisinos. 584p.

Bencke, G. A. 2001. Lista de referência das aves do Rio Grande do Sul. Porto Alegre, Fundação Zoobotânica do Rio Grande do Sul (Publicações Avulsas FZB, 10). 102p.

2004. O caboclinho Sporophila zelichi observado no Rio Grande do Sul, Brasil. Ararajuba 12(2):170-171.

. 2010. New and significant bird records from Rio Grande do Sul, Brazil, with comments on biogeography and conservation of the southern Brazilian avifauna. Iheringia, Série Zoologia, 100(4):XX-XX.

Bencke, G. A.; Burger, M. I.; Dotto, J. C. P.; Guadagnin, D. L.; Leite, T. O. \& Menegheti, J. O. 2007. Aves. In: Becker, F. G.; Ramos, R. A. \& Moura, L. A. orgs. Biodiversidade. Regióes da Lagoa do Casamento e dos Butiazais de Tapes, Planície Costeira do Rio Grande do Sul. Brasília, Ministério do Meio Ambiente. p.316-355.

Bencke, G. A.; Fontana, C. S.; Dias, R. A.; Maurício, G. N. \& Mähler-JR, J. K. F. 2003. Aves. In: Fontana, C. S.; Bencke, G. A. \& ReIs, R. E. eds. Livro vermelho da fauna ameaçada de extinção no Rio Grande do Sul. Porto Alegre, Edipucrs. p.189-479.

Bencke, G. A.; Fontana, C. S. \& Mendonça-Lima, A. 2002. Registro de dois novos passeriformes para o Brasil: Serpophaga griseiceps (Tyrannidae) e Asthenes pyrrholeuca (Furnariidae). Ararajuba 10(2):266-269.

Bencke, G. A.; Jardim, M. M. A.; Borges-Martins, M. \& Zank, C. 2009. Composição e padrões de distribuição da fauna de tetrápodes recentes do Rio Grande do Sul, Brasil. In: Ribeiro, A. M.; Bauermann, S. G. \& Scherer, C. S. eds. Quaternário do Rio Grande do Sul: integrando conhecimentos. Porto Alegre, Sociedade Brasileira de Paleontologia (Série Monografias). p.123-142.

Bencke, G. A.; Kindel, A. \& Mähler-JR, J. K. F. 2000. Adições à avifauna de Mata Atlântica do Rio Grande do Sul. In: Alves, M. A. S.; Cardoso da Silva, J. M.; Sluys, M. V.; Bergallo, H. G. \& Rосна, C. F. D. orgs. A Ornitologia no Brasil, pesquisa atual e perspectivas. Rio de Janeiro, EdUERJ. p.317-323

Bencke, G. A.; Maurício, G. N.; Develey, P. F. \& Goerck, J. M. 2006. Áreas importantes para a conservação das aves no Brasil. Parte I - Estados do Domínio da Mata Atlântica. SAVE Brasil, São Paulo. 494p.

BerlepsCh, H. von \& IHERING, H. von. 1885. Die Vögel der Umgegend von Taquara do Mundo Novo, Prov. Rio Grande do Sul. Zeitschrift für die gesammte Ornithologie 2:97-184.

BirdLife International. 2004. Threatened birds of the world 2004. CD-ROM. Cambridge, UK: BirdLife International.

Blake, E. R. 1977. Manual of Neotropical birds. v.1. Chicago, University of Chicago. 674p.

Bodrati, A. 2005. Nuevos aportes a la distribución de algunas especies de aves argentinas. Nuestras Aves (50):30-33.

Bokermann, W. C. A. 1957. Atualização do itinerário da viagem do Príncipe de Wied ao Brasil (1815-1817). Arquivos de Zoologia do Estado de São Paulo 10(3):209-251.

Bornschein, M. R. \& B. L. Reinert. 1996. The Andean Flamingo in Brazil. Wilson Bulletin 108(4):807-808.

Borsato, E. S.; Marros, C. S.; Rosenau, M. \& Taborda, W. Q. 1993. Observação de psitacídeos no Jardim Botânico de Porto Alegre. In: CONGRESSO BRASILEIRO DE ORNITOLOGIA, $3^{\circ}$. Resumos... Pelotas, Universidade Católica de Pelotas, Sociedade Brasileira de Ornitologia. R.51.

Bosanquet, A. 2000. The Hudsonian Whimbrel in Gwent. Birding World 13:190-193.

BRoOKE, M. 2004. Albatrosses and petrels across the world Oxford, Oxford University. 499p.
Bugoni, L. 2006. Great-winged Petrel Pterodroma macroptera in Brazil. Bulletin of the British Ornithologists' Club 126(1):52-54.

Bugoni, L. \& Furness, R. W. 2009a. Age composition and sexual size dimorphism of albatrosses and petrels off Brazil. Marine Ornithology 37:249-252

2009b. Ageing immature Atlantic Yellow-nosed Thalassarche chlororhynchos and Black-browed $T$. melanophris albatrosses in wintering grounds using bill colour and moult. Marine Ornithology 37:249.252.

Bugoni, L.; McGill, R. A. R. \& Furness, R. W. 2010. The importance of pelagic longline fishery discards for a seabird community determined through stable isotope analysis. Journal of Experimental Marine Biology and Ecology 391:190-200.

Bugoni, L.; Neves, T. S.; Adornes, A. C.; Olmos, F. \& Barquete, V. 2003. Northern Giant Petrel Macronectes halli in Brazil. Atlantic Seabirds 5:127-129.

Bugoni, L.; Neves, T. S.; Peppes, F. V. \& Furness, R. W. 2008. An effective method for trapping scavenging seabirds at sea. Journal of Field Ornithology 79(3):308-313.

Burmeister, H. 1856. Systematische Uebersicht der Thiere Brasiliens. v.2. Berlim, Georg Reimer. 526p.

Cabanis, J. [\& Heine, F.] 1850-1863. Museum Heineanum. Halberstadt, R. Frantz.

Camperi A. R. 1992. Hallazgo extralimital del Burrito Pico Rojo Neocrex erythrops olivascens. Nuestras Aves (27):30-31.

CARlos, C. J. 2005. Notes on the specimen record of the Broadbilled Prion Pachyptila vittata from Rio Grande do Sul, south Brazil. Ararajuba 13(1):124-125.

2008. A critical look at the alleged Brazilian records of the Indian Yellow-nosed Albatross Thalassarche carteri, with comments on mollymawk identification in Brazil (Procellariiformes: Diomedeidae). Revista Brasileira de Ornitologia 16:99-106.

Carlos, C. J.; Colabuono, F. I. \& Vooren, C. M. 2004. Notes on the Northern Royal Albatross Diomedea sanfordi in south Brazil. Ararajuba 12(2):166-167.

Carlos, C. J. \& Volsin, J.-F. 2008. Identifying giant petrels, Macronectes giganteus and $M$. halli, in the field and in the hand. Seabird 21:1-15.

Carlos, C. J.; Voisin, J.-F. \& Vooren, C. M. 2005. Records of Southern Giant Petrel Macronectes giganteus solanderi and Northern Giant Petrel M. halli off southern Brazil. Bulletin of the British Ornithologists' Club 125(4):288-292.

Chebez, J. C. 1996. Aves de la provincia de Misiones. In: Chebez, J. C. Fauna Misionera. Catálogo sistemático y zoogeográfico de los vertebrados de la provincia de Misiones (Argentina). Buenos Aires, L.O.L.A. p.108-179. 2008. Los que se van. Fauna argentina amenazada. v. 2. Buenos Aires, Albatros. 416p.

Claramunt, S. \& Cuello, J. P. 2004. Diversidad de la Biota Uruguaya - Aves. Anales Museo Nacional de Historia Natural y Antropologia (2 $2^{\text {a }}$ Serie) 10(6):1-76.

Collar, N. J.; Gonzaga, L. P.; Krabbe, N.; Madroño Nieto, A.; Naranjo, L. G.; Parker III, T. A. \& Wege, D. C. 1992. Threatened birds of the Americas: The ICBP/IUCN Red Data Book. 3 ed. Cambridge, UK, International Council for Bird Preservation. 1.150p.

Comitê Brasileiro de Registros Ornitológicos - CBRO. 2009. Listas das aves do Brasil. $8^{\mathrm{a}}$ ed. Disponível em <http:// www.cbro.org.br>. Acesso em 04/09/2010.

Comitê Brasileiro de Registros ORNITOLóGICOS - CBRO. 2010. Listas das aves do Brasil. 9a ed. Disponível em <http:// www.cbro.org.br>. Acesso em 04/09/2010.

Comitê Brasileiro de Registros Ornitológicos - CBRO. 2011. Listas das aves do Brasil. $10^{a}$ ed. Disponível em <http:// www.cbro.org.br>. Acesso em 25/01/2011.

Contreras J. R. 1979. Un nuevo hallazgo para la Republica Argentina del Gaviotin negro o fumarel. Historia Natural 1(1): $1-3$.

1986. Sobre presencia del halconito gris, Spiziapteryx circumcinctus (Knaup) en la Provincia de Corrientes, Argentina (Aves: Falconidae). Historia Natural 6(10):91-92.

Cory, C. B. \& Hellmayr, C. E. 1927. Catalogue of birds of the 
Americas. Part V - Tyrannidae. Chicago, Field Museum of Natural History (Publication 242, Zoological Series 13).

Cuthiert, R. J.; Phillips, R. A. \& Ryan, P. G. 2003. Separating the Tristan Albatross and the Wandering Albatross using morphometric measurements. Waterbirds 26(3):338-344.

Damiani, R. V. 2009. Primeiro registro de Phaethornis pretrei (Aves, Trochilidae) para o Rio Grande do Sul, Brasil. Biotemas 22(2): 199-202.

Darrieu, C. A. \& CAmperi, A. R. 1992. Estudio de una colección de aves de Corrientes. III. (Tyrannidae). Hornero 13(3):219-224.

DE LA PeÑa, M. 2002. Burrito pico rojo (Neocrex erythrops) y burrito enano (Coturnicops notatus) en Santa Fe, Argentina. Nuestras Aves (44):21.

2006. Lista y distribución de las aves de Santa Fe y Entre Ríos. Buenos Aires, L.O.L.A. 137p.

Dénes, F. V.; Carlos, C. J. \& Silveira, L. F. 2007. The albatrosses of the genus Diomedea Linnaeus, 1758 (Procellariiformes: Diomedeidae) in Brazil. Revista Brasileira de Ornitologia 15(4):543-550.

Dénes, F. V. \& Silveira, L. F. 2007. Cranial osteology and taxonomy of albatrosses of genus Diomedea Linnaeus, 1758 and Thalassarche Reichenbach, 1853 (Procellariiformes: Diomedeidae). Papéis Avulsos de Zoologia 47(3):43-61.

Dias, R. A. 2000. The occurrence of the European Goldfinch Carduelis carduelis in Brazil. Ornitología Neotropical 11:249-251.

Dias, R. A.; Agne, C. E.; Gianuca, D.; Gianuca, A.; BarcellosSilveira, A. \& Bugoni, L. 2010a. New records, distribution and status of seven seabird species in Brazil. Iheringia, Série Zoologia, 100(4):XX-XX.

Dias, R. A.; Gianuca, A.; Vizentin-Bugoni, J. \& Coimbra, M. A. A. 2010b. New documented records for two bird species in southernmost Brazil, including the first mention of Agriornis murinus for the country and comments on vagrancy. Revista Brasileira de Ornitologia 18(2):124-129.

Dias, R. A. \& Maurício, G. N. 1998. Lista preliminar da avifauna da extremidade sudoeste do saco da Mangueira e arredores, Rio Grande, Rio Grande do Sul. Atualidades Ornitológicas (86): $10-11$

Efe, M. A.; Mohr, L. V. \& Bugoni, L. 2001. Guia ilustrado das aves dos parques de Porto Alegre. Porto Alegre, Proaves/ SMAM/Copesul/Cemave. 144p.

Efe, M. A.; Oliveira, A. C.; Kanegae, M. F.; Alves, V. S.; Rosário, M. A. \& Scherer-Neto, P. 2006. Análise dos dados de recuperação de Sula spp. (Pelecaniformes, Sulidae) ocorridas no Brasil entre 1981 e 2000. Ornithologia 1(2):125-133.

Ferguson-Lees, J. \& Christie, D. A. 2005. Raptors of the world. Princeton e Oxford, Princeton University. 320p.

Fontana, C. S. 2005. A ornitofauna em Porto Alegre no século XX: status de ocorrência e conservação. Comunicações do Museu de Ciências e Tecnologia da PUCRS, Série Zoologia, 18(2):161-206.

Fontana, C. S.; Bencke, G. A. \& Reis, R. E. orgs. 2003. Livro vermelho da fauna ameaçada de extinção no Rio Grande do Sul. Porto Alegre, Edipucrs. 632p.

Fontana, C. S.; Repenning M. \& Roveder, C. E. 2009. Fauna terrestre: Aves. In: BoldRINI, I. I. org. Biodiversidade dos campos do Planalto das Araucárias - PROBIO. Brasília, MMA (Cadernos de Biodiversidade, 30). p.159-207.

Fontana, C. S.; Rovedder, C. E.; Repenning, M. \& Gonçalves, M. L. 2008. Estado atual do conhecimento e conservação da avifauna dos Campos de Cima da Serra do sul do Brasil, Rio Grande do Sul e Santa Catarina. Revista Brasileira de Ornitologia 16(4):281-307

Franz, I.; Ott, P. H.; Machado, R. \& Fausto, I. V. 2008. Primeiros registros de Sula dactylatra Lesson, 1831 (Pelecaniformes, Sulidae) no estado do Rio Grande do Sul. Revista Brasileira de Ornitologia 16(2):178-180.

FREY, J. K. 2009. Distinguishing range expansions from previously undocumented populations using background data from museum records. Diversity and Distributions 15(2):183-187.

Gammonley, J. H. 1996. Cinnamon Teal (Anas cyanoptera). In: Poole, A. ed. The birds of North America online. Ithaca, Cornell Lab of Ornithology. Disponível em <http:// bna.birds.cornell.edu/bna/species/209>.
GianucA, D. 2007. Ocorrência sazonal e reprodução do socócaranguejeiro Nyctanassa violacea no estuário da Lagoa dos Patos, novo limite sul da sua distribuição geográfica. Revista Brasileira de Ornitologia 15(3):464-467.

Gianuca, D.; Quintela, F. M.; Barros, J. A.; Gomes-Jr, A. \& GianucA, N. M. 2008. Ocorrência regular da garça-azul Egretta caerulea (Ciconiiformes, Ardeidae) no estuário da Lagoa dos Patos, Rio Grande do Sul, Brasil. Pan-American Journal of Aquatic Sciences 3(3):328-334.

Gianuca, D.; Vooren, C. M. \& Gianuca, A. 2009. Primeiras informações sobre reprodução e dieta da garça-azul Egretta caerulea no estuário da Lagoa dos Patos, novo limite sul da sua distribuição reprodutiva. In: CONGRESSO BRASILEIRO DE ORNITOLOGIA, $17^{\circ}$, Resumos... Aracruz. Sociedade Brasileira de Ornitologia. BR26.

Giraudo, A.; Chatellenaz, M. L.; Saibene, C. A.; Ordano, M. A.; Krauczuk, E. R.; Alonso, J. \& Di Giácomo, A. S. 2003. In: Giraudo, A. R. coord. Unidad de avifauna. In: Alvarez, B. B. ed. Fauna del Iberá. Buenos Aires, Editorial de la Universidad Nacional del Nordeste, Talleres Gráficos Volpe/Fox. p.195-223.

Gliesch, R. 1925. A fauna de Torres. Porto Alegre, Officinas Graphicas da Escola de Engenharia.

1930. Lista das aves colligidas e observadas no Estado do Rio Grande do Sul. Egatea 15:276-292.

Gonzaga, L. P. \& Castiglioni, G. 2001. Aves das montanhas do sudeste do Brasil. CD de Áudio. Rio de Janeiro, Arquivo Sonoro Prof. Elias Coelho, UFRJ (ASECCD01).

Grantsau, R. 2002. Primeiro registro documentado de Phrygilus fruticeti (Kittlitz, 1833) para o Brasil (Rio Grande do Sul). Ararajuba 10(2):262-263.

Guadagnin, D. L.; Dotto, J. C. \& Burger, M. I. 1995. Ocorrência da marreca-cabocla Dendrocygna autumnalis no noroeste do Rio Grande do Sul, Brasil. Hornero 14:74-75.

Guyra Paraguay. 2005. Atlas de las aves de Paraguay. Asunción, Asociación Guyra Paraguay. 212p.

Harrington, B. A.; Antas, P. T. Z. \& Silva, F. 1986. Northward shorebird migration on the Atlantic coast of southern Brazil. Vida Silvestre Neotropical 1(1):45-54.

HARRISON, P. 1985. Seabirds, an identification guide. London, Christopher Helm. 448p.

Hayes, F. E. 1995. Status, distribution and biogeography of the birds of Paraguay. New York, American Birding Association (Monographs in Field Ornithology, 1). 230p.

Hayman, P.; Marchant, J. \& Prater, T. 1991. Shorebirds: an identification guide to the waders of the world. Boston, Houghton Mifflin. 412p.

Hellmayr, C. E. 1937. Catalogue of birds of the Americas. Part X - Icteridae. Chicago, Field Museum of Natural History (Publication 381, Zoological Series 13).

1938. Catalogue of birds of the Americas. Part XI Ploceidae, Catamblyrhynchidae, Fringillidae. Chicago, Field Museum of Natural History (Publication 430, Zoological Series 13).

Herzog, S. K. 2001. A re-evaluation of Straneck's (1993) data on the taxonomic status of Serpophaga subcristata and $S$. munda (Passeriformes: Tyrannidae): Conspeciûcs or semispecies? Bulletin of the British Ornithologists' Club 121:273-277.

Herzog, S. K. \& Barnett, J. M. 2004. On the validity and confused identity of Serpophaga griseiceps Berlioz 1959, Tyrannidae. Auk 121(2):415-121.

Inering, H. von. 1898. As aves do Estado de São Paulo. Revista do Museu Paulista 3:113-476.

1899. As aves do Estado do Rio Grande do Sul. In: Annuário do Estado do Rio Grande do Sul para o anno de 1900. Porto Alegre. p.113-154.

Jiménez, S.; Domingo, A.; Marquez, A.; Martin, A.; D’ Anatro, A. \& Pereira, A. 2009. Interactions of long-line fishing with seabirds in the southwestern Atlantic Ocean, with a focus on White-capped Albatrosses (Thalassarche steadi). Emu 109(4):321-326.

Kirwan, G. M. \& Williams, R. S. R. 1999. Mantled Hawk Leucopternis polionota in Rio Grande do Sul, Brazil. Cotinga (11):97 (Neotropical Notebook).

Krauczuk, E. R. 2000. Presencia de Chordeiles pusillus como 
nidificante en la provincia de Misiones, Argentina. Ornitología Neotropical 11:85-86.

2008. Riqueza específica, abundancia y ambientes de las aves de Corpus Christi, San Ignacio, Misiones, Argentina. Lundiana 9(1):29-39.

KrüGel, M. M. 2003. Registro documentado de Chondrohierax uncinatus (Temminck, 1822) (Falconiformes: Accipitridae) para o Rio Grande do Sul. Ararajuba 11(1):83-84.

Krügel, M. M.; Gressler, D. T.; Behr, E. R. \& Bueno, A. S. 2007. Identification of a new IBA in the Pampa Biome, State of Rio Grande do Sul, Southern Brazil. In: VIII Congresso de Ornitologia Neotropical. Abstracts... Maturín, Venezula. p.185-186.

LeE, C.-T. \& Birch, A. 2006. Advances in the field identification of North American dowitchers. Birding 38:34-42.

Leveau, L. M. \& Leveau, C. M. 2003. Registro del halconcito gris (Spiziapteryx circumcinctus) en el sudeste de la Província de Buenos Aires, Argentina. Nuestras Aves (45):36.

Madge, S. \& Burn, H. 1988. Wildfowl. An identification guide to the ducks, geese and swans of the world. London, Christopher Helm. 298p.

Mähler-JR, J. K. F.; Repenning, M.; Rovedder, C. \& Fontana, C. S. 2007. Avifauna do município de Osório, nordeste do Rio Grande do Sul, Brasil. In: CONGRESSO BRASILEIRO DE ORNITOLOGIA, $15^{\circ}$, Resumos... Porto Alegre, Pontifícia Universidade Católica do Rio Grande do Sul. p.72.

Malosh, G. R. 2006. Thoughts on the modern approach to field identification of dowitchers. Pennsylvania Birds 20(3): 124-125.

Mata, H.; Fontana, C. S.; Maurício, G. N.; Bornschein, M. R.; Vasconcelos, M. F. \& Bonatto, S. L. 2009. Molecular phylogeny and biogeography of the eastern Tapaculos (Aves: Rhinocryptidae: Scytalopus, Eleoscytalopus): Cryptic diversification in Brazilian Atlantic Forest. Molecular Phylogenetics and Evolution 53(2):450-462.

Maurício, G. N. 2005. Taxonomy of southern populations in the Scytalopus speluncae group, with description of a new species and remarks on the systematics and biogeography of the complex (Passeriformes: Rhinocryptidae). Ararajuba 13(1):7-28

Maurício, G. N.; Bornschein, M. R.; Vasconcelos, M. F. DE; Whitney, B. M.; Pacheco, J. F. \& Silveira, L. F. 2010. Taxonomy of "Mouse-colored Tapaculos". I. On the application of the name Malacorhynchus speluncae Ménétriés, 1835 (Aves: Passeriformes: Rhinocryptidae). Zootaxa (2518):32-48.

Maurício, G. N. \& Dias, R. A. 2000. New distributional information for birds in southern Rio Grande do Sul, Brazil, and the first record of the Rufous Gnateater Conopophaga lineata for Uruguay. Bulletin of the British Ornithologists' Club 120(4):230-237.

Meller, D. A. \& Rocha, M. C. 2010. Primeiro registro documentado do araçari-castanho (Pteroglossus castanotis; Piciformes: Ramphastidae) para o Rio Grande do Sul, Brasil. Atualidades Ornitológicas (158): 10 .

Meyer de Schauensee, R. 1970. A guide to the birds of South America. Wynnewood, The Academy of Natural Sciences of Philadelphia. 470p.

Minns, J.; Buzzetti, D.; Albano, C.; Grosset, A.; Whittaker, A. \& ParrinI, R. 2010. Aves do Brasil, vozes e fotografias. v. 1 - Floresta Atlântica, Cerrado, Caatinga, Pantanal, Campos Sulinos e Costa. Versão 1.0 (DVD-ROM). Vinhedo, Avis Brasilis Editora.

Mohr, L. V. 2003. Primeiro registro documentado da garça-azul Egretta caerulea no Rio Grande do Sul. Atualidades Ornitológicas (116):2-3.

. 2004. Novo registro de pingüim-rei Aptenodytes patagonicus para o Brasil. Ararajuba 12(1):78-79.

Mohr, L. V.; Souza, F. J. \& Santos, J. C. G. 2005. Novo registro do atobá-pardo Sula leucogaster leucogaster (Boddaert, 1783) (Aves: Sulidae) no Rio Grande do Sul, Brasil. Comunicações do Museu de Ciências e Tecnologia da PUCRS, Série Zoologia, 18(2):207-209.

MuRPhy, R. C. 1914. Observation on birds of the south Atlantic. Auk 31(4):439-457.

Narosky, T. \& Di Giácomo, A. 1993. Las aves de la Província de Buenos Aires: distribucion y estatus. Buenos Aires,
Vazquez Mazzini Editores, L.O.L.A., Asociación Ornitológica del Plata. $128 \mathrm{p}$

Narosky, T. \& Yzurieta, D. 2003. Guia para la identificación de las aves de Argentina y Uruguay. 15 ed. Buenos Aires, Vazquez Mazzini Editores. 346p.

Navas, J. R. \& Bó, N. 1991. Aves nuevas o poco conocidas de Misiones, Argentina. IV. Revista del Museo Argentino de Ciencias Naturales "Bernardino Rivadavia", Zool. 15(8): $95-106$

Neves, T. S. \& Olmos, F. 2001. O albatroz-de-tristão Diomedea dabbenena no Brasil. Nattereria 2:19-20.

Neves, T.; Vooren, C. M.; Bugoni, L.; Olmos, F. \& Nascimento, L. 2006. Distribuição e abundância de aves marinhas no sudestesul do Brasil. In: Neves, T.; Bugoni, L. \& Rossi-Wongtschowski, C. L. B. eds. Aves oceânicas e suas interações com a pesca na região Sudeste-Sul do Brasil. São Paulo, USPREVIZEE. p.11-35.

Novelli, R. 1997. Aves marinhas costeiras do Brasil: Identificação e biologia. Porto Alegre. Cinco Continentes. $90 \mathrm{p}$.

O'Brien, M.; Crossley, R. \& Karlson, K. 2006. The shorebird guide. Boston, Houghton Mifflin Harcourt. 496p.

Oliveira, R. G. 1980. O bico-de-lacre, Estrilda astrild, e sua introdução no Rio Grande do Sul. Anais da Sociedade SulRiograndense de Ornitologia 1:25-28.

Olmos, A. 2009. Aves en el Uruguay. Montevideo, Trandinco. $520 \mathrm{p}$.

Olmos, F. 1997. Seabird flocks attending bottom long-line fishing off southeastern Brazil. Ibis 139(4):685-691.

First record of Northern Royal Albatross (Diomedea sanfordi) in Brazil. Ararajuba 10(2):271-273.

Olmos, F.; Martuscelli, P.; Silva, R. S. \& Neves, T. S. 1995. The seabirds of São Paulo, southeastern Brazil. Bulletin of the British Ornithologists' Club 115:117-128.

OLSON, S. L. 1982. Natural history of vertebrates on the Brazilian islands of the mid South Atlantic. National Geographic Society Research Reports 13:481-492.

Olson, S. L.; Irestedt, M.; Ericson, P. G. P. \& Fuelds̊̊, J. 2005. Independent evolution of two Darwinian marsh-dwelling ovenbirds (Furnariidae: Limnornis, Limnoctites). Ornitología Neotropical 16(3):347-359.

Onley, D. \& Scofield, P. 2007. Albatrosses, petrels and shearwaters of the world. London, Christopher Helm. $240 \mathrm{p}$.

Pacheco, J. F. 1995. O Brasil perde cinco espécies de aves! Uma análise crítica dos registros de Ruschi para alguns beija-flores das fronteiras setentrionais brasileiras. Atualidades Ornitológicas (66):7.

2000. O registro brasileiro de Philomachus pugnax (Charadriiformes: Scolopacidae) divulgado por Sick - autoria e elucidação de pequenas questões. Nattereria 1:19.

Pacheco, J. F. \& Bauer, C. 2001. A lista de aves do Espírito Santo de Augusto Ruschi (1953): uma análise crítica. In: AlbuQuerque, J. L. B.; CÂndido-JR, J. F.; Straube, F. C. \& Roos, A. L. eds. Ornitologia e conservação: da ciência às estratégias. Tubarão, Unisul. p.261-278.

PAESSLER, R. 1914. Beiträge zur Verbreitung der Seevögel. Journal für Ornithologie 62:272-278.

Parrini, R. \& Carvalho, C. E. S. 2009. Primeiro registro de Xema sabini (Charadriiformes: Laridae) para o Brasil. Atualidades Ornitológicas (151):53.

Peters, J. L. 1937. Check-list of birds of the world. v. 3 Cambridge, Mass., Harvard University Press. 311p.

Petersen, E. S. \& Petry, M. V. 2009. Confirmação do beija-florde-tesoura (Eupetomena macroura)(Aves,Trochilidae) no Estado do Rio Grande do Sul. Biotemas 22(4):241-242.

Petry, M. V. \& Fonseca, V. S. S. 2002. Effects of human activities in the marine environment on seabirds along the coast of Rio Grande do Sul, Brazil. Ornitología Neotropical 13:137-142.

Piersma, T.; van Gils, J. \& Wiersma, P. 1996. Family Scolopacidae (Sandpipers \& Allies) In: Del Hoyo, J.; Elliott, A. \& Sargatal, J. eds. Handbook of the birds of the world. Hoatzin to auks. Barcelona, Lynx Edicions. v. 3, p.444-533

Pinto, O. M. O. 1944. Catálogo das aves do Brasil. $2^{\text {a }}$ Parte. São Paulo, Departamento de Zoologia, Secretaria da Agricultura, Indústria e Comércio. 446p. 
Putzke, J. 2006. Primeiro registro de tuiuiú (Jabiru mycteria) para a região central do Rio Grande do Sul. Atualidades Ornitológicas (129): 12 .

Raffo, F. C.; De la Peña, M. R.; Silva, R. L.; Capuccio, G. \& Bonín, L. M. 2009. Aves del río Uruguay. s/l, CARU (Publicaciones de la Comision Administradora del Rio Uruguay). 248p.

Raposo, M A.; Stopiglia, R.; Loskot, V. \& Kirwan, G. M. 2006. The correct use of the name Scytalopus speluncae (Ménétriés, 1835), and the description of a new species of Brazilian tapaculo (Aves: Passeriformes: Rhinocryptidae). Zootaxa (1271):37-56.

Rebelato, M. et al. No prelo. First documented record of Sharpbilled Canastero Asthenes pyrrholeuca in Brazil. Bulletin of the British Ornithologists' Club 131.

Rebstock, G. A.; Agüero, M. A.; Boersma, P. D.; Ebert, L. A.; Laich, A.G.; Lisnizer, N.; Svagelu, W. S. \& Trivellini, M. M. 2010. Repeated observations of a Cape Gannet Morus capensis on the coast of Patagonia, Argentina. Ostrich 81(2):167-169.

Remsen-Jr, J. V.; Cadena, C. D.; Jaramillo, A.; Nores, M.; Pacheco, J. F.; Robbins, M. B.; Schulenberg, T. S.; Stiles, F. G.; Stotz, D. F. \& Zimmer, J. K. 2010. Version 26 August 2010. A classification of the bird species of South America. American Ornithologists' Union. Disponível em: <http:// www.museum.1su.edu/ Remsen/SACCBaseline.html>.

Remsen-JR, J. V. \& PARKer III, T. A. 1990. Seasonal distribution of the Azure Gallinule (Porphyrula flavirostris), with comments on vagrancy in rails and gallinules. Wilson Bulletin 102(3):380-399.

Repenning, M. \& Fontana, C. S. 2008. Novos registros de aves raras e/ou ameaçadas de extinção na Campanha do sudoeste do Rio Grande do Sul, Brasil. Revista Brasileira de Ornitologia 16(1):58-63.

Repenning, M.; Roveder, C. E. \& Fontana, C. S. 2010. Distribuição e biologia de aves nos campos de altitude do sul do Planalto Meridional Brasileiro. Revista Brasileira de Ornitologia 18(4):283-306

Ridgely, R. S. \& Tudor, G. 1994. The birds of South America. Vol. 2 - The suboscine passerines. Austin, University of Texas. 814 p.

2009. Field guide to the songbirds of South America. The passerines. Austin, University of Texas. 750p.

Rocha, G. 2006. Aves del Uruguay, el país de los pájaros pintados. v. 2. Montevideo, Banda Oriental. 144 p.

2008. Aves del Uruguay, el país de los pájaros pintados. v. 3. Montevideo, Banda Oriental. 135p.

Roda, M. A. \& López-Lanús, B. 2007. Range of Rufous- rumped Seedeater Sporophila hypochroma extends to the Pampas region of Argentina, with the first nests of the species. Cotinga (30):61-62

RosA, A. O. \& AGNE, C. E. 2010. Primeiro registro documentado da saíra-sapucaia Tangara peruviana (Passeriformes: Thraupidae) para o Rio Grande do Sul, Brasil. Atualidades Ornitológicas (155):20-21.

RosÁrio, L. A. 1996. As aves em Santa Catarina: distribuição geográfica e meio ambiente. Florianópolis, FATMA. 326p.

Rumboll, M. A. E. \& JeHL-JR, J. R. 1977. Observations on pelagic birds in the South Atlantic Ocean in the Austral Spring. San Diego Society of Natural History Transactions 19:1-16.

Ruschel, C. C. B. \& Costa, R. G. A. 2003. Primeiro registro documentado de tuiuiú, Jabiru mycteria (Ciconiidae) em Alegrete, RS. Atualidades Ornitológicas (112):3.

Ruschi, A. 1956. A trochilifauna de Porto Alegre e arredores. Boletim do Museu de Biologia Prof. Mello-Leitão, sér. Biol., (18):1-9.

Sánchez, K. B. \& SAvigny, C. 2005. Nuevos registros del halconcito gris (Spiziapteryx circumcinctus) en el sudeste de la Província de Buenos Aires, Argentina. Nuestras Aves (49):35-36.

SANDER, M. 1982. Nota sobre a presença de Diomedea epomophora Lesson, 1825, no Rio Grande do Sul, Brasil. (Aves Diomedeidae). Pesquisas, Série Zoologia, (33):23-25.

Schmidtuz, C.; Güller, R.; Di Santo, H.; Chevez, R.; Tahmazian, R. \& Quinteros, A. 2001. Nuevos registros para Misiones (Argentina) de la viudita coluda (Muscipipra vetula) y el chacurú grande (Notharcus macrorhynchus). Nuestras Aves (41):4.

Schulenberg, T. S.; Stotz, D. F.; Lane, D. F.; O’Neill, J. P. \&
Parker III, T. A. 2007. Birds of Peru. Princeton e Oxford, Princeton University. 656p.

Sick, H. 1979. Notes on some Brazilian Birds. Bulletin of the British Ornithologists' Club 99(4):115-120.

1985. Ornitologia brasileira, uma introdução. Brasília, Ed. Universidade de Brasília. 827p.

1997. Ornitologia brasileira. Rio de Janeiro, Nova Fronteira. $862 \mathrm{p}$.

Silva, R. R. V. 2006. Primeiro registro documentado de Columbina squammata (Columbidae) para o Rio Grande do Sul, Brasil. Revista Brasileira de Ornitologia 14(2):45-46.

Silva e Silva, R. \& Olmos, F. 2006. Noteworthy bird records from Fernando de Noronha, northeastern Brazil. Revista Brasileira de Ornitologia 14(4):470-474

Soares, E. S.; Amaral, F. S. R.; Carvalho-Filho, E. P. M.; Granzinolli, M. A.; Albuquerque, J. L. B.; Lisboa, J. S.; Azevedo, M. A. G.; Moraes, W.; Sanaiotti, T. \& Guimarães, I. G. 2008. Plano de ação nacional para a conservação de aves de rapina. Brasília, Instituto Chico Mendes de Conservação da Biodiversidade (Série Espécies Ameaçadas, 5). 136p.

Straneck, R. J. 1993. Aportes para la unificación de Serpophaga subcristata y Serpophaga munda, y la revalidación de Serpophaga griseiceps (Aves: Tyrannidae). Revista del Museo Argentino de Ciencias Naturales "Bernardino Rivadavia", Zool., 16:51-63.

. 2007. Una nueva especie de Serpophaga (Aves: Tyrannidae). Revista FAVE - Ciencias Veterinarias 6(1-2):31-42.

Straube, F. C.; Urben-Filho, A. \& Kajiwara, D. 2004. Aves. In: Mikich, S. B. \& BéRnils, R. S. eds. Livro vermelho da fauna ameaçada no Estado do Paraná. Curitiba, Instituto Ambiental. p.143-496.

Taylor, B. \& van Perlo, B. 1998. Rails. A guide to the rails, crakes, gallinules and coots of the world. New Haven e London, Yale University. 600p.

Teixeira, D. M.; Nacinovic, J. B. \& Novelli, R. 1985. Notes on some Brazilian seabirds. Bulletin of the British Ornithologists' Club 105:49-51.

Teixeira, D. M.; Nacinovic, J. B.; Schloemp, I. M. \& Kischlat, E. E. 1988. Notes on some Brazilian seabirds (3). Bulletin of the British Ornithologists' Club 108:136-139.

Traversi, G. S. \& Vooren, C. M. 2010. Interactions between seabirds and the trawl fishery in coastal waters of southern Brazil in summer. Revista Brasileira de Ornitologia 18(3): 183-193.

Vasconcelos, M. F.; Maurício, G. N.; Kirwan, G. M. \& Silveira, L. F. 2008. Range extension for Marsh Tapaculo Scytalopus iraiensis to the highlands of Minas Gerais, Brazil, with an overview of the species' distribution. Bulletin of the British Ornithologists' Club 128:101-106.

Vielliard, J. M. E. 1994. Catálogo dos troquilídeos do Museu de Biologia Mello Leitão. Santa Teresa, MBML, Inst. Bras. do Patr. Cult. e Ministério da Cultura. 94p.

Vinicombe, K. 2010. Hudsonian Whimbrel. Disponível em: < h t t p : / / w w w birdwatch.co.uk/categories/ articleitem.asp?cate $=23 \&$ topic $=117 \&$ item $=463>$. Acesso em: 18 de outubro de 2010

Vooren, C. M. 1985. Migração e ocorrências de aves marinhas na costa sul do Brasil. In: CONGRESSO BRASILEIRO DE ZOOLOGIA, Resumos... Campinas, Universidade Estadual de Campinas. p.266-267.

. The first two records of Sula capensis in Brazil. Ararajuba 12(1):76-77

Vooren, C. M. \& Fernandes, A. C. 1989. Guia de albatrozes e petréis do sul do Brasil. Porto Alegre, Sagra. 99p.

Voss, W. A. 1977. Comunicação sobre a ocorrência da sanãamarela, Porzana flaviventer (Boddaert), em São Leopoldo RS. Pesquisas, Série Zoologia, (30):30-31.

1979. Comunicação sobre a ocorrência do bico-de-lacre, Estrilda astrild (Linné, 1758), na cidade de Novo Hamburgo, RS. Pesquisas, Série Zoologia, (31):25-28.

1982. Comunicação sobre a ocorrência do gavião-pombo, [sic] Leocopternis polionota (Kaup, 1847), no município de Viamão, RS, Brasil (Aves-Accipitridae). Pesquisas, Série Zoologia, (33):27-28.

Votto, A. P.; Gomes-Jr, A.; Bugoni, L. \& Pereira-JR, J. 2006. Sazonalidade da avifauna no Campus Carreiros da Fundação 
Universidade Federal do Rio Grande, Rio Grande do Sul, Brasil. Estudos de Biologia 28:45-55.

White, C. M.; Olsen, V. D. \& Kiff, L. F. 1994. Family Falconidae (Falcons and Caracaras). In: Del Hoyo, J.; ElliotT, A. \& SARGatal, J. eds. Handbook of the birds of the world. $v$. 2. Barcelona, Lynx Editions. p.216-275.

Whitney, B. M.; Vasconcelos, M. F.; Silveira, L. F. \& Pacheco, J. F. 2010. Scytalopus petrophilus (Rock Tapaculo): a new species from Minas Gerais, Brazil. Revista Brasileira de Ornitologia 18(2):73-88.
Wied, M. [Prinzen zu]. 1831. Beiträge zur Naturgeschichte von Brasilien. III(2). Weimar, Landes-IndustrieComptoirs.

Willis, E. O. \& ONiKi, Y. 1991. Nomes gerais para as aves brasileiras. Américo Brasiliense, Gráfica da Região. 55p.

ZimMER, J. 1955. Further notes on tyrant flycatchers (Tyrannidae). American Museum Novitates (1749):1-24.

Zink, R. M.; Rowher, S.; Andreev, A. V. \& Dittmann, D. L. 1995. Trans-Beringia comparison of mitochondrial DNA differentiation in birds. Condor 97(3):639-649.

Apêndice I. Lista das aves do Rio Grande do Sul, Brasil. Evidência: P, pele taxidermizada; E, espécime em meio líquido; O, material osteológico; F, registro fotográfico; Vi, gravação de vídeo; G; gravação de áudio; R, recuperação de anilha; V, registro visual. O asterisco assinala as espécies exóticas (naturalizadas).

\section{Ordem/Família/Espécie}

Struthioniformes

Rheidae

Rhea americana (Linnaeus, 1758)

Tinamiformes

Tinamidae

Tinamus solitarius (Vieillot, 1819)

Crypturellus obsoletus (Temminck, 1815)

Crypturellus noctivagus (Wied, 1820)

Crypturellus parvirostris (Wagler, 1827)

Crypturellus tataupa (Temminck, 1815)

Rhynchotus rufescens (Temminck, 1815)

Nothura maculosa (Temminck, 1815)

Anseriformes

Anhimidae

Chauna torquata (Oken, 1816)

Anatidae

Dendrocygna bicolor (Vieillot, 1816)

Dendrocygna viduata (Linnaeus, 1766)

Dendrocygna autumnalis (Linnaeus, 1758)

Cygnus melancoryphus (Molina, 1782)

Coscoroba coscoroba (Molina, 1782)

Cairina moschata (Linnaeus, 1758)

Sarkidiornis sylvicola Ihering \& Ihering, 1907

Callonetta leucophrys (Vieillot, 1816)

Amazonetta brasiliensis (Gmelin, 1789)

Anas sibilatrix Poeppig, 1829

Anas flavirostris Vieillot, 1816

Anas georgica Gmelin, 1789

Anas bahamensis Linnaeus, 1758

Anas versicolor Vieillot, 1816

Anas discors Linnaeus, 1766

Anas cyanoptera Vieillot, 1816

Anas platalea Vieillot, 1816

Netta peposaca (Vieillot, 1816)

Heteronetta atricapilla (Merrem, 1841)

Nomonyx dominica (Linnaeus, 1766)

Oxyura vittata (Philippi, 1860)

Galliformes

Cracidae

Ortalis guttata (Spix, 1825)

Penelope superciliaris Temminck, 1815

Penelope obscura Temminck, 1815

Aburria jacutinga (Spix, 1825)

Odontophoridae

Odontophorus capueira (Spix, 1825)

Podicipediformes

Podicipedidae

Rollandia rolland (Quoy \& Gaimard, 1824)

Tachybaptus dominicus (Linnaeus, 1766)

Podilymbus podiceps (Linnaeus, 1758)

Podicephorus major (Boddaert, 1783)

Sphenisciformes

Spheniscidae

Aptenodytes patagonicus Miller, 1778

Spheniscus magellanicus (Forster, 1781)

Eudyptes chrysolophus (Brandt, 1837)

Eudyptes chrysocome (Forster, 1781)

Procellariiformes

Diomedeidae

Phoebetria fusca (Hilsenberg, 1822)
Nome em português Evidência

ema

$\mathrm{P}$

macuco

inambuguaçu

jaó-do-litoral

inambuxororó

inambuxintã

perdigão

perdiz ou codorna

tachã

reca-piadeira ou irerê

marreca-asa-branca

cisne-de-pescoço-preto

capororoca

pato-do-mato

pato-de-crista

marreca-de-coleira

marreca-pé-vermelho

marreca-oveira

marreca-pardinha

marreca-parda

marreca-toicinho

marreca-cricri

marreca-de-asa-azu

marreca-colorada

marreca-colhereira

marrecão

marreca-de-cabeça-preta

marreca-de-bico-roxo

marreca-pés-na-bunda

aracuã

jacu-velho ou jacupemba

jacuaçu

jacutinga

uru

$\mathrm{P}$

mergulhão-pequeno

mergulhão

mergulhão-grande

pinguim-rei

pinguim-de-magalhães

pinguim-de-testa-amarela

pinguim-de-penacho-amarelo
$\mathrm{P}$

$\mathrm{P}$

$\mathrm{P}$

$\mathrm{P}$

P

$\mathrm{P}$

$\mathrm{P}$

$\mathrm{P}$

$\mathrm{P}$

$\mathrm{P}$

$\mathrm{P}$

$\mathrm{P}$

$\mathrm{P}$

$\mathrm{P}$

$\mathrm{P}$
$\mathrm{F}$
$\mathrm{P}$
$\mathrm{P}$
$\mathrm{P}$
$\mathrm{P}$
$\mathrm{P}$
$\mathrm{P}$
$\mathrm{P}$
$\mathrm{P}$
$\mathrm{P}$
$\mathrm{P}$
$\mathrm{P}$
$\mathrm{R}$
$\mathrm{P}$
$\mathrm{P}$
$\mathrm{P}$
$\mathrm{P}$
$\mathrm{P}$
$\mathrm{P}$

$\mathrm{P}$

$\mathrm{P}$

$\mathrm{P}$

P

$\mathrm{P}$

P

P

$\mathrm{P}$
$\mathrm{P}$
$\mathrm{P}$
$\mathrm{P}$
$\mathrm{P}$
$\mathrm{P}$
$\mathrm{P}$

P

P

$\mathrm{P}$

$\mathrm{P}$

$\mathrm{P}$

P

$\mathrm{P}$

$\mathrm{P}$ 
Apêndice I (cont.)

Thalassarche chlororhynchos (Gmelin, 1789)

Thalassarche melanophris (Temminck, 1828)

Thalassarche cauta (Gould, 1841)

Diomedea epomophora Lesson, 1825

Diomedea sanfordi Murphy, 1917

Diomedea exulans Linnaeus, 1758

Diomedea dabbenena Mathews, 1929

Procellariidae

Macronectes giganteus (Gmelin, 1789)

Macronectes halli Mathews, 1912

Fulmarus glacialoides (Smith, 1840)

Daption capense (Linnaeus, 1758)

Lugensa brevirostris (Lesson, 1831)

Pterodroma mollis (Gould, 1844)

Pterodroma incerta (Schlegel, 1863)

Pterodroma macroptera (Smith, 1840)

Halobaena caerulea (Gmelin, 1789)

Pachyptila vittata (Forster, 1777)

Pachyptila desolata (Gmelin, 1789)

Pachyptila belcheri (Mathews, 1912)

Procellaria cinerea Gmelin, 1789

Procellaria aequinoctialis Linnaeus, 1758

Procellaria conspicillata Gould, 1844

Calonectris borealis (Cory, 1881)

Calonectris edwardsii (Oustalet, 1883)

Puffinus griseus (Gmelin, 1789)

Puffinus gravis (O’Reilly, 1818)

Puffinus puffinus (Brünnich, 1764)

Hydrobatidae

Fregetta grallaria (Vieillot, 1818)

Oceanites oceanicus (Kuhl, 1820)

Pelecanoididae

Pelecanoides magellani (Mathews, 1912)

Ciconiiformes

Ciconiidae

Ciconia maguari (Gmelin, 1789)

Jabiru mycteria (Lichtenstein, 1819)

Mycteria americana Linnaeus, 1758

Suliformes

Fregatidae

Fregata magnificens Mathews, 1914

Sulidae

Morus capensis (Lichtenstein, 1823)

Sula dactylatra Lesson, 1831

Sula leucogaster (Boddaert, 1783)

Phalacrocoracidae

Phalacrocorax brasilianus (Gmelin, 1789)

Anhingidae

Anhinga anhinga (Linnaeus, 1766)

Pelecaniformes

Ardeidae

Tigrisoma lineatum (Boddaert, 1783)

Botaurus pinnatus (Wagler, 1829)

Ixobrychus exilis (Gmelin, 1789)

Ixobrychus involucris (Vieillot, 1823)

Nycticorax nycticorax (Linnaeus, 1758)

Nyctanassa violacea (Linnaeus, 1758)

Butorides striata (Linnaeus, 1758)

Bubulcus ibis (Linnaeus, 1758)

Ardea cocoi Linnaeus, 1766

Ardea alba Linnaeus, 1758

Syrigma sibilatrix (Temminck, 1824)

Egretta thula (Molina, 1782)

Egretta caerulea (Linnaeus, 1758)

Threskiornithidae

Plegadis chihi (Vieillot, 1817)

Mesembrinibis cayennensis (Gmelin, 1789)

Phimosus infuscatus (Lichtenstein, 1823)

Theristicus caerulescens (Vieillot, 1817)

Theristicus caudatus (Boddaert, 1783)

Platalea ajaja Linnaeus, 1758

Phoenicopteriformes

Phoenicopteridae

Phoenicopterus chilensis Molina, 1782

Phoenicoparrus andinus (Philippi, 1854)

$$
\begin{gathered}
\text { albatroz-de-nariz-amarelo } \\
\text { albatroz-de-sobrancelha } \\
\text { albatroz-arisco } \\
\text { albatroz-real } \\
\text { albatroz-real-do-norte } \\
\text { albatroz-errante } \\
\text { albatroz-de-tristão }
\end{gathered}
$$

pardelão-gigante-de-bico-verde

pardelão-gigante-de-bico-vermelho petrel-prateado pomba-do-cabo

pardela-de-bico-curto pardela-de-colar pardela-de-capuz

pardela-de-cara-cinza petrel-azul

faigão-de-bico-largo faigão-rola

faigão-de-bico-fino pardela-cinza pardela-preta pardela-de-óculos pardela-de-bico-amarelo

pardela-de-cabo-verde pardela-escura

pardela-grande-de-sobre-branco pardela-pequena

painho-de-barriga-branca

$$
\text { alma-de-mestre }
$$

petrel-mergulhador-de-magalhães

$\mathrm{P}$
$\mathrm{P}$
$\mathrm{P}$
$\mathrm{P}, \mathrm{O}, \mathrm{R}$
$\mathrm{P}$
$\mathrm{P}, \mathrm{R}$
$\mathrm{P}$

$\mathrm{P}$

$\mathrm{P}$

$\mathrm{P}$

$\mathrm{P}$

$\mathrm{P}$

$\mathrm{P}$

$\mathrm{P}$

$\mathrm{P}$

$\mathrm{P}$

$\mathrm{P}$

$\mathrm{P}$

$\mathrm{P}$

$\mathrm{P}$

$\mathrm{P}$

$\mathrm{P}$

$\mathrm{P}$

$\mathrm{P}$

$\mathrm{P}$

F

$\mathrm{P}$

$\mathrm{P}$

joão-grande

jabiru ou tuiuiú

cabeça-seca

P

F

tesourão

$\mathrm{P}$

atobá-do-cabo

atobá-grande

atobá-pardo

biguá

biguatinga

$\mathrm{P}$

socó-boi-verdadeiro

socó-boi-baio

socoí-vermelho

socoí-amarelo

$$
\text { savacu }
$$

savacu-de-coroa

socozinho

garça-vaqueira

garça-moura ou socó-grande

garça-branca-grande

maria-faceira

garça-branca-pequena

garça-azul

maçarico-preto

coró-coró

maçarico-de-cara-pelada ou chapéu-velho

maçarico-real

curicaca

colhereiro 
Apêndice I (cont.)

Cathartiformes

Cathartidae

Cathartes aura (Linnaeus, 1758)

Cathartes burrovianus Cassin, 1845

Coragyps atratus (Bechstein, 1793)

Sarcoramphus papa (Linnaeus, 1758)

Accipitriformes

Pandionidae

Pandion haliaetus (Linnaeus, 1758)

Accipitridae

Leptodon cayanensis (Latham, 1790)

Chondrohierax uncinatus (Temminck, 1822)

Elanoides forficatus (Linnaeus, 1758)

Elanus leucurus (Vieillot, 1818)

Harpagus diodon (Temminck, 1823)

Circus cinereus Vieillot, 1816

Circus buffoni (Gmelin, 1788)

Accipiter poliogaster (Temminck, 1824)

Accipiter superciliosus (Linnaeus, 1766)

Accipiter striatus Vieillot, 1808

Accipiter bicolor (Vieillot, 1817)

Ictinia plumbea (Gmelin, 1788)

Busarellus nigricollis (Latham, 1790)

Rostrhamus sociabilis (Vieillot, 1817)

Geranospiza caerulescens (Vieillot, 1817)

Heterospizias meridionalis (Latham, 1790)

Urubitinga urubitinga (Gmelin, 1788)

Urubitinga coronata (Vieillot, 1817)

Rupornis magnirostris (Gmelin, 1788)

Parabuteo unicinctus (Temminck, 1824)

Parabuteo leucorrhous (Quoy \& Gaimard, 1824)

Geranoaetus albicaudatus (Vieillot, 1816)

Geranoaetus melanoleucus (Vieillot, 1819)

Pseudastur polionotus (Kaup, 1847)

Buteo brachyurus Vieillot, 1816

Buteo swainsoni Bonaparte, 1838

Morphnus guianensis (Daudin, 1800)

Harpia harpyja (Linnaeus, 1758)

Spizaetus tyrannus (Wied, 1820)

Spizaetus melanoleucus (Vieillot, 1816)

Spizaetus ornatus (Daudin, 1800)

Falconiformes

Falconidae

Caracara plancus (Miller, 1777)

Milvago chimachima (Vieillot, 1816)

Milvago chimango (Vieillot, 1816)

Herpetotheres cachinnans (Linnaeus, 1758)

Micrastur ruficollis (Vieillot, 1817)

Micrastur semitorquatus (Vieillot, 1817)

Falco sparverius Linnaeus, 1758

Falco rufigularis Daudin, 1800

Falco deiroleucus Temminck, 1825

Falco femoralis Temminck, 1822

Falco peregrinus Tunstall, 1771

Gruiformes

Aramidae

Aramus guarauna (Linnaeus, 1766)

Rallidae

Coturnicops notatus (Gould, 1841)

Aramides ypecaha (Vieillot, 1819)

Aramides cajanea (Statius Muller, 1776)

Aramides saracura (Spix, 1825)

Laterallus melanophaius (Vieillot, 1819)

Laterallus leucopyrrhus (Vieillot, 1819)

Porzana flaviventer (Boddaert, 1783)

Porzana spiloptera Durnford, 1877

Porzana albicollis (Vieillot, 1819)

Neocrex erythrops (Sclater, 1867)

Pardirallus maculatus (Boddaert, 1783)

Pardirallus nigricans (Vieillot, 1819)

Pardirallus sanguinolentus (Swainson, 1837)

Gallinula galeata (Lichtenstein,1818)

Gallinula melanops (Vieillot, 1819)

Porphyrio martinica (Linnaeus, 1766)

Porphyrio flavirostris (Gmelin, 1789)

Fulica armillata Vieillot, 1817

Fulica rufifrons Philippi \& Landbeck, 1861

Fulica leucoptera Vieillot, 1817

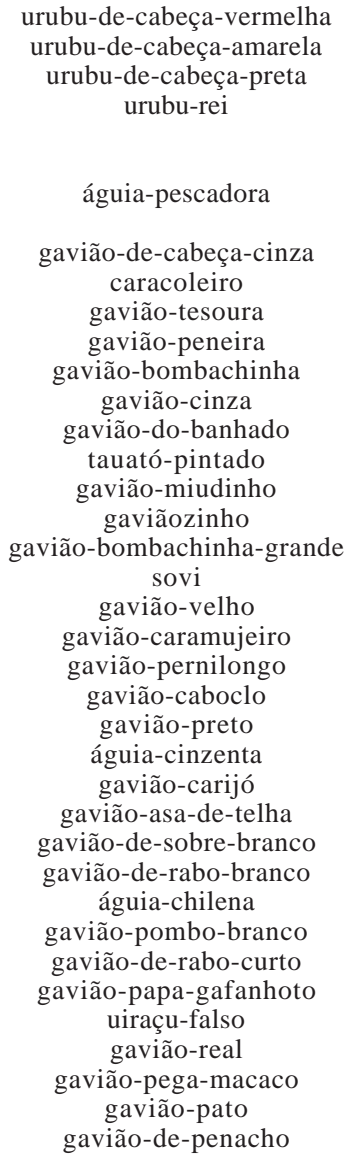

urubu-de-cabeça-vermelha urubu-de-cabeça-amarela urubu-de-cabeça-preta urubu-rei

águia-pescadora

gavião-de-cabeça-cinza caracoleiro

gavião-tesoura gavião-peneira

gavião-bombachinha gavião-cinza

gavião-do-banhado

tauató-pintado

gavião-miudinho gaviãozinho

gavião-bombachinha-grande sovi

gavião-velho

gavião-caramujeiro

gavião-pernilongo

gavião-caboclo

gavião-preto

águia-cinzenta

gavião-carijó

gavião-asa-de-telha

gavião-de-sobre-branco

gavião-de-rabo-branco

águia-chilena

gavião-pombo-branco

gavião-de-rabo-curto

gavião-papa-gafanhoto uiraçu-falso gavião-real

gavião-pega-macaco gavião-pato

gavião-de-penacho

$\mathrm{P}$

$\mathrm{F}$

$\mathrm{F}$
caracará
carrapateiro
chimango
acauã
gavião-caburé
gavião-relógio
quiriquiri

falcão-de-garganta-branca falcão-de-peito-vermelho

falcão-de-coleira

falcão-peregrino

carão

pinto-d'água-pintalgado

saracuruçu

três-potes

saracura-do-mato

pinto-d'água-comum

pinto-d'água-avermelhado

sanã-amarela

sanã-cinza

sanã-carijó

turu-turu

saracura-carijó

saracura-sanã

saracura-do-banhado

galinhola ou frango-d'água

frango-d'água-carijó

frango-d'água-azul

frango-d'água-pequeno

carqueja-de-bico-manchado

carqueja-de-escudo-vermelho

carqueja-de-bico-amarelo
F

P

G

$\mathrm{P}$

P

P

P

P

F

$\mathrm{P}$
$\mathrm{P}$

$\mathrm{P}$
$\mathrm{P}$

P

$\mathrm{P}$

$\mathrm{P}$

$\mathrm{P}$

$\mathrm{P}$

$\mathrm{F}$
$\mathrm{P}$
$\mathrm{G}$
$\mathrm{P}$
$\mathrm{P}$
$\mathrm{P}$
$\mathrm{P}$
$\mathrm{P}$
$\mathrm{P}$
$\mathrm{P}$
$\mathrm{P}$
$\mathrm{P}$
$\mathrm{P}$
$\mathrm{P}$
$\mathrm{P}$
$\mathrm{P}$
$\mathrm{P}$
$\mathrm{P}$
$\mathrm{P}$
$\mathrm{P}$
$\mathrm{V}$
$\mathrm{P}$
$\mathrm{P}$
$\mathrm{P}$
$\mathrm{V}$
$\mathrm{P}$
$\mathrm{P}$
$\mathrm{P}$
$\mathrm{P}$
$\mathrm{P}$
$\mathrm{P}$
$\mathrm{P}$

P

$\mathrm{P}$

P

$\mathrm{P}$

$\mathrm{P}$

$\mathrm{P}$

$\mathrm{P}$

$\mathrm{P}$

$\mathrm{P}$

P

$P$
$P$
$P$
$G$
$P$
$P$
$P$
V
$P$
$P$
$P$

V

$\mathrm{P}$

P

$\mathrm{P}$

$\mathrm{P}$

$\mathrm{P}$

$\mathrm{P}$

P

F

P

V

$P$

P

P

P

$\mathrm{P}$

$\mathrm{F}$

P

P

P 
Apêndice I (cont.)

Cariamiformes

Cariamidae

Cariama cristata (Linnaeus, 1766)

Charadriiformes

Charadriidae

Vanellus chilensis (Molina, 1782)

Pluvialis dominica (Statius Muller, 1776)

Pluvialis squatarola (Linnaeus, 1758)

Charadrius semipalmatus Bonaparte, 1825

Charadrius collaris Vieillot, 1818

Charadrius falklandicus Latham, 1790

Charadrius modestus Lichtenstein, 1823

Oreopholus ruficollis (Wagler, 1829)

Haematopodidae

Haematopus palliatus Temminck, 1820

Recurvirostridae

Himantopus melanurus Vieillot, 1817

Chionidae

Chionis albus (Gmelin, 1789)

Scolopacidae

Gallinago paraguaiae (Vieillot, 1816)

Gallinago undulata (Boddaert, 1783)

Limnodromus griseus (Gmelin, 1789)

Limosa haemastica (Linnaeus, 1758)

Numenius phaeopus (Linnaeus, 1758)

Bartramia longicauda (Bechstein, 1812)

Actitis macularius (Linnaeus, 1766)

Tringa solitaria Wilson, 1813

Tringa melanoleuca (Gmelin, 1789)

Tringa semipalmata (Gmelin, 1789)

Tringa flavipes (Gmelin, 1789)

Arenaria interpres (Linnaeus, 1758)

Calidris canutus (Linnaeus, 1758)

Calidris alba (Pallas, 1764)

Calidris pusilla (Linnaeus, 1766)

Calidris minutilla (Vieillot, 1819)

Calidris fuscicollis (Vieillot, 1819)

Calidris bairdii (Coues, 1861)

Calidris melanotos (Vieillot, 1819)

Calidris himantopus (Bonaparte, 1826)

Tryngites subruficollis (Vieillot, 1819)

Philomachus pugnax (Linnaeus, 1758)

Phalaropus tricolor (Vieillot, 1819)

Jacanidae

Jacana jacana (Linnaeus, 1766)

Rostratulidae

Nycticryphes semicollaris (Vieillot, 1816)

Stercorariidae

Stercorarius chilensis Bonaparte, 1857

Stercorarius antarcticus (Lesson, 1831)

Stercorarius pomarinus (Temminck, 1815)

Stercorarius parasiticus (Linnaeus, 1758)

Stercorarius longicaudus Vieillot, 1819

Laridae

Xema sabini Sabine, 1819

Chroicocephalus maculipennis (Lichtenstein, 1823)

Chroicocephalus cirrocephalus (Vieillot, 1818)

Leucophaeus pipixcan (Wagler, 1831)

Larus atlanticus Olrog, 1958

Larus dominicanus Lichtenstein, 1823

Sternidae

Anous stolidus (Linnaeus, 1758)

Sternula antillarum Lesson, 1847

Sternula superciliaris (Vieillot, 1819)

Phaetusa simplex (Gmelin, 1789)

Gelochelidon nilotica (Gmelin, 1789)

Chlidonias leucopterus (Temminck, 1815)

Chlidonias niger (Linnaeus, 1758)

Sterna hirundo Linnaeus, 1758

Sterna paradisaea Pontoppidan, 1763

Sterna hirundinacea Lesson, 1831

Sterna trudeaui Audubon, 1838

Thalasseus acuflavidus (Cabot, 1847)

Thalasseus maximus (Boddaert, 1783)

Rynchopidae

Rynchops niger Linnaeus, 1758

\begin{tabular}{|c|c|}
\hline seriema & $\mathrm{P}$ \\
\hline quero-quero & $\mathrm{P}$ \\
\hline batuiruçu & $\mathrm{P}$ \\
\hline batuiruçu-de-axila-preta & $\mathrm{P}$ \\
\hline batuíra-norte-americana & $\mathrm{P}$ \\
\hline batuíra-de-coleira & $\mathrm{P}$ \\
\hline batuíra-de-coleira-dupla & $\mathrm{P}$ \\
\hline batuíra-de-peito-avermelhado & $\mathrm{P}$ \\
\hline batuíra-de-papo-ferrugíneo & $\mathrm{P}$ \\
\hline piru-piru & $\mathrm{P}$ \\
\hline pernilongo & $\mathrm{P}$ \\
\hline pomba-antártica & $\mathrm{P}$ \\
\hline narceja & $\mathrm{P}$ \\
\hline narcejão & $\mathrm{P}$ \\
\hline maçarico-de-costas-brancas & $\mathrm{F}$ \\
\hline maçarico-de-bico-virado & $\mathrm{P}$ \\
\hline maçarico-de-bico-torto & $\mathrm{F}$ \\
\hline maçarico-do-campo & $\mathrm{P}$ \\
\hline maçarico-pintado & $\mathrm{P}$ \\
\hline maçarico-solitário & $\mathrm{P}$ \\
\hline maçarico-grande-de-perna-amarela & $\mathrm{P}$ \\
\hline maçarico-de-asa-branca & $\mathrm{P}$ \\
\hline maçarico-de-perna-amarela & $\mathrm{P}$ \\
\hline vira-pedra & $\mathrm{P}$ \\
\hline maçarico-de-papo-vermelho & $\mathrm{P}$ \\
\hline maçarico-branco & $\mathrm{P}$ \\
\hline maçarico-miúdo & $\mathrm{P}$ \\
\hline maçariquinho & $\mathrm{P}$ \\
\hline maçarico-de-sobre-branco & $\mathrm{P}$ \\
\hline maçarico-de-bico-fino & $\mathrm{P}$ \\
\hline maçarico-de-colete & $\mathrm{P}$ \\
\hline maçarico-pernilongo & $\mathrm{P}$ \\
\hline maçarico-acanelado & $\mathrm{P}$ \\
\hline combatente & $\mathrm{V}$ \\
\hline pisa-n’água & $\mathrm{P}$ \\
\hline jaçanã & $\mathrm{P}$ \\
\hline narceja-de-bico-torto & $\mathrm{P}$ \\
\hline gaivota-rapineira-chilena & $\mathrm{P}$ \\
\hline gaivota-rapineira-antártica & $\mathrm{P}$ \\
\hline gaivota-rapineira-pomarina & $\mathrm{O}, \mathrm{F}$ \\
\hline gaivota-rapineira-comum & $\mathrm{P}$ \\
\hline gaivota-rapineira-de-cauda-comprida & $\mathrm{P}$ \\
\hline gaivota-de-sabine & $\mathrm{F}$ \\
\hline gaivota-maria-velha & $\mathrm{P}$ \\
\hline gaivota-de-cabeça-cinza & $\mathrm{P}$ \\
\hline gaivota-de-franklin & $\mathrm{F}$ \\
\hline gaivota-de-rabo-preto & $\mathrm{F}$ \\
\hline gaivotão & $\mathrm{P}$ \\
\hline trinta-réis-escuro & $\mathrm{P}$ \\
\hline trinta-réis-miúdo & $\mathrm{F}$ \\
\hline trinta-réis-anão & $\mathrm{P}$ \\
\hline trinta-réis-grande & $\mathrm{P}$ \\
\hline trinta-réis-de-bico-preto & $\mathrm{P}$ \\
\hline trinta-réis-negro-de-asa-branca & $\mathrm{F}$ \\
\hline trinta-réis-negro & $\mathrm{V}$ \\
\hline trinta-réis-boreal & $\mathrm{P}$ \\
\hline trinta-réis-ártico & $\mathrm{P}$ \\
\hline trinta-réis-de-bico-vermelho & $\mathrm{P}$ \\
\hline trinta-réis-de-coroa-branca & $\mathrm{P}$ \\
\hline trinta-réis-de-bico-amarelo & $\mathrm{P}$ \\
\hline trinta-réis-real & $\mathrm{P}$ \\
\hline talha-mar & $\mathrm{P}$ \\
\hline
\end{tabular}


Apêndice I (cont.)

Columbiformes

Columbidae

Columbina talpacoti (Temminck, 1811)

Columbina squammata (Lesson, 1831)

Columbina picui (Temminck, 1813)

Claravis pretiosa (Ferrari-Perez, 1886)

Columba livia Gmelin, 1789

Patagioenas picazuro (Temminck, 1813)

Patagioenas maculosa (Temminck, 1813)

Patagioenas cayennensis (Bonnaterre, 1792)

Patagioenas plumbea (Vieillot, 1818)

Zenaida auriculata (Des Murs, 1847)

Leptotila verreauxi Bonaparte, 1855

Leptotila rufaxilla (Richard \& Bernard, 1792)

Geotrygon montana (Linnaeus, 1758)

Psittaciformes

Psittacidae

Anodorhynchus glaucus (Vieillot, 1816)

Primolius maracana (Vieillot, 1816)

Aratinga leucophthalma (Statius Muller, 1776)

Pyrrhura frontalis (Vieillot, 1817)

Myiopsitta monachus (Boddaert, 1783)

Brotogeris tirica (Gmelin, 1788)

Brotogeris chiriri (Vieillot, 1818)

Pionopsitta pileata (Scopoli, 1769)

Pionus maximiliani (Kuhl, 1820)

Amazona vinacea (Kuhl, 1820)

Amazona pretrei (Temminck, 1830)

Amazona aestiva (Linnaeus, 1758)

Triclaria malachitacea (Spix, 1824)

Cuculiformes

Cuculidae

Micrococcyx cinereus (Vieillot, 1817)

Piaya cayana (Linnaeus, 1766)

Coccyzus melacoryphus Vieillot, 1817

Coccyzus americanus (Linnaeus, 1758)

Coccyzus euleri Cabanis, 1873

Crotophaga major Gmelin, 1788

Crotophaga ani Linnaeus, 1758

Guira guira (Gmelin, 1788)

Tapera naevia (Linnaeus, 1766)

Dromococcyx phasianellus (Spix, 1824)

Dromococcyx pavoninus Pelzeln, 1870

Strigiformes

Tytonidae

Tyto alba (Scopoli, 1769)

Strigidae

Megascops choliba (Vieillot, 1817)

Megascops sanctaecatarinae (Salvin, 1897)

Pulsatrix perspicillata (Latham, 1790)

Pulsatrix koeniswaldiana (Bertoni \& Bertoni, 1901)

Bubo virginianus (Gmelin, 1788)

Strix hylophila Temminck, 1825

Strix virgata (Cassin, 1849)

Glaucidium brasilianum (Gmelin, 1788)

Athene cunicularia (Molina, 1782)

Aegolius harrisii (Cassin, 1849)

Asio clamator (Vieillot, 1808)

Asio stygius (Wagler, 1832)

Asio flammeus (Pontoppidan, 1763)

Caprimulgiformes

Nyctibiidae

Nyctibius griseus (Gmelin, 1789)

Caprimulgidae

Antrostomus rufus (Boddaert, 1783)

Antrostomus sericocaudatus Cassin, 1849

Lurocalis semitorquatus (Gmelin, 1789)

Hydropsalis albicollis (Gmelin, 1789)

Hydropsalis parvula (Gould, 1837)

Hydropsalis anomala (Gould, 1838)

Hydropsalis longirostris (Bonaparte, 1825)

Hydropsalis torquata (Gmelin, 1789)

Hydropsalis forcipata (Nitzsch, 1840)

Chordeiles pusillus Gould, 1861

Chordeiles nacunda (Vieillot, 1817)

Chordeiles minor (Forster, 1771)

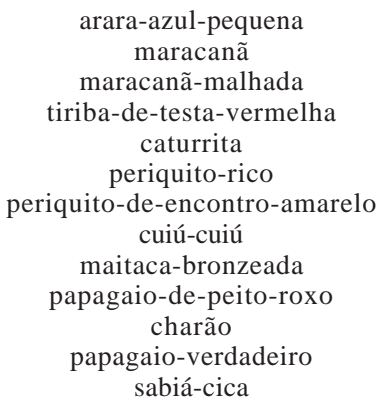

arara-azul-pequena

maracanã

maracanã-malhada

tiriba-de-testa-vermelha

caturrita

periquito-rico

periquito-de-encontro-amarelo cuiú-cuiú

maitaca-bronzeada

papagaio-de-peito-roxo charão

papagaio-verdadeiro sabiá-cica

papa-lagarta-cinzento alma-de-gato

papa-lagarta-verdadeiro

papa-lagarta-norte-americano

papa-lagarta-de-euler

anu-coroca

anu-preto

anu-branco

$$
\text { saci }
$$

peixe-frito-verdadeiro

peixe-frito-pavonino

coruja-de-igreja

corujinha-do-mato

corujinha-do-sul

murucututu

murucututu-de-barriga-amarela

jacurutu

coruja-listrada

coruja-do-mato caburé

coruja-do-campo

caburé-acanelado

coruja-orelhuda

mocho-diabo

mocho-dos-banhados

urutau

joão-corta-pau

bacurau-rabo-de-seda

tuju

bacurau

bacurau-pequeno

curiango-do-banhado

bacurau-da-telha

bacurau-tesoura

bacurau-tesoura-gigante

bacurauzinho

corucão

bacurau-norte-americano
$\mathrm{P}$

G

F

$\mathrm{P} *$

$\mathrm{P}$

$\mathrm{P}$

P

$\mathrm{V}$
$\mathrm{P}$
$\mathrm{P}$
$\mathrm{P}$
$\mathrm{P}$
$\mathrm{F}$
$\mathrm{F}^{*}$
$\mathrm{P}$
$\mathrm{P}$
$\mathrm{P}$
$\mathrm{P}$
$\mathrm{F}^{*}$
$\mathrm{P}$

P

$\mathrm{P}$
$\mathrm{P}$

F

$\mathrm{P}$

P

P

P

G

P

P

P

F

P

P

$\mathrm{P}$

P

P

G

$\mathrm{P}$

P

P

P

P

$\mathrm{P}$

V

P 
Apêndice I (cont.)

Apodiformes

Apodidae

Cypseloides fumigatus (Streubel, 1848)

Cypseloides senex (Temminck, 1826)

Streptoprocne zonaris (Shaw, 1796)

Streptoprocne biscutata (Sclater, 1866)

Chaetura cinereiventris Sclater, 1862

Chaetura meridionalis Hellmayr, 1907

Trochilidae

Phaethornis pretrei (Lesson \& Delattre, 1839)

Phaethornis eurynome (Lesson, 1832)

Eupetomena macroura (Gmelin, 1788)

Aphantochroa cirrochloris (Vieillot, 1818)

Florisuga fusca (Vieillot, 1817)

Colibri serrirostris (Vieillot, 1816)

Anthracothorax nigricollis (Vieillot, 1817)

Stephanoxis lalandi (Vieillot, 1818)

Lophornis magnificus (Vieillot, 1817)

Chlorostilbon lucidus (Shaw, 1812)

Thalurania glaucopis (Gmelin, 1788)

Hylocharis chrysura (Shaw, 1812)

Leucochloris albicollis (Vieillot, 1818)

Polytmus guainumbi (Pallas, 1764)

Amazilia versicolor (Vieillot, 1818)

Amazilia fimbriata (Gmelin, 1788)

Clytolaema rubricauda (Boddaert, 1783)

Heliomaster furcifer (Shaw, 1812)

Calliphlox amethystina (Boddaert, 1783)

Trogoniformes

Trogonidae

Trogon surrucura Vieillot, 1817

Trogon rufus Gmelin, 1788

Coraciiformes

Alcedinidae

Megaceryle torquata (Linnaeus, 1766)

Chloroceryle amazona (Latham, 1790)

Chloroceryle americana (Gmelin, 1788)

Momotidae

Baryphthengus ruficapillus (Vieillot, 1818)

Galbuliformes

Bucconidae

Notharchus swainsoni (Gray, 1846)

Nystalus chacuru (Vieillot, 1816)

Nonnula rubecula (Spix, 1824)

Piciformes

Ramphastidae

Ramphastos toco Statius Muller, 1776

Ramphastos dicolorus Linnaeus, 1766

Selenidera maculirostris (Lichtenstein, 1823)

Pteroglossus bailloni (Vieillot, 1819)

Pteroglossus castanotis Gould, 1834

Picidae

Picumnus temminckii Lafresnaye, 1845

Picumnus nebulosus Sundevall, 1866

Melanerpes candidus (Otto, 1796)

Melanerpes flavifrons (Vieillot, 1818)

Veniliornis spilogaster (Wagler, 1827)

Veniliornis mixtus (Boddaert, 1783)

Piculus aurulentus (Temminck, 1821)

Colaptes melanochloros (Gmelin, 1788)

Colaptes campestris (Vieillot, 1818)

Celeus flavescens (Gmelin, 1788)

Dryocopus galeatus (Temminck, 1822)

Dryocopus lineatus (Linnaeus, 1766)

Campephilus robustus (Lichtenstein, 1818)

Campephilus leucopogon (Valenciennes, 1826)

Passeriformes

Thamnophilidae

Myrmeciza squamosa Pelzeln, 1868

Myrmotherula gularis (Spix, 1825)

Myrmotherula unicolor (Ménétriès, 1835)

Stymphalornis acutirostris Bornschein, Reinert \& Teixeira, 1995

Dysithamnus mentalis (Temminck, 1823)

Thamnophilus ruficapillus Vieillot, 1816

Thamnophilus caerulescens Vieillot, 1816

Hypoedaleus guttatus (Vieillot, 1816)

Batara cinerea (Vieillot, 1819)

andorinhão-preto-da-cascata

andorinhão-velho-da-cascata

andorinhão-de-coleira

andorinhão-de-coleira-falha

andorinhão-de-sobre-cinzento

andorinhão-do-temporal

rabo-branco-acanelado

rabo-branco-de-garganta-rajada

beija-flor-tesoura

beija-flor-cinza

beija-flor-preto-de-rabo-branco

beija-flor-de-orelha-violeta

beija-flor-de-veste-preta

beija-flor-de-topete

topetinho-vermelho

besourinho-de-bico-vermelho

beija-flor-de-fronte-violeta beija-flor-dourado

beija-flor-de-papo-branco beija-flor-de-bico-curvo

beija-flor-de-banda-branca

beija-flor-de-garganta-verde

beija-flor-papo-de-fogo

beija-flor-de-barba-azul estrelinha

$\mathrm{P}$

$\mathrm{P}$

$\mathrm{P}$

P

F

P

F

$\mathrm{P}$

F

$\mathrm{P}$

$\mathrm{P}$

$\mathrm{P}$

$\mathrm{P}$

$\mathrm{P}$

$\mathrm{P}$

F

$\mathrm{P}$

$\mathrm{P}$

E

$\mathrm{P}$

surucuá-variado

surucuá-de-barriga-amarela

$\mathrm{P}$
$\mathrm{P}$

martim-pescador-grande

martim-pescador-verde

martim-pescador-pequeno

juruva

capitão-do-mato joão-bobo

macuru

V

$\mathrm{P}$

tucanuçu

tucano-de-bico-verde

araçaripoca

araçari-banana

araçari-castanho

pica-pau-anão-de-coleira

pica-pau-anão-carijó

pica-pau-branco

benedito-de-testa-amarela

picapauzinho-verde-carijó

picapauzinho-chorão

pica-pau-dourado

pica-pau-verde-barrado

pica-pau-do-campo joão-velho

pica-pau-de-cara-amarela

pica-pau-de-banda-branca pica-pau-rei

pica-pau-de-barriga-preta

$\mathrm{P}$

$\mathrm{P}$

P

$\mathrm{P}$

$\mathrm{P}$
$\mathrm{P}$

F

$\mathrm{P}$

$\mathrm{P}$

$\mathrm{P}$

$\mathrm{P}$

$\mathrm{P}$

$\mathrm{P}$

$\mathrm{P}$

$\mathrm{P}$
$\mathrm{P}$

$\mathrm{P}$

$\mathrm{P}$
$\mathrm{P}$

$\mathrm{P}$

$\mathrm{P}$

$\mathrm{P}, \mathrm{V}$

papa-formiga-de-grota

choquinha-de-garganta-pintada

choquinha-cinzenta

bicudinho-do-brejo choquinha-lisa

choca-de-boné-vermelho

choca-da-mata

chocão-carijó

matracão

$\mathrm{P}$

P

P 
Apêndice I (cont.)

Mackenziaena leachii (Such, 1825)

Mackenziaena severa (Lichtenstein, 1823)

Pyriglena leucoptera (Vieillot, 1818)

Drymophila rubricollis (Bertoni, 1901)

Drymophila malura (Temminck, 1825)

Conopophagidae

Conopophaga lineata (Wied, 1831)

Grallariidae

Grallaria varia (Boddaert, 1783)

Hylopezus nattereri (Pinto, 1937)

Rhinocryptidae

Eleoscytalopus indigoticus (Wied, 1831)

Scytalopus speluncae (Ménétriés, 1835)

Scytalopus pachecoi Maurício, 2005

Scytalopus iraiensis Bornschein, Reinert \& Pichorim, 1998

Psilorhamphus guttatus (Ménétriès, 1835)

Formicariidae

Formicarius colma Boddaert, 1783

Chamaeza campanisona (Lichtenstein, 1823)

Chamaeza ruficauda (Cabanis \& Heine, 1859)

Scleruridae

Sclerurus scansor (Ménétriès, 1835)

Geositta cunicularia (Vieillot, 1816)

Dendrocolaptidae

Dendrocincla turdina (Lichtenstein, 1820)

Sittasomus griseicapillus (Vieillot, 1818)

Xiphorhynchus fuscus (Vieillot, 1818)

Campylorhamphus falcularius (Vieillot, 1822)

Drymornis bridgesii (Eyton, 1850)

Lepidocolaptes angustirostris (Vieillot, 1818)

Lepidocolaptes falcinellus (Cabanis \& Heine, 1859)

Dendrocolaptes platyrostris Spix, 1825

Xiphocolaptes albicollis (Vieillot, 1818)

Furnariidae

Xenops rutilans Temminck, 1821

Cinclodes pabsti Sick, 1969

Cinclodes fuscus (Vieillot, 1818)

Furnarius rufus (Gmelin, 1788)

Limnornis curvirostris Gould, 1839

Phleocryptes melanops (Vieillot, 1817)

Lochmias nematura (Lichtenstein, 1823)

Automolus leucophthalmus (Wied, 1821)

Philydor lichtensteini Cabanis \& Heine, 1859

Philydor atricapillus (Wied, 1821)

Philydor rufum (Vieillot, 1818)

Heliobletus contaminatus Berlepsch, 1885

Anabacerthia amaurotis (Temminck, 1823)

Syndactyla rufosuperciliata (Lafresnaye, 1832)

Cichlocolaptes leucophrus (Jardine \& Selby, 1830)

Leptasthenura platensis Reichenbach, 1853

Leptasthenura striolata (Pelzeln, 1856)

Leptasthenura setaria (Temminck, 1824)

Spartonoica maluroides (d'Orbigny \& Lafresnaye, 1837)

Pseudoseisura lophotes (Reichenbach, 1853)

Phacellodomus striaticollis (d'Orbigny \& Lafresnaye, 1838)

Phacellodomus ruber (Vieillot, 1817)

Phacellodomus ferrugineigula (Pelzeln, 1858)

Clibanornis dendrocolaptoides (Pelzeln, 1859)

Anumbius annumbi (Vieillot, 1817)

Coryphistera alaudina Burmeister, 1860

Schoeniophylax phryganophilus (Vieillot, 1817)

Certhiaxis cinnamomeus (Gmelin, 1788)

Synallaxis ruficapilla Vieillot, 1819

Synallaxis cinerascens Temminck, 1823

Synallaxis frontalis Pelzeln, 1859

Synallaxis albescens Temminck, 1823

Synallaxis spixi Sclater, 1856

Asthenes baeri (Berlepsch, 1906)

Asthenes pyrrholeuca (Vieillot, 1817)

Asthenes hudsoni (Sclater, 1874)

Limnoctites rectirostris (Gould, 1839)

Cranioleuca sulphurifera (Burmeister, 1869)

Cranioleuca pyrrhophia (Vieillot, 1818)

Cranioleuca obsoleta (Reichenbach, 1853)

Pipridae

Manacus manacus (Linnaeus, 1766)

Chiroxiphia caudata (Shaw \& Nodder, 1793)

$\begin{array}{cc}\text { brujarara-assobiador } & \mathrm{P} \\ \text { borralhara } & \mathrm{P} \\ \text { papa-taoca } & \mathrm{P} \\ \text { trovoada-de-bertoni } & \mathrm{P} \\ \text { choquinha-carijó } & \mathrm{P}\end{array}$

chupa-dente

tovacuçu

pinto-do-mato

macuquinho

tapaculo-preto

tapaculo-ferreirinho

macuquinho-da-várzea

macuquinho-pintado

galinha-do-mato

tovaca-campainha

tovaca-de-rabo-vermelho

vira-folha

curriqueiro

arapaçu-liso

arapaçu-verde

arapaçu-rajado

arapaçu-de-bico-torto

arapaçu-do-espinilho

arapaçu-do-cerrado

arapaçu-escamoso-do-sul

arapaçu-grande

arapaçu-grande-de-garganta-branca

bico-virado-carijó

teresinha ou pedreiro

pedreiro-dos-andes

joão-de-barro

joão-da-palha

bate-bico

joão-porca

barranqueiro-de-olho-branco

limpa-folha-ocráceo

limpa-folha-coroado

limpa-folha-de-testa-baia

trepadorzinho

limpa-folha-miúdo

trepador-quiete

trepador-sobrancelha

rabudinho

grimpeirinho

grimpeiro

boininha

coperete

tio-tio

graveteiro

joão-botina

cisqueiro

cochicho

corredor-crestudo

bichoita

curutié

pichororé

pi-puí

petrim

uí-pi

joão-teneném

lenheiro

lenheiro-de-rabo-comprido

lenheiro-platino

arredio-do-gravatá

arredio-de-papo-manchado arredio

arredio-oliváceo

rendeira

dançador 
Apêndice I (cont.)

Tityridae

Oxyruncus cristatus Swainson, 1821

Schiffornis virescens (Lafresnaye, 1838)

Tityra inquisitor (Lichtenstein, 1823)

Tityra cayana (Linnaeus, 1766)

Pachyramphus viridis (Vieillot, 1816)

Pachyramphus castaneus (Jardine \& Selby, 1827)

Pachyramphus polychopterus (Vieillot, 1818)

Pachyramphus validus (Lichtenstein, 1823)

Xenopsaris albinucha (Burmeister, 1869)

Cotingidae

Procnias nudicollis (Vieillot, 1817)

Pyroderus scutatus (Shaw, 1792)

Carpornis cucullata (Swainson, 1821)

Phibalura flavirostris Vieillot, 1816

Phytotoma rutila Vieillot, 1818

Incertae sedis

Platyrinchus mystaceus Vieillot, 1818

Platyrinchus leucoryphus Wied, 1831

Piprites chloris (Temminck, 1822)

Piprites pileata (Temminck, 1822)

Tachuris rubrigastra (Vieillot, 1817)

Rhynchocyclidae

Mionectes rufiventris Cabanis, 1846

Leptopogon amaurocephalus Tschudi, 1846

Corythopis delalandi (Lesson, 1830)

Phylloscartes eximius (Temminck, 1822)

Phylloscartes ventralis (Temminck, 1824)

Phylloscartes kronei Willis \& Oniki, 1992

Phylloscartes difficilis (Ihering \& Ihering, 1907)

Tolmomyias sulphurescens (Spix, 1825)

Poecilotriccus plumbeiceps (Lafresnaye, 1846)

Myiornis auricularis (Vieillot, 1818)

Hemitriccus diops (Temminck, 1822)

Hemitriccus obsoletus (Miranda-Ribeiro, 1906)

Hemitriccus orbitatus (Wied, 1831)

Hemitriccus margaritaceiventer (d'Orbigny \& Lafresnaye, 1837)

Tyrannidae

Hirundinea ferruginea (Gmelin, 1788)

Euscarthmus meloryphus Wied, 1831

Tyranniscus burmeisteri Cabanis \& Heine, 1859

Camptostoma obsoletum (Temminck, 1824)

Elaenia flavogaster (Thunberg, 1822)

Elaenia spectabilis Pelzeln, 1868

Elaenia chilensis Hellmayr, 1927

Elaenia parvirostris Pelzeln, 1868

Elaenia mesoleuca (Deppe, 1830)

Elaenia obscura (d'Orbigny \& Lafresnaye, 1837)

Suiriri suiriri (Vieillot, 1818)

Myiopagis caniceps (Swainson, 1835)

Myiopagis viridicata (Vieillot, 1817)

Capsiempis flaveola (Lichtenstein, 1823)

Phyllomyias virescens (Temminck, 1824)

Phyllomyias fasciatus (Thunberg, 1822)

Phyllomyias griseocapilla Sclater, 1862

Culicivora caudacuta (Vieillot, 1818)

Polystictus pectoralis (Vieillot, 1817)

Pseudocolopteryx sclateri (Oustalet, 1892)

Pseudocolopteryx flaviventris (d'Orbigny \& Lafresnaye, 1837)

Serpophaga nigricans (Vieillot, 1817)

Serpophaga subcristata (Vieillot, 1817)

Serpophaga griseicapilla Straneck, 2007

Serpophaga munda Berlepsch, 1893

Attila phoenicurus Pelzeln, 1868

Attila rufus (Vieillot, 1819)

Legatus leucophaius (Vieillot, 1818)

Myiarchus swainsoni Cabanis \& Heine, 1859

Myiarchus ferox (Gmelin, 1789)

Myiarchus tyrannulus (Statius Muller, 1776)

Sirystes sibilator (Vieillot, 1818)

Pitangus sulphuratus (Linnaeus, 1766)

Machetornis rixosa (Vieillot, 1819)

Myiodynastes maculatus (Statius Muller, 1776)

Megarynchus pitangua (Linnaeus, 1766)

Myiozetetes similis (Spix, 1825)

Tyrannus melancholicus Vieillot, 1819

Tyrannus savana Vieillot, 1808

\begin{tabular}{|c|c|}
\hline araponga-do-horto & $\mathrm{F}$ \\
\hline flautim & $\mathrm{P}$ \\
\hline anambé-branco-de-bochecha-parda & $\mathrm{P}$ \\
\hline anambé-branco-de-rabo-preto & $\mathrm{P}$ \\
\hline caneleirinho-verde & $\mathrm{P}$ \\
\hline caneleirinho & $\mathrm{P}$ \\
\hline caneleirinho-preto & $\mathrm{P}$ \\
\hline caneleiro-de-chapéu-preto & $\mathrm{P}$ \\
\hline tijerila & $\mathrm{F}$ \\
\hline araponga ou ferreiro & $\mathrm{P}$ \\
\hline pavó & $\mathrm{P}$ \\
\hline corocoxó & $\mathrm{P}$ \\
\hline tesourinha-do-mato & $\mathrm{P}$ \\
\hline corta-ramos-de-rabo-branco & $\mathrm{P}$ \\
\hline patinho & $\mathrm{P}$ \\
\hline patinho-gigante & $\mathrm{P}$ \\
\hline papinho-amarelo & $\mathrm{P}$ \\
\hline caneleirinho-de-boné-preto & $\mathrm{P}$ \\
\hline papa-piri & $\mathrm{P}$ \\
\hline supi-de-cabeça-cinza & $\mathrm{P}$ \\
\hline cabeçudo & $\mathrm{P}$ \\
\hline estalador & $\mathrm{P}$ \\
\hline barbudinho & $\mathrm{P}$ \\
\hline borboletinha-do-mato & $\mathrm{P}$ \\
\hline maria-da-restinga & G \\
\hline estalinho & $\mathrm{P}$ \\
\hline bico-chato-de-orelha-preta & $\mathrm{P}$ \\
\hline tororó & $\mathrm{P}$ \\
\hline miudinho & $\mathrm{P}$ \\
\hline olho-falso & $\mathrm{P}$ \\
\hline catraca & $\mathrm{P}$ \\
\hline tiririzinho-do-mato & $\mathrm{P}$ \\
\hline olho-de-ouro & $\mathrm{F}, \mathrm{G}$ \\
\hline birro & $\mathrm{P}$ \\
\hline barulhento & $\mathrm{P}$ \\
\hline piolhinho-chiador & $\mathrm{P}$ \\
\hline risadinha & $\mathrm{P}$ \\
\hline guaracava-de-barriga-amarela & $\mathrm{P}$ \\
\hline guaracava-grande & $\mathrm{P}$ \\
\hline guaracava-de-crista-branca & $\mathrm{P}$ \\
\hline guaracava-de-bico-curto & $\mathrm{P}$ \\
\hline tuque & $\mathrm{P}$ \\
\hline tucão & $\mathrm{P}$ \\
\hline suiriri-cinzento & $\mathrm{P}$ \\
\hline guaracava-cinzenta & $\mathrm{P}$ \\
\hline guaracava-de-crista-alaranjada & $\mathrm{P}$ \\
\hline marianinha-amarela & $\mathrm{P}$ \\
\hline piolhinho-verdoso & $\mathrm{P}$ \\
\hline piolhinho & $\mathrm{P}$ \\
\hline piolhinho-serrano & $\mathrm{V}$ \\
\hline papa-moscas-do-campo & $\mathrm{F}$ \\
\hline papa-moscas-canela & $\mathrm{P}$ \\
\hline tricolino & $\mathrm{P}$ \\
\hline amarelinho-do-junco & $\mathrm{P}$ \\
\hline joão-pobre & $\mathrm{P}$ \\
\hline alegrinho & $\mathrm{P}$ \\
\hline alegrinho-trinador & G \\
\hline alegrinho-de-barriga-branca & $\mathrm{P}$ \\
\hline capitão-castanho & $\mathrm{P}$ \\
\hline capitão-de-saíra & $\mathrm{P}$ \\
\hline bem-te-vi-pirata & $\mathrm{P}$ \\
\hline irré & $\mathrm{P}$ \\
\hline maria-cavaleira & $\mathrm{P}$ \\
\hline maria-cavaleira-de-rabo-ferrugem & $\mathrm{P}$ \\
\hline suiriri-assobiador & $\mathrm{P}$ \\
\hline bem-te-vi & $\mathrm{P}$ \\
\hline suiriri-cavaleiro & $\mathrm{P}$ \\
\hline bem-te-vi-rajado & $\mathrm{P}$ \\
\hline neinei & $\mathrm{P}$ \\
\hline bem-te-vi-pequeno & $\mathrm{F}$ \\
\hline suiriri & $\mathrm{P}$ \\
\hline tesourinha & \\
\hline
\end{tabular}


Apêndice I (cont.)

Griseotyrannus aurantioatrocristatus (d'Orbigny \& Lafresnaye, 1837)

Empidonomus varius (Vieillot, 1818)

Colonia colonus (Vieillot, 1818)

Myiophobus fasciatus (Statius Muller, 1776)

Sublegatus modestus (Wied, 1831)

Pyrocephalus rubinus (Boddaert, 1783)

Fluvicola albiventer (Spix, 1825)

Arundinicola leucocephala (Linnaeus, 1764)

Gubernetes yetapa (Vieillot, 1818)

Alectrurus tricolor (Vieillot, 1816)

Alectrurus risora (Vieillot, 1824)

Cnemotriccus fuscatus (Wied, 1831)

Lathrotriccus euleri (Cabanis, 1868)

Contopus cinereus (Spix, 1825)

Lessonia rufa (Gmelin, 1789)

Knipolegus cyanirostris (Vieillot, 1818)

Knipolegus lophotes Boie, 1828

Knipolegus nigerrimus (Vieillot, 1818)

Hymenops perspicillatus (Gmelin, 1789)

Satrapa icterophrys (Vieillot, 1818)

Xolmis cinereus (Vieillot, 1816)

Xolmis coronatus (Vieillot, 1823)

Xolmis irupero (Vieillot, 1823)

Xolmis dominicanus (Vieillot, 1823)

Agriornis murinus (Orbigny \& Lafresnaye, 1837)

Neoxolmis rufiventris (Vieillot, 1823)

Muscipipra vetula (Lichtenstein, 1823)

Vireonidae

Cyclarhis gujanensis (Gmelin, 1789)

Vireo olivaceus (Linnaeus, 1766)

Hylophilus poicilotis Temminck, 1822

Corvidae

Cyanocorax caeruleus (Vieillot, 1818)

Cyanocorax chrysops (Vieillot, 1818)

Hirundinidae

Pygochelidon cyanoleuca (Vieillot, 1817)

Alopochelidon fucata (Temminck, 1822)

Stelgidopteryx ruficollis (Vieillot, 1817)

Progne tapera (Vieillot, 1817)

Progne chalybea (Gmelin, 1789)

Tachycineta albiventer (Boddaert, 1783)

Tachycineta leucorrhoa (Vieillot, 1817)

Tachycineta leucopyga (Meyen ,1834)

Riparia riparia (Linnaeus, 1758)

Hirundo rustica Linnaeus, 1758

Petrochelidon pyrrhonota (Vieillot, 1817)

Troglodytidae

Troglodytes musculus Naumann, 1823

Cistothorus platensis (Latham, 1790)

Polioptilidae

Polioptila lactea Sharpe, 1885

Polioptila dumicola (Vieillot, 1817)

Turdidae

Turdus flavipes Vieillot, 1818

Turdus rufiventris Vieillot, 1818

Turdus leucomelas Vieillot, 1818

Turdus amaurochalinus Cabanis, 1850

Turdus subalaris (Seebohm, 1887)

Turdus albicollis Vieillot, 1818

Mimidae

Mimus saturninus (Lichtenstein, 1823)

Mimus triurus (Vieillot, 1818)

Motacillidae

Anthus lutescens Pucheran, 1855

Anthus furcatus d'Orbigny \& Lafresnaye, 1837

Anthus correndera Vieillot, 1818

Anthus nattereri Sclater, 1878

Anthus hellmayri Hartert, 1909

Coerebidae

Coereba flaveola (Linnaeus, 1758)

Thraupidae

Saltator fuliginosus (Daudin, 1800)

Saltator coerulescens Vieillot, 1817

Saltator similis d'Orbigny \& Lafresnaye, 1837

Saltator maxillosus Cabanis, 1851

Saltator aurantiirostris Vieillot, 1817

Nemosia pileata (Boddaert, 1783)

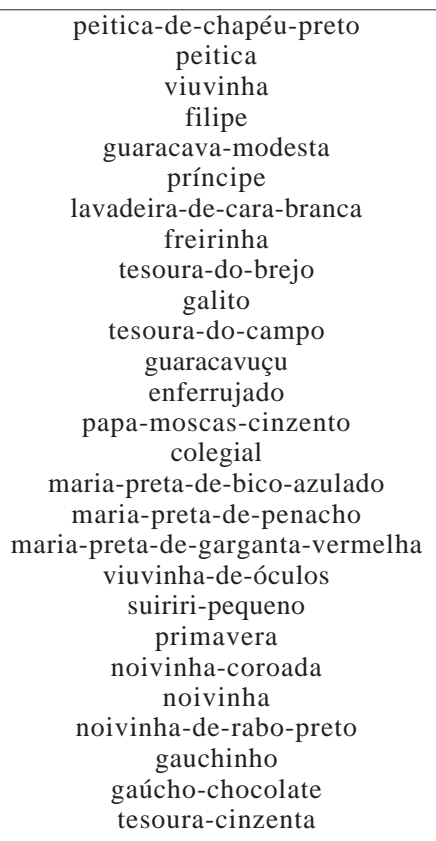

bico-de-pimenta sabiá-gongá

trinca-ferro-verdadeiro bico-grosso

bico-duro ou bico-de-ouro saíra-de-chapéu-preto
$\mathrm{P}$
$\mathrm{P}$
$\mathrm{P}$
$\mathrm{P}$
$\mathrm{P}$
$\mathrm{P}$
$\mathrm{P}$
$\mathrm{P}$
$\mathrm{P}$
$\mathrm{P}$
$\mathrm{P}$
$\mathrm{P}$
$\mathrm{P}$
$\mathrm{P}$
$\mathrm{P}$
$\mathrm{P}$
$\mathrm{P}$
$\mathrm{P}$
$\mathrm{P}$
$\mathrm{P}$
$\mathrm{P}$
$\mathrm{P}$
$\mathrm{P}$
$\mathrm{P}$
$\mathrm{F}$
$\mathrm{P}$
$\mathrm{P}$

$\mathrm{P}$

$\mathrm{P}$

$\mathrm{P}$

$\mathrm{P}$

$\mathrm{P}$

$\mathrm{P}$

$\mathrm{P}$

$\mathrm{P}$

$\mathrm{P}$

$\mathrm{P}$

$\mathrm{P}$

$\mathrm{P}$

$\mathrm{P}$

$\mathrm{P}$

$\mathrm{P}$

$\mathrm{P}$

$\mathrm{P}$

$\mathrm{P}$

$\mathrm{P}$

$\mathrm{P}$

$\mathrm{P}$

$\mathrm{P}$

$\mathrm{F}$

$\mathrm{P}$ 
Apêndice I (cont.)

Orthogonys chloricterus (Vieillot, 1819)

Pyrrhocoma ruficeps (Strickland, 1844)

Tachyphonus coronatus (Vieillot, 1822)

Lanio cucullatus (Statius Muller, 1776)

Lanio melanops (Vieillot, 1818)

Tangara seledon (Statius Muller, 1776)

Tangara cyanocephala (Statius Muller, 1776)

Tangara sayaca (Linnaeus, 1766)

Tangara cyanoptera (Vieillot, 1817)

Tangara palmarum (Wied, 1823)

Tangara peruviana (Desmarest, 1806)

Tangara preciosa (Cabanis, 1850)

Stephanophorus diadematus (Temminck, 1823)

Diuca diuca (Molina, 1782)

Cissopis leverianus (Gmelin, 1788)

Paroaria coronata (Miller, 1776)

Paroaria capitata (d'Orbigny \& Lafresnaye, 1837)

Pipraeidea melanonota (Vieillot, 1819)

Pipraeidea bonariensis (Gmelin, 1789)

Tersina viridis (Illiger, 1811)

Dacnis cayana (Linnaeus, 1766)

Hemithraupis guira (Linnaeus, 1766)

Hemithraupis ruficapilla (Vieillot, 1818)

Conirostrum speciosum (Temminck, 1824)

Emberizidae

Zonotrichia capensis (Statius Muller, 1776)

Ammodramus humeralis (Bosc, 1792)

Phrygilus fruticeti (Kittlitz, 1833)

Haplospiza unicolor Cabanis, 1851

Donacospiza albifrons (Vieillot, 1817)

Poospiza thoracica (Nordmann, 1835)

Poospiza nigrorufa (d'Orbigny \& Lafresnaye, 1837)

Poospiza cabanisi Bonaparte, 1850

Poospiza melanoleuca (d'Orbigny \& Lafresnaye, 1837)

Sicalis flaveola (Linnaeus, 1766)

Sicalis luteola (Sparrman, 1789)

Emberizoides herbicola (Vieillot, 1817)

Emberizoides ypiranganus Ihering \& Ihering, 1907

Embernagra platensis (Gmelin, 1789)

Volatinia jacarina (Linnaeus, 1766)

Sporophila frontalis (Verreaux, 1869)

Sporophila plumbea (Wied, 1830)

Sporophila collaris (Boddaert, 1783)

Sporophila lineola (Linnaeus, 1758)

Sporophila caerulescens (Vieillot, 1823)

Sporophila leucoptera (Vieillot, 1817)

Sporophila bouvreuil (Statius Muller, 1776)

Sporophila hypoxantha Cabanis, 1851

Sporophila ruficollis Cabanis, 1851

Sporophila palustris (Barrows, 1883)

Sporophila cinnamomea (Lafresnaye, 1839)

Sporophila melanogaster (Pelzeln, 1870)

Sporophila angolensis (Linnaeus, 1766)

Arremon semitorquatus Swainson, 1838

Gubernatrix cristata (Vieillot, 1817)

Cardinalidae

Piranga flava (Vieillot, 1822)

Habia rubica (Vieillot, 1817)

Cyanoloxia moesta (Hartlaub, 1853)

Cyanoloxia brissonii (Lichtenstein, 1823)

Cyanoloxia glaucocaerulea (d'Orbigny \& Lafresnaye, 1837)

Parulidae

Parula pitiayumi (Vieillot, 1817)

Geothlypis aequinoctialis (Gmelin, 1789)

Basileuterus culicivorus (Deppe, 1830)

Basileuterus leucoblepharus (Vieillot, 1817)

Icteridae

Procacicus solitarius (Vieillot, 1816)

Cacicus chrysopterus (Vigors, 1825)

Cacicus haemorrhous (Linnaeus, 1766)

Icterus pyrrhopterus (Vieillot, 1819)

Gnorimopsar chopi (Vieillot, 1819)

Amblyramphus holosericeus (Scopoli, 1786)

Agelasticus cyanopus (Vieillot, 1819)

Agelasticus thilius (Molina, 1782)

Chrysomus ruficapillus (Vieillot, 1819)

Xanthopsar flavus (Gmelin, 1788) catirumbava

cabecinha-castanha

tiê-preto

tico-tico-rei

tiê-de-topete

saíra-de-sete-cores

saíra-militar

sanhaçu-cinzento

sanhaçu-de-encontro-azul

sanhaçu-do-coqueiro

saíra-sapucaia

saíra-preciosa

sanhaçu-frade

diuca

tiê-tinga

cardeal

cavalaria

saíra-viúva

sanhaçu-papa-laranja

saí-andorinha

saí-azul

papo-preto

saíra-ferrugem

figuinha-de-rabo-castanho

tico-tico

tico-tico-do-campo

canário-andino-negro cigarra-bambu

tico-tico-do-banhado

peito-pinhão

quem-te-vestiu quete

capacetinho

canário-da-terra-verdadeiro tipio

canário-do-campo

canário-do-brejo

sabiá-do-banhado tiziu

pixoxó

patativa

coleiro-do-brejo

bigodinho

coleirinho

chorão

caboclinho

caboclinho-de-barriga-vermelha

caboclinho-de-papo-escuro

caboclinho-de-papo-branco

caboclinho-de-chapéu-cinzento

caboclinho-de-barriga-preta curió

tico-tico-do-mato

cardeal-amarelo

sanhaçu-de-fogo

tiê-do-mato-grosso

negrinho-do-mato

azulão

azulinho

mariquita

pia-cobra

pula-pula

pula-pula-assobiador

iraúna-de-bico-branco tecelão

guaxe

encontro

chopim ou graúna

cardeal-do-banhado

carretão

sargento

garibaldi

veste-amarela
$\mathrm{P}$

$\mathrm{P}, \mathrm{F}$

$P$

$\mathrm{P}$

$\mathrm{P}$

$\mathrm{P}$

$\mathrm{P}$

$\mathrm{P}$

$\mathrm{P}$

$\mathrm{P}$

$\mathrm{P}$

$\mathrm{P}$

F

$\mathrm{P}$

$\mathrm{P}$

$\mathrm{P}$

F

P

P

$\mathrm{P}$

P

$\mathrm{P}$
$\mathrm{P}$

$\mathrm{P}$

P

$\mathrm{P}$
$\mathrm{P}$

F

$\mathrm{P}$
$\mathrm{P}$

P

$\mathrm{P}$

$\mathrm{P}$
$\mathrm{P}$

$\mathrm{P}$
$\mathrm{P}$

P 


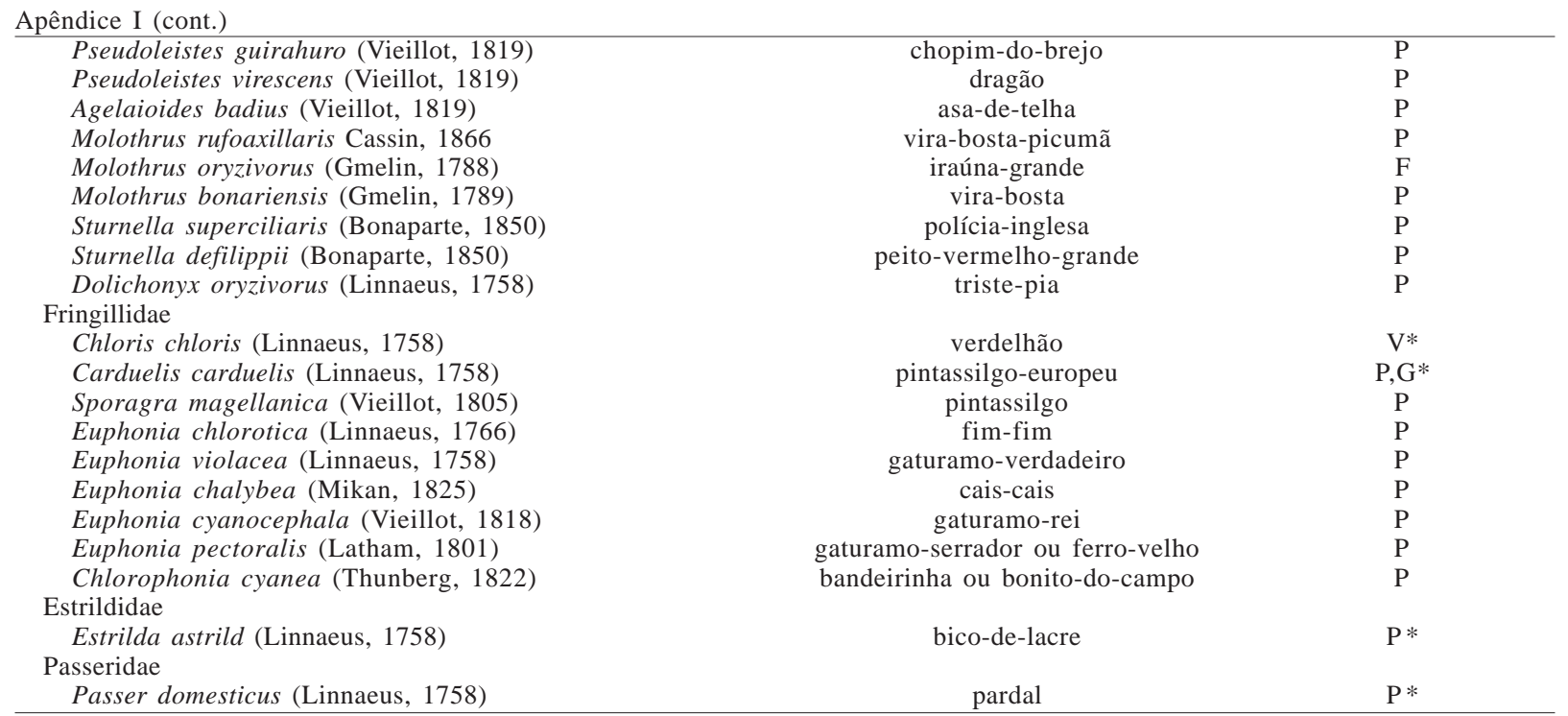

Apêndice II. Espécies de aves de ocorrência provável no Rio Grande do Sul, Brasil.

\begin{tabular}{lc}
\hline Espécie & Nome em português \\
\hline Pterodroma lessonii (Garnot, 1826) & pardela-de-cabeça-branca \\
Spiziapteryx circumcincta (Kaup, 1852) & falcãozinho-cinza \\
Laterallus exilis (Temminck, 1831) & sanã-do-capim \\
Thinocorus rumicivorus (Eschscholtz, 1829) & agachadeira-mirim \\
Leucophaeus atricilla (Linnaeus, 1758) & gaivota-alegre \\
Progne elegans Baird, 1865 & andorinha-do-sul \\
Donacobius atricapilla (Linnaeus, 1766) & japacanim \\
Ramphocaenus melanurus Vieillot, 1819 & bico-assovelado \\
Sporophila hypochroma Todd, 1915 & caboclinho-de-sobre-ferrugem \\
Dendroica striata (Forster, 1772) & mariquita-de-perna-clara \\
\hline
\end{tabular}

Apêndice III. Espécies de aves de ocorrência hipotética no Rio Grande do Sul, Brasil.

\begin{tabular}{lc}
\hline Espécie & Nome em português \\
\hline Phoebetria palpebrata (Forster, 1785) & piau-de-costas-claras \\
Thalassarche chrysostoma (Forster, 1785) & albatroz-de-cabeça-cinza \\
Phaethon aethereus Linnaeus, 1758 & rabo-de-palha-de-bico-vermelho \\
Cochlearius cochlearius (Linnaeus, 1766) & arapapá \\
Gampsonyx swainsonii Vigors, 1825 & gaviãozinho \\
Buteo nitidus (Latham, 1790) & gavião-pedrês \\
Stercorarius maccormicki Saunders, 1893 & mandrião-do-sul \\
Forpus xanthopterygius (Spix, 1824) & tuim \\
Chordeiles acutipennis (Hermann, 1783) & bacurau-de-asa-fina \\
Ramphodon naevius (Dumont, 1818) & beija-flor-rajado \\
Glaucis hirsutus (Gmelin, 1788) & balança-rabo-de-bico-torto \\
Ramphastos vitellinus Lichtenstein, 1823 & tucano-de-bico-preto \\
Picumnus cirratus Temminck, 1825 & pica-pau-anão-barrado \\
Tyrannus albogularis Burmeister, 1856 & suiriri-de-garganta-branca \\
Campylorhynchus turdinus (Wied, 1831) & catatau \\
Diuca speculifera (Lafresnaye \& d'Orbingy, 1837) & \\
\hline
\end{tabular}

Recebido em dezembro de 2010. Aceito em dezembro de 2010. ISSN 0073-4721 Artigo disponível em: www.scielo.br/isz Impresso e distribuído em 2011. 